\title{
THE ECONOMICS OF SMOKING
}

Frank J. Chaloupka

Kenneth E. Warner

Working Paper 7047

http://www.nber.org/papers/w7047

\section{NATIONAL BUREAU OF ECONOMIC RESEARCH 1050 Massachusetts Avenue \\ Cambridge, MA 02138 \\ March 1999}

This work has been supported by a grant from the Robert Wood Johnson Foundation of Princeton, NJ to the University of Michigan (Warner). The authors would like to thank the following individuals for helpful comments on a draft of this chapter: Philip Cook, William Evans, Michael Grossman, Jeffrey Harris, Thomas Hodgson, Chee-Ruey Hsieh, Teh-wei Hu, Prabhat Jha, Andrew Jones, Donald Kenkel, Willard Manning, David Merriman, Joseph Newhouse, Rosalie Pacula, Tomas Philipson, Harold Pollack, Henry Saffer, and Mark Showalter. Any views expressed in this paper are those of the author only and not those of Columbia University or the National Bureau of Economic Research.

(0) 1999 by Frank J. Chaloupka and Kenneth E. Warner. All rights reserved. Short sections of text, not to exceed two paragraphs, may be quoted without explicit permission provided that full credit, including ${ }^{(0)}$ notice, is given to the source. 
The Economics of Smoking

Frank J. Chaloupka and Kenneth E. Warner

NBER Working Paper No. 7047

March 1999

JEL No. 118

\begin{abstract}
$\underline{\text { ABSTRACT }}$
While the tobacco industry is among the most substantial and successful economic enterprises, tobacco consumption kills more people than any other product. Economic analysis of tobacco product markets, particularly for cigarettes, has contributed considerable insight to debates about the industry's importance and appropriate public policy roles in grappling with health consequences of tobacco. The most significant example is the rapidly expanding and increasingly sophisticated body of research on the effects of price increases on cigarette consumption. Because excise tax is a component of price, the resultant literature has been prominent in legislative debates about taxation as a tool to discourage smoking, and has contributed theory and empirical evidence to the growing interest in modeling demand for addictive products.

This chapter examines the research and several equity and efficiency concerns accompanying cigarette taxation debates. It includes economic analysis of other tobacco control policies, such as advertising restrictions, prominent in tobacco control debates. Research addressing the validity of tobacco-industry arguments that its contributions to employment, tax revenues, and trade balances are vital to economic health in states and nations is also considered, as it is the industry's principal weapon in the battle against policy measures to reduce tobacco consumption.
\end{abstract}

Frank J. Chaloupka

Department of Economics

University of Illinois at Chicago

601 S. Morgan Street (M/C 144)

Chicago, Illinois 60607-7121

and NBER

fjc@uic.edu
Kenneth E. Warner

Department of Health Management Policy

University of Michigan

109 S. Observatory

Ann Arbor, MI 48109-2029 
Table of Contents

1. Introduction and overview

1.1 Coverage

1.1 Health consequences of tobacco consumption

2. The impact of price on the demand for tobacco products

2.1 Conventional studies of cigarette demand

2.1.1 Analysis of aggregate data

2.1.2 Analysis of individual level data

2.2 Addiction models and cigarette demand

2.2.1 Imperfectly rational addiction models

2.2.2 Myopic addiction models

2.2.3 Rational addiction models

2.2.4 Critiques of the rational addiction model

2.3 Behavioral economic analyses of cigarette demand

2.4 Econometric studies of the demand for other tobacco products

3. Cigarette and other tobacco taxation

3.1 Comparative standards and the effects of tax on price

3.1.1 Purposes and methods of taxation

3.1.2 Effects of taxes on retail price

3.1.3 Variations in cigarette tax across countries and states and the issue of smuggling

3.2 Fairness standards

3.2.1 Horizontal and vertical equity

3.2.2 The benefit principle

3.3 Public health standards

3.3.1 The social cost of smoking

3.3.2 The health benefits of increasing cigarette taxes

3.4 Economic efficiency and the pursuit of an optimal cigarette tax

3.4.1 Negative externalities associated with smoking

3.4.2 Other efficiency considerations

4. Advertising, promotion, and the demand for tobacco products

4.1 Theoretical and conceptual issues

4.2 Econometric evidence

4.3 Findings from the non-economic literature

5. Other tobacco control policies and demand

5.1 Health information and counter-advertising

5.2 Restrictions on cigarette smoking

5.3 Limits on youth access to tobacco products

6. Agricultural policy and the macroeconomic implications of tobacco

6.1 Size and nature of the tobacco industry

6.1 .1 The global industry

6.1.2 The U.S. tobacco industry

6.2 The impact of the U.S. tobacco agriculture regulatory system 6.2.1 Nature of the system and its impact on tobacco farming 6.2.2 Relevance of the tobacco program to smoking and health

6.3 The contribution of the tobacco industry to the economy 6.3.1 States and nations

6.3.2 Tobacco farm communities

7. Conclusion

References 


\section{Introduction and overview}

Historically one of the oldest and most important crops in the United States, tobacco has become embroiled in the second half of the twentieth century in a struggle pitting American economic against public health interests. While the tobacco industry ranks among the most substantial and successful economic enterprises in the U.S., tobacco products are associated with more deaths than any other product (U.S. Department of Health and Human Services, 1989, 1998). Tobacco products, and particularly cigarettes, which account for 95\% of U.S. tobacco product sales, are credited with approximately one-fifth of the nation's annual death toll. Cigarettes cause fully a third of deaths during middle age. The leading cause of lung cancer and chronic obstructive pulmonary disease mortality, as well as a major cause of cardiovascular death, cigarette smoking leads all other causes of death in virtually all industrialized nations. According to an epidemiological analysis sponsored by the World Health Organization, tobacco will become the leading cause of death in developing countries during the first third of the 21 st century. By 2030, tobacco will be responsible for 10 million deaths annually worldwide (Peto et al., forthcoming), a toll that will exceed by far that associated with any other cause of disease (Murray and Lopez, 1996).

Formal economic analysis of tobacco dates back at least half a century trennant, 1950). At that time, most tobacco industry economic analysis was motivated by the factors that prompted market analysis of any other product or service, such as a desire on the part of an industry to understand the degree of price elasticity of demand for its product, or the interest of government and academic economists in the causes and implications of market concentration. Beginning in the late 1960s, however, following publication of seminal British and American reports on smoking and health (Royal College of Physicians, 1962; U.S. Department of Health, Education, and Welfare, 1964), the focus of economic research shifted from a general industrial organization orientation toward analysis self-consciously relevant to the public health damage wrought by tobacco. The subsequent economic analysis has been motivated by a desire to determine how economic forces influence tobacco consumption, with continuing emphasis on refining the scientific rigor of the work; but the objective of much of the research is now to determine how to harness economic forces and logic, how to use economic tools, to decrease smoking, with the ultimate goal being to reduce the toll of tobacco.

Certainly the most important example of this phenomenon has been the rapidly expanding and increasingly sophisticated body of research on the effects of price increases on cigarette consumption. Because excise tax comprises an important component of price, the resultant literature has played a prominent role in legislative debates about using taxation as a principal tool to discourage smoking in individual states, in the U.S. as a whole, and in numerous other countries as well. In the United States in the late 1990s, the findings of this literature have been showcased in the intense

congressional debate over whether to adopt comprehensive tobacco control legislation, with a major price increase lying at the heart of all proposals (Chaloupka, 1998).

\subsection{Coverage}

This chapter examines in detail economic analysis of the relationships among taxation, price, consumption, and disease outcomes, as well as considering how analysis has enlightened other debates about the economics of tobacco. The relationship between price and cigarette consumption has been the focal point of economic research on smoking, and the locus of increasingly sophisticated and interesting development of theory and methodology. For these reasons, and because the resultant literature constitutes the most important contribution of economics to understanding tobacco policy, this chapter's principal emphasis is on this body of research. The chapter devotes special consideration to recent attempts to model nicotine addiction in the context of rational economic behavior. Borne of a generic interest in the role of addiction in economic behavior, new theoretical models have received their best empirical testing through the use of data on cigarette smoking. ${ }^{2}$

1 Not all of the research is motivated by a desire to decrease smoking. Some authors express the opinion that more respect should be accorded consumer sovereignty, despite the issues of addiction and youthful initiation of smoking that have led many economists to perceive the market for cigarettes as suffering from important market imperfections (Warner et al., 1995). See, for example, Viscusi (1992) and Tollison and Wagner (1992).

2 As is discussed below, numerous variables other than price influence the demand for 
The chapter also considers a variety of equity and efficiency concerns that invariably accompany debates about cigarette taxation, including the validity of the externality or social cost argument frequently invoked by the public health community in calls for higher taxes; whether there are other legitimate grounds in economic theory to support increased excise taxation; whether cigarette tax increases are regressive, and if so how much; and whether large tax hikes produce substantial cross-border smuggling of cigarettes. Recent economic studies have explored subtle impacts of cigarette taxation that receive attention here as well; for example, cross-price elasticity issues include how cigarette taxation may shift demand toward other tobacco products, such as smokeless tobacco, or, within the cigarette family, from lower to higher tar and nicotine cigarettes.

Coverage in this chapter also includes attention to economic analysis of the role of advertising in the demand for cigarettes, as well as the role of restrictions or bans on advertising. The effects of advertising and of advertising and other marketing restrictions are of special interest due to their prominence in debates about tobacco control at all levels of government, from municipalities, which have restricted cigarette advertising on public transit and on billboards, to international bodies, which have called for complete bans (Roemer, 1993). Although its value is constrained by obvious limitations, econometric analysis offers insights into the role of advertising, and of advertising restrictions, on the demand for cigarettes.

The chapter also examines what is known about the influence of other tobacco control policies on the demand for cigarettes, including the development and dissemination of information on the health consequences of smoking; media advocacy by means of "counteradvertising;" the adoption and implementation of laws or policies that limit smoking in public places; and legal restrictions on youth access to tobacco products.

Given tobacco's role in employment, tax revenues, and, in selected countries, trade balances, governments have a legitimate interest in the "health" of their tobacco industries. Tobacco companies tout the industry's economic contribution in attempts to combat tobacco control policy measures. In recent years, independent economists have countered the industry's economic argument by carrying out macroeconomic analyses that examine the net contributions of tobacco to economies, rather than the gross contributions featured by the industry. This literature, and its role in the debate over tobacco control policy, are examined toward the end of the chapter. Also considered briefly is the influence of tobacco agriculture support policies so prominent in the agricultural policies of the United States and the European Union.

Despite its wide scope of coverage, this chapter does not examine all of the economic contributions relating to smoking and health. To illustrate with two examples, the chapter does not consider the growing literature on the cost-effectiveness of smoking cessation interventions (Cromwell et al., 1997; Warner, 1997) and it omits the newly emerging and potentially quite important analysis of the economics of the market for nicotine replacement products (Oster et al., 1996; Hu et al., 1998). Another limitation on coverage is that we consider almost exclusively English language publications, believed to comprise a very sizable majority of the peer-reviewed literature. Further, reflecting the authors' knowledge of this field and familiarity with data, examples draw heavily, although not exclusively, on the U.S. experience. In particular, there is little coverage of the economics of smoking in developing countries, the result primarily of the dearth of studies on the subject. Although specific empirical conclusions from a given country may not apply precisely to other nations, the general phenomena described and findings presented should apply qualitatively to all countries, unless otherwise indicated.

Before turning to the economics literature, the remainder of this introductory section presents a brief "primer" on the health consequences of tobacco use. We deem this important background for understanding the nature and social significance of the economic issues.

\subsection{Health consequences of tobacco consumption}

cigarettes, including consumers' knowledge of the hazards of smoking, parental and sibling smoking behavior, smoking by peers, role modeling, income, and education (U.S. Department of Health and Human Services, 1994). The near-exclusive focus of this chapter on price and taxation reflects the facts that tax is the most policy-tractable variable influencing the demand for cigarettes and that the economics literature has focused on price, taxation, and addiction. 
The health implications of tobacco have been contemplated for at least the past millenium. During the first half of that period, the predominant view held that tobacco afforded users a wide variety of health benefits. The Amerindians employed tobacco as an analgesic and as a treatment for such diverse ailments as intestinal problems, asthma, rheumatism, headaches, toothaches, boils, worms, fevers, and the pains of childbirth (Goodman, 1993).

Serious medical and scientific attention to the health consequences of smoking is a phenomenon of the present century, primarily of its second half. This is a reflection of the development of the science of epidemiology during this period and of the relatively modest number of victims claimed by tobacco prior to the 20 th century. Before this century, relatively few people reached the ages at which tobacco takes its greatest toll (average life expectancy in the U.S. was 47 in 1900; currently it is 75). More importantly, widespread intensive use of the most dangerous form of tobacco consumption, cigarette smoking, began only in the very late 1800s. Lung cancer, today the source of $30 \%$ of all cancer deaths in the U.S. (U.S. Department of Health and Human Services, 1989), was a rarity until earlier cigarette smoking spawned the epidemic first widely observed during the 1930s.

Although a few scientific studies associated smoking with disease prior to midcentury (Broders, 1920; Lombard and Doering, 1928; Pearl, 1938), the first evidence that strongly implicated smoking in disease (specifically, lung cancer) was published in the 1950s (Wynder and Graham, 1950; Doll and Hill, 1954, 1956; Hammond and Horn, 1958a, 1958b). Since then, some 70,000 scientific articles have implicated smoking in a wide variety of ailments, constituting the largest and best documented literature linking any behavior to disease in humans (U.S. Department of Health and Human Services, 1994).

Today, cigarette smoking is established as the leading cause of lung cancer (responsible for approximately 90\% of lung cancer deaths in the U.S.), the leading cause of chronic bronchitis and emphysema (responsible for over 80\% of chronic obstructive pulmonary disease deaths), and a major cause of heart disease and stroke. Smoking also causes aneurysms, atherosclerotic peripheral vascular disease, oral cavity and laryngeal cancer, intrauterine growth retardation and neonatal death, including SIDS (Sudden Infant Death Syndrome). It is associated with additional cancers (bladder, pancreatic, renal, gastric, and cervical) (U.S. Department of Health and Human Services, 1989), as well as a host of other conditions affecting a wide variety of organ systems and disease processes, including, for example, vision and hearing problems, slowed healing from injuries, and increased susceptibility to certain infections Napier, 1996). Chronic inhalation of environmental tobacco smoke (ETS) causes lung cancer in nonsmokers and an assortment of diseases and functional limitations in the children of smokers (Environmental Protection Agency, 1994). ETS may be responsible for tens of thousands of heart disease deaths annually (Glantz and Parmley, 1995).

All told, smoking is far and away the leading cause of premature death and of avoidable morbidity and disability in the United States and in most industrialized nations. As indicated above, the intensification of smoking in the world's less affluent nations will soon bring the same distinction to smoking in the developing countries. Barring substantial and unexpected decreases in tobacco use worldwide, a few decades hence the global death toll from tobacco will dwarf all other causes, with the majority of deaths occurring in the developing nations. The World Health Organization estimates that fully 500 million of the 5 billion people alive at the beginning of this decade will die as a result of consumption of tobacco products (Peto et al., forthcoming).

The mortality toll of tobacco reflects not only the lethality of tobacco products but also the prevalence of their consumption. In the United States, approximately 45

3 Concern about the health consequences of smoking predates the "modern era" by nearly four centuries. In 1604, for example, King James I of England lambasted smoking as "a custome lothsome to the eye, hatefull to the Nose, harmefull to the braine, dangerous to the Lungs, and in the blacke stinking fume thereof, neerest resembling the horrible Stigian smoke of the pit that is bottomlesse" (as quoted in Sullum, 1998, p. 18). King James subsequently raised the tax on tobacco by $1000 \%$, deriving significant revenues for his coffers. This illustrates the profound dilemma that has confronted policy decision makers ever since: whatever its health consequences, tobacco has long been truly a "golden leaf" for farmers and politicians alike. Its role in the very earliest commerce between England and the American colonies is legendary, as is its role in contemporary politics (Taylor, 1984; Fritschler and Hoefler, 1996). 
miliion adults, almost a quarter of the adult population, smoke cigarettes (down from a high of 42\% in 1965 (U.S. Department of Health and Human Services, 1989)). Worldwide, tobacco products are used by approximately one billion people. The large numbers of tobacco consumers, combined with their frequent use of tobacco products, account not only for the disease toll of tobacco, but also for the substantial size of the tobacco industry. Important features of the structure and economic importance of the industry are reviewed in section 6 below.

\section{The impact of price on the demand for tobacco products}

Many researchers once viewed cigarette smoking and other addictive behaviors as irrational and therefore not suitable for conventional economic analysis Elster, 1979; Winston, 1980; Schelling, 1984b). They believed that the demand for cigarettes (and other addictive substances) did not follow the basic laws of economics, including perhaps the most fundamental law, that embodied in the downward-sloping demand curve. As the nowsubstantial body of economic research demonstrates, however, the demand for cigarettes clearly responds to changes in prices and other factors, as found in applications of both traditional models of demand and more recent studies that explicitly account for the addictive nature of smoking.

Conceptually, economists use a relatively broad definition of price that includes not only the monetary price of purchasing a product, but also the time and other costs associated with using the product. Restrictions on smoking in public places and private work sites, for example, impose additional costs on smokers by forcing them outdoors to smoke, raising the time and discomfort associated with smoking, or by imposing fines for smoking in restricted areas. Similarly, limits on youth access to tobacco mayraise the time and potential legal costs associated with smoking by minors, while new information on the health consequences of tobacco use can raise the perceived long-term costs of smoking.

This section focuses on the effects of monetary price on demand, while section 5 below considers the effects of other aspects of full price.

In addition to price, a variety of other factors can affect the demands for cigarettes and other tobacco products, including income, advertising and other promotional activities, and tastes. In the industrialized nations, the relationship between income and cigarette consumption has reversed. Early demand studies (for example, Ippolito, et al., 1979; Fujii, 1980) concluded that cigarette smoking was a normal good, with cigarette consumption rising as income rose. More recent studies, however, have found that cigarettes have become an inferior good, in that the likelihood of smoking declines as income rises (Wasserman, et al., 1991; Townsend et al., 1994). The effects of advertising and promotion on the demand for cigarettes have been the subject of numerous studies; these are reviewed in detail in section 4 below. Finally, nearlyall econometric studies of cigarette demand use a variety of factors to control for tastes, including gender, race, education, marital status, employment status, and religiosity. Given the focus of this book on economics, the impact of these socio-demographic determinants of demand will not be reviewed. ${ }^{4}$

This section begins with a review of conventional studies of the impact of money price on cigarette demand. This is followed by a discussion of economic models of addiction and their applications to cigarette demand. Implications for the effects of price on cigarette demand from the relatively new field of behavioral economics are then reviewed. The section closes with a short consideration of the relatively limited research on the effects of price on the demand for other tobacco products.

\subsection{Conventional studies of cigarette demand}

Numerous investigators have estimated the effects of price on cigarette demand using conventional models of demand that do not account for the addictive nature of cigarette smoking. Their studies have used diverse econometric and other statistical methods on

4 The importance of these variables should not be downplayed, however. In many instances, these and other variables, such as parental and peer smoking behavior and societal norms, are as important or more important than the variables which economists have studied (U.S. Department of Health and Human Services, 1994). Variations in these and other variables help to explain why large variations in prices across countries are often not associated with comparably large variations in smoking prevalence. Economists' interests focus on the marginal impact of price, advertising, and other economic variables on the demand for cigarettes. 
data from numerous countries. Many used aggregate time-series data for a single geographical unit, while others employed pooled cross-sectional time series data; still others used individual level data taken from surveys. The price elasticity estimates for overall cigarette demand from recent studies fall within the relatively wide range from 0.14 to -1.23 , but most fall in the narrower range from -0.3 to -0.5 .

\subsubsection{Analysis of aggregate data}

Many recent studies use aggregate data and appropriate econometric methods to examine the effects of price on cigarette demand, controlling for income, tobacco control policies, and a variety of socioeconomic and demographic factors. The exceptions Baltagi and Goel, 1987; Peterson et al., 1992) compared changes in cigarette consumption in states that had raised cigarette taxes to consumption in states where taxes had not changed. The estimated price elasticities from these quasi-experimental studies, in the range from 0.17 to -0.56 , are consistent with those obtained from the econometric studies.

Although there are numerous studies of the price-demand relationship in

industrialized nations, until recently there were almost no estimates for developing countries. Warner (1990) argued that price responsiveness in less developed countries is likely to be greater than in more affluent countries, given the relatively low incomes and relatively low levels of cigarette consumption by smokers in the poorer countries. Findings from studies using data from Papua New Guinea (Chapman and Richardson, 1990), China (Mao, 1996; Xu, Hu and Keeler, 1998) South Africa (van der Merwe, 1998a), Zimbabwe (Maranvanyika, 1998), and Taiwan (Hsieh and Hu, 1997) are consistent with this argument. Several difficulties are encountered in studies using time-series data.

Particularly troubling are the high correlations among many of the key independent variables and price. Consequently, estimates of the impact of price and other factors on demand can be sensitive to the inclusion and exclusion of other variables. Including highly correlated variables can result in multicollinearity and unstable estimates for the parameters of interest. Excluding potentially important variables, however, can produce biased estimates of the impact of price on demand. Recent studies using state-of-the-art econometric methods have addressed many of these difficulties Seldon and Boyd, 1991; Simonich, 1991; Flewelling et al., 1992; Sung et al., 1994; Barnett et al, 1995; Keeler et al., 1996). Nearly all of the estimates from these studies have produced estimates for the price elasticity of demand in a relatively narrow range, centered on -0.4.

Other problems are encountered when using pooled cross-sectional time-series data. The measure of cigarette smoking employed in these studies is typically annual state-level tax-paid cigarette sales. Interstate differences in cigarette prices, resulting from wide variation in state cigarette taxes (Tobacco Institute, 1998), can lead to casual and organized smuggling of cigarettes from low-tax to high-tax states, however (Advisory Commission on Intergovernmental Relations (ACIR), 1977, 1985). As such, tax-paid sales data are likely to overstate cigarette consumption in states with low cigarette taxes and underestimate it in high tax states. 5 Filing to account for this will produce upwardbiased estimates of the impact of price on cigarette demand. Many of the more recent studies employing pooled time-series cross-sectional state data have controlled for the potential for smuggling (ACIR, 1977, 1985; Baltagi and Levin, 1986; Chaloupka and Saffer, 1992; Keeler et al., 1996). These studies have also produced estimates of the price elasticity of cigarette demand generally falling in a relatively narrow range centered on -0.4 .

The fact that cigarette prices, sales, and consumption are simultaneously determined creates an additional complication in the analysis of cigarette demand and supply. Failing to account for this simultaneity would lead to biased estimates of the price elasticity of demand. Again, many of the recent studies employing aggregate time-series data for a single country or other geographical unit, as well as many of those using pooled cross-sectional time-series data, have avoided this problem by theoretically and empirically modeling cigarette demand and supply (Bishop and Yoo, 1985; Porter, 1986; Showalter, 1991; Sung et al., 1994; Barnett et al., 1995; Tremblay and Tremblay, 1995; and Keeler et al., 1996). Other studies have taken advantage of natural experiments, most notably 25-cent increases in the California and Massachusetts cigarette excise taxes, to

5 The same problem exists in time-series studies using aggregate country-level data for countries with relatively high taxes and prices compared to neighboring countries. See Joossens (1998) for a discussion of factors other than price that influence smuggling across country borders. 
look at the impact of price on demand (Keeler et al., 1993; Hu et al., 1994, 1995b; Sung et al., 1994; Harris et al., 1996). After accounting for the potential simultaneity or taking advantage of natural experiments, most of these studies produce estimates of the price elasticity of demand that fall into the same narrow range found in other studies. Finally, studies employing aggregate data are generally limited to examining the impact of cigarette prices and other factors on aggregate or per capita measures of cigarette consumption. Consequently, these studies are typically unable to evaluate the differential impact of prices on smoking by various population subgroups of particular interest, especially youth and young adults. Nor can they differentiate between the impact of price on smoking prevalence and quantity, or smoking initiation and cessation.

A few recent analyses have attempted to address these limitations. For example, Harris (1994) used annual time-series data on U.S. smoking prevalence taken from the National Health Interview Surveys, coupled with aggregate measures of cigarette consumption, to estimate the effects of price on smoking prevalence and average cigarette consumption by smokers for the period from 1964 through 1993. His estimate of the unconditional price elasticity of demand fell into the same narrow range generally found in other studies. He estimated that approximately half of the impact of price was on smoking prevalence, with the price elasticity of smoking participation being -0.238, while the unconditional price elasticity of demand was -0.47. Townsend et al. (1994) looked at the differential effects of price on cigarette smoking for various population subgroups defined by age, gender, and socioeconomic status, using data aggregated from the 1972 through 1990 British General Household Surveys. They concluded that women were more responsive to price than men, that both men and women in lower socioeconomic groups were more sensitive to price than those that were better off, and that youth (16-19 years) and young adults (20-24 years) were less responsive to price than adults.

\subsubsection{Analysis of individual level data}

A relatively small but growing number of cigarette demand studies have used data on individuals taken from large-scale surveys. In general, their estimated priceelasticities of demand are comparable to those estimated using aggregate data. The use of individuallevel data helps avoid some of the problems inherent in using aggregate data. For example, because an individual's smoking decisions are too small to affect the market price of cigarettes, potential simultaneity biases are less likely. Similarly, individual-level income data and measures of socio-demographic determinants of demand are less correlated with price and policy variables than comparable aggregate measures.

Other problems persist but can be addressed somewhat more easily usingindividuallevel data. For example, failing to account for interstate differences in cigarette prices will again produce a biased estimate of the price elasticity of demand (biased towards 0 in this case). Thus, given information on where an individual resides, studies using individual-level data have employed a variety of approaches to control for potential cross-border shopping in response to interstate price differentials. Some have limited their samples to individuals who do not live near lower-price localities tewit and Coate, 1982; Wasserman et al., 1991; Chaloupka and Grossman, 1996; Chaloupka and Wechsler, 1997).

Others have included a measure of the price differential tewit et al., 1981; Chaloupka and Pacula, 1998a, 1998b). Still others have used a weighted average price based on the price in the own-locality and other nearby localities (Chaloupka, 1991).

As with the state tax-paid sales data, self-reported data on cigarette smoking yield inaccurate measures of true consumption, given potential reporting biases. Based on a comparison of self-reported consumption with aggregate sales data, Warner (1978) demonstrated that survey-based self-reported consumption significantly and substantially understated actual sales. Studies using individual-level survey data have implicitly treated underreporting as proportional to true consumption across groups of interest (e.g., age, gender, or socioeconomic groups). If the assumption is true, estimates of the price elasticity of demand will not be systematically biased. The assumption has yet to be demonstrated, however.

Finally, as Wasserman et al. (1991) observed, studies using individual-level data may be subject to a substantial ecological bias in that omitted variables affecting

6 As we discuss below, other studies have derived the opposite conclusions concerning the relative price responsiveness by gender (e.g., Lewit and Coate, 1982; Mullahy, 1985; Chaloupka, 1990) and different age groups (e.g. Lewit, et al., 1981; Chaloupka and Grossman, 1996). 
tobacco use may be correlated with the included determinants of demand. Failing to account for this can produce biased estimates for the included variables. For example, unobserved sentiment against smoking may affect both cigarette sales and the strength of tobacco control policies (including taxes and, consequently, prices). Ohsfeldt et al. (1998) considered this possibility in their analysis of cigarette smoking and other tobacco use that employed data from the 1992/93 Current Population Survey Tobacco Use Supplements. Surprisingly, after modeling cigarette taxes and other tobacco control policies as a function of cigarette smoking, various other indicators of sentiment against smoking, and other factors, they found that taxes have a larger impact on demand.

Using individual-level data allows researchers to examine issues that generally cannot be addressed with aggregate data. For example, most studies using individual-level data separately consider the effects of price on the probability of smoking and on average cigarette consumption by smokers. In addition, several consider the differential effects of price on demand for various population subgroups (defined by age or gender, for example). Finally, some have taken advantage of retrospective or longitudinal data to examine the effects of prices and other factors on smoking initiation and cessation decisions.

The earliest of the cigarette demand studies employing individual-level data were conducted by Lewit and his colleagues (Lewit et al., 1981; Lewit and Coate, 1982). Lewit and Coate used data from the 1976 National Health Interview Survey to examine the effects of price on cigarette smoking, estimating an overall price elasticity of demand of -0.42 and an elasticity of smoking participation of -0.26 . In addition, they found an inverse relationship between (the absolute value of) price elasticity and age, estimating a total price elasticity of demand for 20 through 25 year-olds more than double that of persons 26 and older. The researchers found that most of the effect of price for young adults was on the decision to smoke (participation elasticity of -0.74 and conditional demand elasticity of -0.20), but was about evenly split for those over 35 years of age (participation and conditional demand elasticities of -0.15). Finally, they also looked at differences in price responsiveness by gender, concluding that men, particularly young men, were very responsive to price, while women were generally insensitive to price.

Lewit et al. (1981) and Grossman et al. (1983) confirmed the Lewit and Coate (1982) conclusion concerning the inverse relationship between price elasticity of cigarette demand and age. Using data from Cycle III of the Health Examination Survey, Lewit et al. estimated that the price elasticity of smoking participation for 12-17 year-olds was 1.20, while the conditional demand elasticity was -0.25 . Their estimated total price elasticity of youth cigarette demand of -1.44 was more than three times Lewit and Coate's (1982) estimate for adults. These conclusions were generally supported by Grossman et al.'s (1983) analysis of data from the National Household Surveys on Drug Use conducted during the 1970 s.

Lewit et al. (1981) offered two reasons why youth should be moreprice sensitive than adults, at least in the short run. First, given the addictive nature of smoking, long-term adult smokers are likely to adjust less quickly to changes in price than youth who have been smoking for a relatively short time, if at all. In addition, peer behavior is likely to be much more influential for youth, multiplying the effects of price on youth smoking. That is, an increase in cigarette price directly reduces youth smoking and then again indirectly reduces it through its impact on peer smoking. Grossman and Chaloupka (1997) offered two additional reasons. First, the fraction of disposable income a young smoker spends on cigarettes is likely to exceed that spent by an adult smoker. Second, compared to adults, youth are more likely to be present-oriented. In the context of an economic model of addictive behavior (discussed below), Becker et al. (1991) predicted that changes in money price will have a greater impact on individuals with higher discount rates since they give less weight to the future consequences of addictive consumption.

The conclusion that youth cigarette demand is more price elastic than adult demand was widely accepted until an influential 1991 Rand study by Wasserman and colleagues (1991). These researchers evaluated adults' cigarette demand using data from several of the National Health Interview Surveys from the $1970 \mathrm{~s}$ and $1980 \mathrm{~s}$ and youth demand with data from the Second National Health and Nutrition Examination Survey of the late-1970s. Using a generalized linear model, the authors concluded that adult demand in the earlier years of their data was relatively unresponsive to price, but that demand had become more price elastic over time. Based on the trends in price elasticity, they predicted an overall price elasticity of adult cigarette demand of -0.283 for 1988 . Estimates from a two-part model of adult cigarette demand implied that the effects of price on the decision to smoke were almost double the impact of price on conditional demand. However, the authors did not find a statistically significant impact of price on youth smoking. They attributed 
their relatively low estimates of price elasticity, particularly those for youth, to the inclusion in their models of an index of restrictions on smoking. These restrictions, which they note are positively correlated with price, had not been included in most previous studies of cigarette demand. Indeed, they obtained very similar estimates to Lewit and Coate (1982) when leaving the restriction index out of models estimated using the 1976 survey data.

Several more recent studies of youth and young adult smoking have supported the earlier conclusions reached by Lewit and his colleagues (Lewit et al., 1981; Lewit and Coate, 1982; Grossman et al., 1983) that the price sensitivity of cigarette demand is inversely related to age. Chaloupka and Grossman (1996) examined the impact of price, numerous tobacco control policies (including smoking restrictions and limits on youth access to tobacco), and a variety of other socioeconomic and demographic factors on youth smoking, using data from the 1992, 1993, and 1994 Monitoring the Future Surveys of eighth, tenth, and twelfth grade students. They estimated a total price elasticity of youth cigarette demand of -1.31 , strikingly similar to the estimates obtained by Lewit et al. (1981) 15 years earlier. In contrast to Lewit and his colleagues, however, chaloupka and Grossman found that the effects of price on smoking participation and conditional demand were similar (-0.68 for smoking participation and -0.64 for conditional demand). Chaloupka and Pacula (1998b) used the same data to look at the differential response by gender and race, concluding that young men and young blacks are more responsive to price than young women and young whites.

Chaloupka and Wechsler (1997) reached similar conclusions using data on young adult smoking taken from the 1993 College Alcohol Survey. Also controlling for numerous other determinants of cigarette demand, including a variety of restrictions on smoking, they estimated a price elasticity of smoking participation of -0.53 and an unconditional price elasticity of demand of -1.11 for college students. Noting that their sample was not a random sample of all young adults, Chaloupka and Wechsler suggested that the price elasticity of cigarette demand by young adults may be even higher, given the evidence that cigarette demand is relatively less elastic for more educated or higher-income individuals (Townsend, 1987; Chaloupka, 1991; Townsend et al., 1994; Farrelly et al., 1998).

Farrelly and his colleagues (1998) found similar evidence for young adults and adults, based on 13 waves of the National Health Interview Survey conducted between 1976 and 1992. They estimated that demand was more than twice as elastic for their sample of young adults, ages 18 to 24 years (total elasticity of -0.58), as for their full sample (total elasticity of -0.25). Similarly, they estimated that blacks were about twice as responsive as whites to cigarette prices, while Hispanics were even moreprice sensitive.

In addition, they found that men were more price sensitive than women. Finally, they estimated that individuals with family incomes below the sample median were about 70 percent more responsive to price than those with higher family incomes.

Additional support for the inverse relationship between price sensitivity and age is provided by recent studies by Lewit and his colleagues (1997), Evans and Huang (1998), and Tauras and Chaloupka (1998). Lewit and his colleagues used data for ninth grade students in 1990 and 1992 collected in the 22 North American communities involved in the National Cancer Institute's Community Intervention Trial for Smoking Cessation (COMMIT). They found that both youth smoking participation and intentions to smoke among young nonsmokers were inversely related to price, with estimated price elasticities of -0.87 and 0.95, respectively. Evans and Huang used state level aggregated data on smoking prevalence constructed from the 1977 through 1992 Monitoring the Future surveys to estimate a price elasticity of youth smoking participation of -0.20. Unlike other studies on youth smoking that largely rely on the cross-sectional variation in state cigarette taxes and prices, Evans and Huang took advantage of the long time period covered by their data and used the time series variation in state cigarette taxes to identify the impact of cigarette taxes on smoking participation. While their estimated elasticity for the 1977 through 1992 period is relatively low, Evans and Huang concluded that youth smoking has become more price sensitive over time, estimating an elasticity of -0.50 for youth smoking participation in the period from 1985 through 1992. Most recently, Tauras and Chaloupka (1998) used the longitudinal data from the Monitoring the Future surveys of high school seniors conducted from 1976 through 1993 to estimate the price elasticity of smoking for young adults; respondents in their sample ranged in age from 17 to 35 years. In models controlling for unobserved state and individual factors affecting demand, they estimated an overall price elasticity of demand centered on -0.79 .

In general, researchers examining the effects of price on smoking participation using individual-level data from cross-sectional surveys have assumed that much of the price effect estimated for youth reflects the impact of price on smoking initiation, while 
the estimate for adults is largely capturing the effects of price on smoking cessation. few recent studies have attempted to directly examine the impact of cigarette prices on smoking initiation. With retrospective data from the smoking supplements to the 1978 and 1979 National Health Interview Surveys, Douglas and Hariharan (1994) studied the ages at which survey respondents reported that they began smoking. Based on current state of residence, they matched data on cigarette prices to the survey data to estimate the impact of price on smoking initiation. They estimated a hazard model in which "failure" was defined as a never smoker taking up smoking and used a relatively general variation on standard duration methods: the split population duration model developed by Schmidt and Witte (1989). This model allows for a large part of their sample to never begin smoking. Finally, Douglas and Hariharan's theoretical and empirical framework was based on the Becker and Murphy (1988) rational addiction model (described below). As anticipated, Douglas and Hariharan found that a number of socioeconomic and demographic factors had a significant effect on smoking initiation. However, their estimates for cigarette prices were insignificant. Given the errors-in-variables problem associated with both the retrospective data on smoking initiation and the cigarette price data, they noted that price effects will be biased towards zero. Nevertheless, they found no evidence that higher cigarette prices reduced smoking initiation.

Douglas (1998) extended this work by estimating a time-varying covariate model that allows the hazard of smoking initiation to respond dynamically to changes in prices and other factors. In addition to initiation, Douglas also estimated the hazard of smoking cessation in a similar empirical framework, as well as estimating the impact of smoking regulations and information on initiation and cessation (these findings are discussed later). Using data from the cancer risk factor supplement to the 1987 National Health Interview Survey, Douglas again concluded that cigarette price has little impact on smoking initiation. As with the earlier analysis, however, there are likely to be errorsin-variables problems that could account for this finding.

DeCicca et al. (1998a) employed data from the National Education Longitudinal Survey of 1988 to examine the impact of price on initiation of daily smoking. This data set contains data on youth smoking at several points in time (eighth, tenth, and twelfth grades). Treating the three waves as independent cross-sections, they obtained estimates of the price elasticity of youth smoking participation comparable to other recent estimates. In an effort to examine the impact of price on smoking initiation, they attempted to exploit the longitudinal aspect of their data by looking at the probability of smoking in twelfth grade for a sample that excluded those who were smokers in eighth grade. Their estimates for the effect of cigarette taxes on the probability of starting to smoke between the eighth and twelfth grade are not statistically significantly different from zero, supporting the findings of Douglas and Hariharan (1994) and Douglas (1998) that raised doubts about the hypothesis that higher cigarette prices lead to significant reductions in youth smoking. DeCicca et al. attributed the inconsistency in their two sets of results to the possibility that cigarette tax rates are a proxy for unobserved sentiment against cigarette smoking. If true, then estimates based on crosssectional studies are likely to significantly overstate the impact of price on smoking.

Dee and Evans (1998) reexamined the longitudinal data used by DeCicca et al., arguing that their finding that price has no impact on smoking initiation was largely the result of the way in which their sample was constructed. In particular, rather than following DeCicca et al. in deleting the large number of observations with missing values for key independent variables (including income, parental education, and number of siblings), Dee and Evans included these along with dummy variables indicating observations for which the data are missing. In addition, they included a variety of binary indicators for categorically collected data, rather than constructing "continuous" measures from these data as did DeCicca et al. (e.g. parental and family attributes). After making these changes but otherwise following the same basic approach, Dee and Evans estimated a negative and significant impact of cigarette taxes on smoking initiation. Their estimated price elasticity of smoking onset is -0.63 , consistent with several other recent studies of youth smoking employing cross-sectional data.

In response to Dee and Evans (1998), Decicca and his colleagues (1998b) conducted a reanalysis of the NELS data that used an alternative approach for dealing with the missing data problem. Where possible, they used information from the longitudinal sample to fill in missing values; when this could not be done, they used a conditional mean imputation approach. Their reanalysis produced somewhat more significant estimates for the effect of cigarette taxes on the onset of daily smoking, with implied priceelasticities from alternative specifications ranging from -0.025 to -0.505; somewhat smaller, less significant estimates were obtained from models using price rather than tax. In addition, 
their estimates for samples based on race/ethnicity implied that higher cigarette taxes significantly reduced smoking onset among Hispanics, but had little impact on whites and blacks.

Clearly, the use of longitudinal data to examine the impact of cigarette tax and price changes on smoking initiation and cessation is an important advance. The findings from studies using relatively longer panels that control for unobserved state and/or individual factors affecting demand (i.e. Evans and Huang, 1998; Tauras and Chaloupka, 1998) are consistent with the findings that price sensitivity is inversely related to age, as found in several earlier studies based on cross-sectional data. The inconsistent findings from a few recent studies (DeCicca et al., 1998a, 1998b; Dee and Evans, 1998) directly addressing the effects of price on smoking initiation with a relatively short panel should be viewed with caution.

Hu et al. (1995a) introduced an innovation in cigarette demand estimation, using data from California's Behavioral Risk Factor Surveys for 1985 through 1991 to examine the possible effects on adult smoking of the interdependence of cigarette smoking with other risk factors, including alcohol use and obesity. Estimates of the smoking participation elasticity from models that included other behavioral risk factors were significantly lower than when these factors were ignored, while conditional demandelasticities were generally unaffected. Using two-part methods, Hu et al. estimated an overall price elasticity of -0.46 from the models that included other risks, with the effects of price about equally divided between smoking participation and conditional demand. The authors noted, however, that their estimate of the price elasticity might be relatively high given that they did not control for other tobacco control efforts.

Evans and Farrelly (forthcoming) recently examined a phenomenon not previously studied by economists. Using data from the 1979 Smoking Supplement and the 1987 Cancer Control Supplement to the National Health Interview Surveys, the authors investigated the compensating behavior by smokers in response to tax and price changes. The supplements contain unique information on smokers' choices of types of cigarettes, which Evans and Farrelly combined with data from the Federal Trade Commission on the tar and nicotine content of cigarette brands to construct a variety of measures of daily smoking intensity (including cigarette consumption, total length of cigarettes consumed, tar intake, and nicotine intake). They also constructed comparable aggregate measures for $1964-1993$ from the data used by Harris (1994) on aggregate smoking prevalence and cigarette consumption.

They found consistent evidence that, although smokers reduced daily cigarette consumption in response to higher taxes, they also compensated in several ways. In particular, smokers in high-tax states consumed longer cigarettes and those that are higher in tar and nicotine, with young adults smokers also most likely to engage in this compensating behavior. As a result, they argued that the perceived health benefits associated with higher cigarette taxes are likely to be somewhat overstated. Given this compensating behavior, Evans and Farrelly suggest that if cigarette taxes are to be used to reduce the health consequences of smoking, then taxes based on tar and nicotine content would be appropriate, an idea first suggested by Harris (1980).

\subsection{Addiction models and cigarette demand}

The first discussion by an economist of the effects of addiction on demand can be

found in Marshall's (1920) Principles of Economics, where he observed that

Whether a commodity conforms to the law of diminishing or increasing return, the increase in consumption arising from a fall in price is gradual; and, further, habits which have once grown up around the use of a commodity while its price is low are not so quickly abandoned when its price rises again. (Appendix H, section 3, page 807)

As Phlips (1983) noted, Marshall's statement clearly introduced the three basic dimensions of addiction (U.S. Department of Health and Human Services, 1988) of gradual adaptation (tolerance), irreversibility (withdrawal), and positive effects of habits (reinforcement) that are used in many of the more recent formal models of addictive behavior. Until recently, however, economists have either ignored the addictive nature of goods such as cigarettes when estimating demand or have assumed that behaviors such as smoking were irrational and could not be analyzed in the rational, constrained utility maximizing framework of economics.

Many of the most recent studies of cigarette demand explicitly address the addictive nature of cigarette smoking. Economic models of addiction can be divided into three basic groups: imperfectly rational models of addictive behavior, models of myopic addictive behavior, and models of rational addictive behavior. 


\subsubsection{Imperfectly rational addiction models}

Elster (1979), McKenzie (1979), Winston (1980), and Schelling (1978, 1980, 1984a, 1984b) best exemplify the economic models of imperfectly rational addictive behavior. These models generally assume stable but inconsistent short-run andlong-run preferences.

This is seen, for example, in Schelling's (1978) description of a smoker trying to "kick the habit":

Everybody behaves like two people, one who wants clean lungs and long life and another who adores tobacco.... The two are in a continual contest for control; the "straight" one often in command most of the time, but the wayward one needing only to get occasional control to spoil the other's best laid plan. (p. 290)

Thus, the farsighted personality may enroll in a smoking cessation program, only to be undone by the shortsighted personality's relapse in a weak moment. Winston (1980)

formally modeled this behavior and described how this contest between personalities leads to the evolution of what he called "anti-markets," which he defined as firms or institutions that individuals will pay to help them stop consuming.

Strotz (1956) was the first to develop a formal model of such behavior, describing the constrained utility maximization process as one in which an individual chooses a future consumption path that maximizes current utility, but later in life changes this plan "even though his original expectations of future desires and means of consumption are verified" (p. 165). This inconsistency between current and future preferences only arises when a non-exponential discount function is used? Strotz went on to suggest that rational persons will recognize this inconsistency and plan accordingly, by pre-committing their future behavior or by modifying consumption plans to be consistent with future preferences when unable to pre-commit. Pollak (1968) went one step further, arguing that an individual may behave naively even when using an exponential discount function. Thaler and Shefrin (1981) described the problem similarly, referring to an individual at any point in time as both a "farsighted planner and a myopic doer" (p. 392), with the two in continual conflict. While these models present interesting discussions of some aspects of addictive behavior, they have not been applied empirically to cigarette smoking or other addictions.

\subsubsection{Myopic addiction models}

The naive behavior described in some of the imperfectly rational moels of addiction is the basis for many of the myopic models of addictive behavior. As Pollak (1975) observed, behavior is naive in the sense that an individual recognizes the dependence of current addictive consumption decisions on past consumption, but then ignores the impact of current and past choices on future consumption decisions when making current choices.

Many of these models treat preferences as endogenous, allowing tastes to change over time in response to past consumption (Gorman, 1967; Pollak, 1970, 1976, 1978; von Weizsacker, 1971; Hammond, 1976a, 1976b; El-Safty, 1976a, 1976b).

These models are similar in spirit to those in which tastes change in response to factors other than past consumption, including advertising Dixit and Norman, 1978; Galbraith, 1958, 1972) and prices (Pollak, 1977). Others allow past consumption to affect current consumption through an accumulated stock of past consumption (e.g., Houthakker and Taylor, 1966, 1970). These models are comparable to those of the demand for durable consumer goods that use a stock adjustment process (e.g, Chow's (1960) model of the demand for automobiles, and Garcia dos Santos' (1972) analysis of the demands for household durables). As Phlips (1983) noted, however, the distinction between models with endogenous tastes and those with stable preferences within a household production framework is purely semantic, since the underlying mathematics of the two are the same.

The earliest theoretical models of demand in the context of myopic addiction can be traced to the irreversible demand models (Haavelmo, 1944; Duesenberry, 1949; Modigliani, 1949; Farrell, 1952). Farrell, for example, described an irreversible demand function as one in which current demand depends on all past price and income combinations. As a result, price and income elasticities are constant, but may differ for increases and decreases in price and income. Farrell tested this model empirically, using U.K. data on

${ }^{7}$ Vuchinich and Simpson (1998) provided an interesting application of this idea to the demand for alcoholic beverages, comparing behavior under hyperbolic versus exponential discounting. 
the demands for tobacco and beer from 1870 through 1938, in a model that included not only current price and income, but also price, income, and consumption in the prior year. In general, his estimates were inconclusive, although he did find limited evidence of habit formation for tobacco use.

The notion of asymmetric responses to price and income reappeared in Scitovsky (1976) and was applied to cigarette demand by Young (1983) andPekurinen (1989), using data from the U.S. and Finland, respectively. Both found that smoking was almost twice as responsive to price reductions as it was to price increases, which they interpreted as evidence of addiction.

Most empirical applications of myopic models of addiction are based on the pioneering work by Houthakker and Taylor (1966, 1970) that formally introduced the dependence of current consumption on past consumption by modeling current demand as a function of a "stock of habits" representing the depreciated sum of all past consumption.

Houthakker and Taylor estimated demand functions for a variety of goods, including cigarettes, using annual aggregates for the U.S. and several Western European countries. Their estimates provided considerable support for their hypothesis of habit formation in demand for almost all of the non-durable consumer goods they examined, including cigarettes.

Mullahy (1985) took a similar approach in his empirical examination of cigarette demand using individual level data from the 1979 National Health Interview Survey. In his model, the stock of past cigarette consumption has a negative impact on the production of commodities such as health and the satisfaction received from current smoking. Mullahy used a two-part model to estimate cigarette demand, as well as instrumentalvariables methods to account for the unobserved individual heterogeneity likely to be correlated with the stock of past consumption. Mullahy found strong support for the hypothesis that cigarette smoking is an addictive behavior, as shown by the positive and significant estimates he obtained for the addictive stock in both the smoking participation and conditional demand equations. His estimates for price are quite similar to those obtained by Lewit and Coate (1982), with the overall price elasticity of demand centered on -0.47.

In addition, Mullahy estimated that men were more price responsive than women (total price elasticities of -0.56 and -0.39 , respectively). Finally, using an interaction between the addictive stock and price, Mullahy concluded that more-addicted smokers (defined as those with a larger addictive stock) were less responsive to price than their less-addicted counterparts. Other approaches to estimating myopic demand models have similarly concluded that cigarette smoking is an addictive behavior and that price has a significant impact on cigarette demand (e.g. Jones, 1989 Baltagi and Levin, 1986).

\subsubsection{Rational addiction models}

Several researchers have modeled addiction as a rational behavior. In this context, rationality simply implies that individuals incorporate the interdependence between past, current, and future consumption into their utility maximization process. This is in contrast to the assumption, implicit in myopic models of addictive behavior, that future implications are ignored when making current decisions. In other words, myopic behavior implies an infinite discounting of the future, while rational behavior implies that future implications are considered, while not ruling out a relatively high discount rate. Several of the rational addiction models, including those of Lluch (1974), Spinnewyn (1981), and Boyer (1983), assume that tastes are endogenous. These models build on the significant contributions of Ryder and Heal (1973), Boyer (1978), and others in the optimal growth literature who have developed endogenous taste models with rational behavior. Spinnewyn (1981) and Phlips and Spinnewyn (1982) argued that incorporating rational decision making into models of habit formation results in models that are "formally equivalent to models without habit formation" (Spinnewyn, 1981, p. 92). Thus, they argue, assuming rationality only leads to unnecessary complications.

This assertion was challenged by Pashardes (1986) who derived demand equations for a rational consumer in which current consumption is determined by past consumption and current preferences with full knowledge about the impact of current decisions on the future costs of consumption. Pashardes found considerable empirical evidence to support the hypothesis of rational behavior in general, as well as evidence that cigarette smoking is an addictive behavior. Finally, he noted that expectations concerning the future price and other costs of consumption played an important role in consumer behavior.

Becker and Murphy (1988) similarly rejected the notion that myopic behavior is empirically indistinguishable from rational behavior in their theory of rational addiction. They assumed that individuals consistently maximize utility over their life cycle, taking into account the future consequences of their choices. In their model, 
utility at any point in time depends on current addictive consumption current nonaddictive consumption, and the stock of past addictive consumption. Tolerance is incorporated by assuming that the marginal utility of the addictive stock is negative. Reinforcement is modeled by assuming that an increase in the addictive stock raises the marginal utility of current addictive consumption. Finally withdrawal is captured since total utility falls with the cessation of addictive consumption.

Becker and Murphy (1988) and Becker et al. (1991) developed several hypotheses from this basic model. First, addictive consumption displays "adjacent complementarity"; that is, due to reinforcement, the quantities of the addictive good consumed in different time periods are complements. As a result, current consumption of an addictive good is inversely related to not only the current price of the good, but also to all past and future prices. Consequently, the long-run effect of a permanent change in price will exceed the short-run effect. Moreover, in the Becker and Murphy model, the ratio of the long-run to short-run price effect rises as the degree of addiction rises. In addition, they predict that the effect of an anticipated price change will be greater than the impact of a comparable unanticipated price change, while a permanent price change will have a larger impact on demand than a temporary price change. Finally, price responsiveness varies with time preference: addicts with higher discount rates will be relatively more responsive to changes in money price than those with lower discount rates.

The opposite will be true with respect to the effects of information concerning the future consequences of addictive consumption. Thus, the model suggests that younger, less educated, and lower income persons will be relatively more responsive to changes in the money price of cigarettes, while older, more educated, and higher income persons will be relatively more responsive to new information on the health consequences of cigarette smoking.

Strong adjacent complementarity, reflecting strong addiction, can lead to unstable steady states in the Becker and Murphy model. This is a key feature of their rational addiction theory, helping to explain the binge behavior and "cold turkey" quit behavior observed among addicts. Furthermore, these unstable steady states imply that there will be a bimodal distribution of consumption, again something that is observed for many addictive goods. In addition, Becker and Murphy's model implies that temporary events, including price reductions, peer pressure, or stressful events, can lead to permanent addictions.

Chaloupka (1988, 1990, 1991, 1992) used data from the Second National Health and Nutrition Examination Survey conducted in the late 1970s in the first empirical application of the rational addiction model. He found consistent evidence that cigarette smoking was an addictive behavior and that smokers did not behave myopically. Chaloupka's (1991) estimates of the long-run price elasticity of demand fell in the range from -0.27 to -0.48 , larger than the elasticities obtained from conventional demand equations using the same data. In addition to estimating the rational addiction demand equations for the full sample, Chaloupka also explored the implications of the Becker and Murphy model with respect to the rate of time preference by estimating comparable demand equations for subsamples based on age and educational attainment. Chaloupka's (1991) estimates were generally consistent with the hypothesis that less educated or younger persons behave more myopically than their more educated or older counterparts. In addition, less educated persons were more price responsive, with long-run price elasticities ranging from -0.57 to -0.62, than were more educated persons, who were generally unresponsive to price. Chaloupka (1990) also estimated separate demand equations for subsamples based on gender, concluding that men behaved more myopically and were relatively responsive to price (longrun price elasticity centered on -0.60) than women (statistically insignificant effect of price on demand).

Similar findings were obtained by Becker et al. (1994) using aggregate, state-level sales data for the U.S. over the period from 1955 through 1985 . They found clear evidence that smoking was addictive, as well as evidence of non-myopic, although not fully rational, behavior. ${ }^{10}$ Estimates from other studies employing U.S. data (Keeler et al.,

8 Myopic addiction models also predict that the long run price elasticity of demand will be larger than the short run elasticity.

9 See Chaloupka (1988, 1990, 1992) or Becker et al. (1994) for a more formal discussion of these price effects.

10 The authors concluded that there was insufficient information in the data to 
1993; Sung et al., 1994) and data from other countries, including Finland Pekurinen, 1991) and Australia (Bardsley and Olekalns, 1998), are generally consistent with the hypothesis of rational addiction. In contrast, Duffy (1996a), Cameron (1997), and Conniffe (1995), using annual time-series data for the U.K., Greece, and Ireland, respectively, found little support for the rational addiction model. These latter studies, however, are generally limited by the relatively small number of observations available for their analyses, and by the use of several highly correlatedregressors.

As noted above, Douglas (1998) used hazard models to examine the determinants of smoking initiation and cessation in the context of the Becker and Murphy (1988) rational addiction model. In contrast to his finding that price does not significantly affect the hazard of smoking initiation, Douglas concluded that increases in price significantly increase the likelihood (hazard) of smoking cessation. He estimateda price elasticity for the duration of the smoking habit of -1.07 with respect to future price, consistent with the hypothesis of rational addiction; paradoxically, past and current prices were not found to have a statistically significant effect on cessation. Similarly, his parametric and non-parametric results imply that the hazard of smoking cessation hasa positive duration dependence, a finding Douglas suggested is consistent with rational addiction in that the rational smoker will discount future health costs less as they become more imminent.

\subsubsection{Critiques of the rational addiction model}

While the rational addiction model has gained acceptance among some economists, many object to several assumptions of the model. Perhaps the most criticized aspect of the model is the assumption of perfect foresight. As Winston (1980) explained, in the context of the stigler and Becker (1977) model:

[T] he addict looks strange because he sits down at period j=0, surveys future income, production technologies, investment/addiction functions, and consumption preferences over his lifetime to period $T$, maximizes the discounted value of his expected utility, and decides to be an alcoholic. That's the way he will get the greatest satisfaction out of life. Alcoholics are alcoholics because they want to be alcoholics, ex ante, with full knowledge of its consequences. (page 302)

Similarly, Akerlof (1991) noted that individuals who become addicted in the rational addiction model do not regret their past decisions, given that they are assumed to have been fully aware of the consequences of their consumption of a potentially addictive good when making those decisions.

A recent theoretical paper by Orphanides and Zervos (1995) addressed this and other perceived inconsistencies of the rational addiction model that arise largely from the assumption of perfect foresight. In particular, the authors introduced uncertainty into the model by assuming that inexperienced users are not fully aware of the potential harm associated with consuming an addictive substance. Instead, in their model, an individual's knowledge comes from the observed effects of the addictive good on others as well as through his or her own experimentation with that good. More specifically, they assume that the harmful effects (including addiction) of consuming a potentially addictive good are not the same for all individuals, that each individual possesses a subjective understanding of his or her potential to become addicted, and that this subjective belief is updated via a Bayesian learning process as the individual consumes the addictive good.

Thus, an individual who underestimates his or her potential for addiction and experiments with an addictive substance can end up becoming addicted. Rather than the "happy addicts" implied by the rational addiction model (Winston, 1980), these addicts will regret becoming addicted. As Orphanides and Zervos noted, the incorporation of subjective beliefs into the rational addiction model helps explain youthful experimentation, the importance of peer influences, and other commonly observed facets of addiction.

More recently, in a model focusing on cigarette smoking, Suranovic et

al. (forthcoming) also reconsidered the Becker and Murphy (1988) model of rational addiction. As described above, adjacent complementarity is a key feature of the rational addiction model. Suranovic et al. noted, however, that one implication of adjacent complementarity is that efforts to reduce current consumption will lead to reductions in utility. These "quitting costs" are an important feature of their model and help explain 
the seeming inconsistency between smokers' stated wishes to quit smoking and their continued cigarette consumption. In addition, they help explain why smokers engage in various behavior modification treatments, such as the use of the nicotine patch, which help make quitting easier.

A second point of departure from the Becker and Murphy model concerns the timing of the consequences of smoking, which Suranovic et al. assume are concentrated at the end of a smoker's life. In addition, rather than assuming that individuals choose a lifetime consumption path that maximizes the present value of their lifetime utility, Suranovic et al. assume "boundedly rational" behavior, implying that individuals choose current consumption only. As a result, their model suggests that aging is enough to induce cessation among some smokers. As in the Becker and Murphy model, their model implies that quitting "cold-turkey" is likely in the case of a strong addiction (one where quitting costs rise rapidly for small reductions in consumption). However, in contrast to Becker and Murphy, Suranovic et al. predicted gradual reductions in consumption progressing to quitting in the case of relatively weak addictions. Interestingly, some newly emerging epidemiologic evidence supports this prediction (Earkas, 1998).

In addition, as Becker and Mulligan (1997) describe, addiction and time preference may be related. As discussed above, the Becker and Murphy (1988) model of rational addiction implied that people who discount the future more heavily were more likely to become addicted. In their theoretical discussion on the determination of time preference, Becker and Mulligan suggest that addictive consumption, by raising current utility at the expense of future utility, can make even rational persons behave more myopically.

Finally, Showalter (1998), in his analysis of the behavior of firms producing an addictive good, suggests an alternative interpretation for the finding in most empirical applications of the rational addiction model that future consumption has a significant impact on current consumption. Rather than resulting from rational behavior on the part of consumers, Showalter shows that the same finding could result from myopic behavior by consumers coupled with rational behavior by firms. In his empirical applications of this model, Showalter finds that the rational and myopic demand models produce similar predictions, but that neither does well in predicting actual behavior, a finding he attributes to the difficulties of accurately forecasting prices.

\subsection{Behavioral economic analyses of cigarette demand}

Behavioral economics involves the application of the principles of consumer demand theory to experimental psychology (Hursh and Bauman, 1987). Over the past decade, there have been numerous behavioral economic analyses of a variety of addictive behaviors, including cigarette smoking (Bickel and DeGrandpre, 1996). These studies examine the impact of price and other factors on the self-administration of a number of addictive substances by humans as well as a variety of non-human species in a laboratory setting. Price, in this context, is defined as the response or effort requiredto receive one dose of a drug (Bickel et al., 1993). As in standard economic analyses, an increase in price is expected to lead to a reduction in the quantity of drug demanded. One advantage of this experimental approach for the analysis of cigarette demand, both in general and as it relates to policy debates specifically, is that it allows researchers to study the effects on demand of changes in cigarette prices that are many times larger than the price differences that are observed in the cross-sectional or time-series data that have been used in the econometric studies of demand. One limitation of the approach, however, is that these methods are generally applicable only to dependent individuals. For example, for ethical reasons (and others), they cannot be used to address issues related to the effect of price on smoking initiation.

The behavioral economics of cigarette smoking is the most extensively researched area in the behavioral economics of drug abuse (Bickel and Madden, 1998). In a series of papers, Bickel, DeGrandpre, and their colleagues have reported the results of research on cigarette smoking conducted in their behavioral economics laboratory Bickel et al., 1991 ; DeGrandpre et al., 1992; DeGranpre et al., 1994; Bickel et al., 1995; DeGrandpre and Bickel, 1995; Bickel and DeGrandpre, 1996; Bickel and Madden, 1998). These experiments typically involve individuals ages 18 and older who smoke a pack or more of cigarettes per day who participate in between two and five three-hour experimental sessions per week. Price, in these experiments, is defined as the number of complete pulls and resets of a

11 For a discussion of a number of other requirements for the participants and more detail on the features of these experiments, see Bickel and Madden (1998). 
plunger required to receive a preset number of puffs on a cigarette. For example, 50 pulls on the plunger may be required to obtain two puffs on a cigarette. Puffs are monitored by a puff-volume sensor so that each subject receives essentially the same dose per puff (Bickel and Madden, 1998).

A wide range of prices is used in these experiments. In some of the experiments, respondents were also presented with an opportunity to earn money for pulls on the plunger that could then be spent on cigarettes. As in the econometric studies described above, the behavioral economic analyses have consistently found an inverse relationship between cigarette smoking and price. Estimates of the price elasticity of demand obtained from these studies are surprisingly consistent with those obtained from econometric studies. For example, Bickel et al. (1995) estimated a mean price elasticity of demand of -0.56 for five subjects in an experiment in which price ranged from 12 to 1600 pulls per puff. A particularly interesting finding from the behavioral economics research is that the price elasticity of demand rises as price rises. For example, DeGrandpre and Bickel (1995) estimated a mean price elasticity of -1.58 for prices ranging from 400 to 4500 pulls per puff. These findings appear to be generalizable not only across drugs but also across species (Bickel et al., 1990).

\subsection{Econometric studies of the demand for other tobacco products}

In contrast to the relatively large literature examining the impact of cigarette prices on cigarette smoking, few studies look at the effects of price on the use of other tobacco products, and fewer still consider cross-price effects for cigarettes and other tobacco products. Much of this research has been conducted by Ohsfeldt and his colleagues (Ohsfeldt and Boyle, 1994; Ohsfeldt et al., 1997, 1998). Using state-level aggregates constructed from the September 1985 tobacco use supplement to the Current Population Survey, Ohsfeldt and Boyle (1994) examined the impact of state smokeless tobacco taxes and cigarette excise taxes on the prevalence of smokeless tobacco use by males ages 16 years and older. The authors concluded that higher smokeless tobacco taxes would significantly reduce the prevalence of smokeless tobacco use. In addition, Ohsfeldt and Boyle found evidence of substitution among tobacco products, in that higher cigarette excise taxes have a positive and significant effect on the prevalence of smokeless tobacco use. Given this finding, they suggested that the increase in smokeless tobacco use observed among young males in the $1980 \mathrm{~s}$ was at least in part due to the increases in state cigarette taxes which were rising more rapidly during this time than state taxes on other tobacco products.

Similarly, Thompson and McLeod (1976) and Pekurinen (1989, 1991) concluded that some Canadian and Finnish cigarette smokers, respectively, would switch from manufactured cigarettes to less expensive hand-rolled cigarettes in response to increases in the prices of manufactured cigarettes. Pekurinen also found a negative and significant relationship between the demands for pipe tobacco and cigars and their own-prices. Leu (1984), however, found little evidence of substitution among tobacco products by Swiss tobacco users in response to changes in their relative prices.

The findings obtained by Ohsfeldt and Boyle based on aggregate data are confirmed by their subsequent analyses using individual-level data from the September 1985 CPS (Ohsfeldt et al., 1997) and the september 1992, January 1993, and May 1993 CPS Qhsfeldt et al., 1998). In the more recent analysis, the authors estimatedan own-tax elasticity for smokeless tobacco use of -0.10 for their sample of males ages 16 and older and again concluded that smokeless tobacco products are substitutes for cigarettes. In addition, as seen for cigarette demand, they estimated an inverse relationship between the elasticity of demand for smokeless tobacco products and age.

This finding was confirmed by Chaloupka et al.'s (1997) recent analysis of smokeless tobacco use among young males using data from the 1992, 1993, and 1994 Monitoring the Future surveys of eighth, tenth, and twelfth grade students. The researchers estimated an overall price elasticity of young males' smokeless tobacco use of -0.746 , and a participation elasticity of -0.523 .

\section{Cigarette and other tobacco taxation ${ }^{12}$}

12 As most of the evidence and concern pertaining to tobacco taxation relates to cigarette excise taxation, we refer specifically to cigarette taxation in most of the discussion in this section. However, we do present the evidence pertaining to the taxation of other tobacco products where it applies. 
With retail price an important determinant of the demand for cigarettes, and excise tax often a significant component of retail cigarette price, the issue of whether to increase cigarette excise taxes has been highly visible in legislative debates on both governmental revenue raising and tobacco control for decades. Cigarette excise taxation offers an unusual attraction for legislators: given the evidence on demandelasticities, increases in cigarette taxes of politically plausible magnitude will produce a public health benefit, by discouraging smoking, particularly among children. At the same time, they will generate additional revenues for the governmental unit in question, typically at a fairly low administrative cost. Further, polls often find support for cigarette excise increases among American voters, frequently even including smokers.

Still, the prospect of increased taxation raises a myriad of complicated

philosophical and practical questions. Among the former are the following: What is the "right" level of cigarette taxation, if any? What is the basis for determining that it is "right"? Are cigarette taxes fair, given their distributional burdens in terms of both vertical and horizontal equity? In particular, since more low-income than high-income people smoke (in developed countries), will increased cigarette taxes impose an unfair regressive burden on low-income taxpayers? What are the proper tradeoffs between the interests of individuals (liberty interests, tax burden) and the societal interest in the public's health? Practical questions include the following: Given theoligopolistic nature of the cigarette industry, as well as estimated supply and demandelasticities, how will taxation affect cigarette price? With differences in tax rates by jurisdiction defining much of the difference in prices across borders of states and nations, will a given increase in excise tax in a relatively high-tax jurisdiction result in a significant amount of smuggling from a neighboring low-tax jurisdiction? What are the revenue implications of a tax increase of given magnitude? How will a given tax-induced price increase influence smoking, and consequently, what impacts will it have on the public's health?

Economists have made numerous important conceptual and empirical contributions to the policy debate on cigarette taxation, primarily, although not exclusively, through their evaluation of the relationship between cigarette price and consumption, reviewed in the preceding section. In this section, we review economists' contributions to better understanding the rationale for (or against), and additional effects of, cigarette excise taxation.

\subsection{Comparative standards and the effects of tax on price \\ 3.1.1 Purposes and methods of taxation}

Cigarettes and other tobacco products have been taxed for centuries, primarily because the relatively inelastic demand for these products makes them an easy source of revenues. In the U.S., for example, tobacco has been taxed since colonial times, rising with revenue needs and declining during more prosperous times. Since the Civil War, tobacco taxes have remained a part of the U.S. federal tax system, often increasing during wartime and falling again in peacetime. Similar historical patterns are observed in many other developed countries. However, the importance of tobacco taxes as a share of total revenues has generally declined over time in most countries. In the U.S. for example, tobacco taxes currently account for less than one-half of one percent of total federal revenues, down from 3.36 percent of revenues in 1950.

In recent decades, the increased taxation of cigarettes and other tobacco products has been motivated not only by the revenue generating potential of these taxes, but also as a means to reduce cigarette consumption. Warner (1981b) concluded that the information on the health consequences of cigarette smoking that began appearing in the $1950 \mathrm{~s}$ and early 1960s led a number of states to increase cigarette taxes as a way of discouraging cigarette demand. More recently, a number of countries have adopted or considered large tax increases on cigarettes and other tobacco products as a way to reduce consumption. In Canada, for example, steady federal and provincial tobacco tax increases throughout the $1980 \mathrm{~s}$ and early-1990s were motivated in part by concerns over the health consequences of smoking. Similar concerns were behind the recent large increases in cigarette taxes in California, Massachusetts, Arizona, Oregon, and other U.S. states.

Large tax increases can generate both significant declines in cigarette smoking as well as considerable increases in cigarette tax revenues. In Canada, for example, the over 500 percent increase in taxes between 1982 and 1992 led to an increase in real cigarette prices of 170 percent, reducing total cigarette smoking by 38 percent \$weanor and Martial, 1994). Total federal and provincial cigarette tax revenues rose by 240 percent during this period, even with the development of a significant black market in cigarettes. 
Cigarettes and other tobacco products are taxed in a variety of ways. The most commonly used methods of taxation include excise taxes, value added and other adfalorem taxes, and import duties. Most cigarette excise taxes are specified as an amount per $x$ number of cigarettes (e.g., the U.S., Canada, and many others), while others are based on the weight of tobacco contained in the cigarette (e.g., Australia and Malaysia).

Similarly, there are a variety of ad-valorem taxes, including the value added taxes imposed by most European and many other countries, as well as the sales taxes applied in most U.S. states and elsewhere. There are comparable differences in the types of import duties applied by nearly all countries to tobacco products. Some of the distinctive features of these taxes include: earmarking for tobacco-related education, counteradvertising, and other health related activities (e.g., Finland, Denmark, Peru, Romania, Nepal, and several U.S. states); the use of tax revenues to create the state-run Health Promotion Foundations in several Australian states and the Health Sponsorship Council in New Zealand, to fund sporting and artistic events previously backed by the tobacco industry; and the differential taxes on cigarettes with high tar and nicotine content used in previous years in the U.K. (WHO, 1997; Roemer, 1993).

\subsubsection{Effects of taxes on retail price}

Increases in cigarette and other tobacco taxes result in higher prices for these products. When excise taxation is the primary form of tobacco taxation, however, the real value of the tax will fall over time, unless regularly increased to account for inflation.

Given that taxes are an important component of price, one consequence of an excise tax system for tobacco products with relatively infrequent tax increases is that the real price of these products will fall over time as the prices of other goods and services increase more rapidly. In the U.S., for example, due to the relative stability of federal and state cigarette excise taxes throughout the 1970s, real cigarette prices fell by nearly 40 percent. Between 1981 and 1996, however, real cigarette prices in the U.S. rose by over 65 percent, due in part to the tripling of the federal cigarette excise tax and numerous state tax increases. ${ }^{13}$ In contrast, the real value of an ad-valorem tax on tobacco products is maintained when the prices of these products rise with the prices of other goods and services.

The oligopolistic nature of the cigarette industry and the addictive nature of cigarette demand have important implications for the effects of cigarette tax increases on cigarette prices. In a perfectly competitive market with constant long-run costs of production, any tax increase would be fully passed on to consumers. At the other extreme, a monopolist would share the burden of the tax increase with consumers, with consumers bearing relatively more of the burden when demand is relatively inelastic. In most developed countries, the cigarette industry, however, is clearly at neither extreme, but is instead an oligopoly. In the U.S., for example, the five leading cigarette producers accounted for virtually the entire cigarette market, with the top three (Philip Morris, R.J. Reynolds, and Brown \& Williamson) controlling over 90 percent of the market (Federal Trade Commission, 1997). In some countries, however, particularly developing countries, a domestic monopoly controls most of the market.

Most of the empirical analyses of the relationship between cigarette taxes and prices are based on data from the U.S. Early studies produced generally inconsistent findings (Barzel, 1976; Johnson, 1978; Sumner, 1981; Sumner and Ward, 1981; Bulow and Pfleiderer, 1983; Bishop and Yoo, 1985; Sullivan, 1985; Sumner and Wohlgenant, 1985; Ashenfelter and Sullivan, 1987). One general weakness of these studies is that they failed to account for the dynamic interaction of firms in anoligopolistic industry. Instead, they generally assumed that the rules for firm behavior were established and then worked backwards to estimate the degree of competition in the industry (Harris, 1987).

More recent studies have attempted to model the dynamic nature of an oligopolistic industry when estimating the impact of cigarette taxes on cigarette prices. Harris (1987) used data on wholesale and retail cigarette prices as well as manufacturing costs to estimate the change in cigarette prices that resulted from the doubling of the U.S. federal cigarette tax in 1983. He concluded that the eight-cent tax increase led to a 17cent price increase that was not explained by increased manufacturing costs. Instead, Harris argued that the scheduled tax increase served as a mechanism for a coordinated,

13 Increases in the non-tax component of price, however, account for most of the rise in U.S. cigarette prices between 1981 and 1996. During this period, cigarette taxes as a percentage of price fell from just over one-third to under one-quarter. 
oligopolistic price increase.

Barnett and his colleagues (1995) noted that Harris' analysis did not fully account for underlying trends in cigarette prices. Consequently, they argued that Harris attributed too much of the increase in price to the increase in the tax since the upward trend in cigarette prices predated the debate over the federal tax increase. Instead, they argued that the introduction of generic cigarettes in 1981 allowed cigarette producers to engage in coordinated increases in the prices of premium cigarettes since the generic cigarettes would keep more price-sensitive smokers in the market.

Keeler and his colleagues (Keeler et al., 1996; Barnett et al., 1995; Sung et al., 1994) used national and state level data in empirical analyses of the effects of tax increases on price. Their models account for the interaction of supply and demand, the oligopolistic nature of the cigarette industry, and, in some, the addictive nature of cigarette demand. Using annual state-level data for the period from 1960 through 1990, Keeler et al. (1996) estimated that a one-cent increase in a state's cigarette tax would raise retail prices in that state by 1.11 cents. In addition, they estimated that increases in federal cigarette taxes would generate larger increases in cigarette prices than those resulting from state tax hikes (Barnett et al., 1995). They attributed this finding to the potential of cross-border shopping for cigarettes in response to a state tax increase. Finally, Keeler et al. (1996) concluded that cigarette producers price discriminate by state, in that stronger state and local anti-smoking laws are offset by lower prices. However, they noted that the effect of price discrimination is not large relative to retail cigarette prices.

Based on the Becker and Murphy (1988) rational addiction model, Becker et al. (1994) suggested an alternative explanation for the finding that cigarette prices increase by more than cigarette taxes when taxes are raised. They argued that when taxes are raised, cigarette companies will raise price by more to obtain maximum profit from current, addicted smokers. These increased current profits help offset the future losses from the reduced smoking initiation resulting from the price increase. Becker and his colleagues explained this apparent paradox as follows: "If smokers are addicted and if the industry is oligopolistic, an expected rise in future taxes and hence in future prices induces a rise in current prices even though current demand falls when future prices are expected to increase" (page 413). They went on to explain that because of the addictive nature of smoking, cigarette producers set prices below their short-run profit maximizing level in order to "hook" consumers on their addictive product, thus raising the future demand for this product. Showalter (1998) makes a similar argument with respect to advertising, suggesting that cigarette producers might engage in apparently excessive advertising in order to attract a few new customers.

\subsubsection{Variations in cigarette tax across countries and states and the issue of smuggling}

The share of cigarette taxes in cigarette prices varies widely among countries. Denmark, Ireland, and the U.K., for example, over 80 percent of cigarette prices are accounted for by cigarette taxes (Sweanor, 1997), while taxes in most others were between 65 and 80 percent. ${ }^{14}$ In contrast, among developed countries, cigarette taxes are less than half of price only in the U.S., where they account for 35 percent of price, on average (21 percent in the lowest taxing state and 47 percent in the highest). The large difference in cigarette taxes leads to a five-fold difference in cigarette prices among these countries. As the WHO (1997) has observed, inter-country differences in wages and prices can understate the difference in price when expressed in a single currency. When expressed in terms of minutes of labor required to earn the price of a pack of cigarettes, the differences are even larger.

One consequence of the differences in cigarette taxes and prices, both across countries as well as among different taxing jurisdictions within countries, is the potential for casual and organized cigarette smuggling and other forms of tax evasion. The cigarette industry, for example, frequently argues that cigarette tax increases will actually lead to reductions in tax revenues due to smuggling and other tax evasion (British American Tobacco, 1994). The smuggling problem is exacerbated by the relative ease with which tobacco products can be transported, the potential profits from this illegal activity, the presence of an informal distribution network in many countries, the availability of tax-free and duty-free cigarettes, and nonexistent or relatively weak policies concerning cigarette smuggling and their lack of enforcement Joossens and van 
der Merwe, 1997; Joossens and Raw, 1995, 1998; Advisory Commission on Intergovernmental Relations (ACIR), 1977 and 1985). Joosens and Raw (1995, 1998) argued that many of these other factors can be as important as price differences in spawning cigarette smuggling. For example, they noted that there is little evidence of cigarette smuggling in some of the highest priced European countries, including France, Norway, Sweden and the U.K., while there is extensive evidence of smuggling in those with relatively low prices, such as Spain and Italy. Moreover, they concluded that much of the cigarette smuggling that does occur in Europe and elsewhere is actually encouraged by the large, multinational tobacco companies. Thursby and Thursby (1994) provided empirical support for this argument, based on their analysis of data from the U.S. from which they concluded that increases in federal cigarette excise taxes lead to increased commercial cigarette smuggling.

There have been relatively few econometric analyses of the impact of price differentials on organized and casual cigarette smuggling. All of these studies are based on annual state-level cigarette sales data from the U.S. and all have concluded that the casual and organized smuggling of cigarettes from major tobacco producing states, as well as other states with relatively low cigarette prices compared to neighboring states, accounts for a significant share of sales in these states (Saba et al., 1995; Becker et al., 1994; Chaloupka and Saffer, 1992; Baltagi and Levin, 1986; ACIR, 1977, 1985; Manchester, 1976).

Perhaps the most widely cited example of the link between cigarette tax increases and smuggling is the Canadian experience during the late-1980s and early-1990s. In 1980, when Canada adopted an ad-valorem approach to cigarette taxation, Canadian cigarette prices were somewhat higher than prices in the U.S. By 1984, the gap had widened as Canadian cigarette taxes doubled and real cigarette prices rose by 25 percent. In 1984 , in response to industry pressure, the ad-valorem tax was replaced by an excise tax. Over the next few years, growth in Canadian cigarette taxes slowed, with most tax increases taking place at the provincial level. In 1988, however, the federal government mounted an aggressive anti-smoking campaign that included significant tax increases. In 1989, the federal tax was raised by two cents per cigarette, followed by a three cents per cigarette increase in 1991; provincial taxes continued to increase as well. By early 1994, the average Canadian tax per pack was $\$ 2.96$ (in U.S. dollars), more than five times the U.S. average (Sweanor and Martial, 1994).

The large tax and price disparities between the U.S. and Canada led to substantial cigarette smuggling from the U.S. Smuggling was a relatively minor problem prior to 1992 ; however, beginning in 1992, smuggling rapidly increased after the repeal of a Canadian tax on cigarette exports. In addition, the smuggling problem was exacerbated by the long undefended border between the U.S. and Canada, relatively weak border controls, and the high concentration of the Canadian population near U.S. borders (Sweanor and Martial, 1994). Much of the black market trade was in cigarettes originally produced in Canada, exported to the U.S. tax-free, and then smuggled back into Canada; relatively little involved U.S. produced cigarettes given their use of a blend of tobacco different from that preferred by Canadian smokers.

In response to an aggressive industry-sponsored campaign, the Canadian federal cigarette tax was reduced by $\$ 5.00$ per carton on February 9, 1994, with an agreement to match provincial tax reductions of up to another $\$ 10.00$ per carton. Quebec quickly lowered its provincial tax by $\$ 11.00$ per carton, for a total tax cut of $\$ 26.00$ per carton, cutting cigarette prices in half. Several other provinces followed and by the end of 1996, the average tax per pack was less than $\$ 2.00$. Canadian tax revenues fell and rates of smoking increased, particularly among youth.

The variations in taxes across countries and within countries over time reflect a myriad of practical and political considerations, with smuggling but one of them. In contrast to the legislators who must set taxes based on such considerations, academic economists approach the issue of the desirable level of cigarette taxation by contemplating the application of a number of economic principles relating to both equity and efficiency. The remainder of section 3 examines these principles and their relevance to the determination of a theoretically optimal cigarette excise tax. The discussion also compares and contrasts the perspective of the economist with that of the public health professional, for whom different criteria define "optimality" in cigarette taxation.

\subsection{Fairness standards}

The search for an optimal tax encompasses considerations of efficiency and equity. Each of these domains has featured prominently in policy debates on increasing cigarette taxes as well. From an efficiency point of view, the principal economic theory argument 
favoring imposition of a product-specific (excise) tax relates to the creation of negative externalities through production or consumption of the product. The nature and extent of such externalities with regard to smoking have been the subject of considerable debate among economists, as is discussed later in this section. ${ }^{1516}$

First, however, we examine a central issue in cigarette taxation, namely whether it violates widely accepted standards of fairness, with an emphasis on vertical equity. In developed countries such as the U.S., proportionately more lower-income people smoke than do those with high incomes. As a consequence, the burden of a tax on cigarettes is experienced disproportionately by the poor. The tax is criticized as being highly regressive.

\subsubsection{Horizontal and vertical equity}

In terms of tax policy, the principle of horizontal equity is that equals should be treated equally. Clearly, cigarette taxation violates this principle if one accepts that people who are identical except for their smoking behavior should be deemed "equals." Arguments in favor of cigarette taxation thus ignore this principle, while opponents of taxation appeal directly to it (although rarely in the language of economists). Violation of the horizontal equity principle has never been the focal point of critics' concern, however. Rather, they have focused on questions of vertical equity, specifically the apparent regressivity of cigarette taxes. Cigarette taxes would be regressive with respect to income if poorer and more affluent consumers smoked at the same rate. The potential problem of regressivity is exacerbated, in many developed countries at least, by the above-mentioned tendency for smoking prevalence to be inversely related to income.

Recent empirical analysis has muted this concern somewhat, concluding that the degree of regressivity is substantially less than appears at face value. Using data from the 1984-85 Consumer Expenditure Survey, analysts at the Congressional Budget Office (1990) found that expenditures on tobacco products increased with income, except for those in the highest income quintile. In part this reflects an increasing intensity of smoking (numbers of cigarettes) among smokers as income rises, and a propensity for higher-income smokers to buy products that are more expensive per unit. As a percentage of post-tax income, however, tobacco spending varied inversely with income level, with the lowest quintile spending $4 \%$ on tobacco.

When the CBO analysts examined tobacco spending as a percentage of expenditures on all good and services, however, they found that the share of tobacco expenditures fell gradually over the first four income quintiles (from 1.6 to 1.1\%) and dropped sharply in the top quintile (to 0.7\%). Consequently, CBO concluded, if annual family expenditures are more reflective of lifetime income than annual family income, then tobacco

15 Less frequently debated is a pragmatic consideration: whether cigarette taxation violates the Ramsey Rule, namely that when dealing with consumption taxes, tax rates should vary inversely with the elasticity of demand for products (holding supply elasticity constant). The purpose is to ensure that revenue-raising occurs in a manner that will minimize distortions in consumers' choices among goods and services and in their decisions of how much to spend and how much to save. Until recently, the empirical evidence has suggested that cigarettes are an excellent target for taxation, consistent with the Ramsey Rule, given the consensus view on their relatively low demand elasticities, discussed in the preceding section. Jones and Posnett (1988) estimated that a 1\% increase in the cigarette tax rate would generate about a $0.9 \%$ increase in revenue. As noted in the preceding section, however, long-run demand elasticities may be as much as twice short-run elasticities, as reflected in the findings associated with application of the rational addiction model to cigarette smoking (Becker et al., 1994). Use of these greater long-run elasticities would suggest a lower level of tax efficiency.

16 The issues raised in this discussion would apply also to many other behaviors and consumption goods, such as consuming large quantities of fat (a risk factor for heart disease and cancer) or driving motorcycles (a risk factor for serious injury). Despite the logical parallels, few economists or public health professionals have advocated a fat tax or a special injury-related tax on motorcycles. Cigarettes (and alcohol; see the chapter by Cook and Moore) have been identified as unique in terms of the magnitude of the health damage and negative externalities they create. The "slippery slope" argument -once negative externalities are used to justify taxing tobacco and alcohol, cars will be next, then fat, then salt, etc. -- is not addressed in this chapter. 
expenditures are only slightly regressive over income classes. CBO also noted that younger families spend a higher proportion of their income on tobacco and that their share of tobacco spending as a percentage of total expenditures was higher as well.

To examine the distributional impact of a cigarette excise tax increase, cBO simulated the effects of doubling the then (1990) 16-cent federal per pack excise tax. When income tax brackets and transfer payments were indexed to account for the price increases associated with the excise tax increase, the apparent regressivity was reversed; the adjustments had the effect of lowering individual income taxes and raising transfer payments. Relative to expenditures, CBO found the burden of the increased tax to be closer to proportional than regressive. The largest share of the simulated tax increase was paid for by families in the third and fourth income quintiles, with the smallest share borne by families in the two lowest quintiles (first and second).

To control for the intertemporal nature of cigarette smoking, Lyon and Schwab (1995) examined the distributional effects of cigarette (and other "sin") taxes across measures of permanent or lifetime income. The authors did not find important differences in regressivity patterns compared to studies based on current income.

Recent research on differences in the price elasticity of demand for cigarettes by various measures of socioeconomic status has produced findings that suggest that the degree of regressivity normally attributed to cigarette taxation is considerably overstated. Townsend and colleagues (1994) found that (the absolute value) of price elasticity was inversely related to social class in Great Britain, with members of the highest social class exhibiting little price responsiveness and those in the lowest social class having an elasticity close to unity. In the U.S., Chaloupka (1991) concluded that less-educated persons were more price responsive than the more-educated, whileFarrelly and his colleagues (1998) found that cigarette demand by lower income persons was more elastic than that by higher income persons. Given the high correlation between income and both social class in Great Britain and education in the U.S., these studies indicate that increased cigarette taxes would reduce observed differences in smoking among socioeconomic groups. This mitigates conclusions about regressivity that derive from analyses that have failed to consider the inverse relationship between elasticity and income. The latter has characterized all studies to date.

Regardless of whether regressivity proves to be a serious concern or not with regard to cigarette taxation per se, analysts have pointed out that the goal of tax policy is for the overall impact of a tax and expenditure system to be progressive or proportional, rather than regressive (Congressional Budget Office, 1990; Warner et al., 1995). Related to this notion, various proposals to increase cigarette taxes have earmarked a portion of revenues to expenditures designed to aid the poorer members of society. These have ranged from smoking-specific expenditures (e.g., provision of smoking cessation services for the poor) to proposals to fund health care for the poor in part with cigarette tax revenues.

\subsubsection{The benefit principle}

Another perspective on fairness is that smokers should bear the costs of smoking that they impose on other members of the society. This consists of two categories of costs: those associated with diseases experienced by nonsmokers due to exposure to environmental tobacco smoke; and smokers' own publicly-funded medical costs subsidized by nonsmoking taxpayers. Related to the latter, excise taxation might be partially justified on the basis of the benefit principle, the notion that people who derive benefits from government activities should be taxed to cover their costs of production.

In the most direct application of this "user fee" concept, proponents argue that smokers should pay, through cigarette taxes, for the publicly-funded health care that smoking necessitates, primarily in the U.S. through the Medicaid program for the indigent and the Medicare program for the elderly. Although appealing at first blush, the logic underlying this argument can be challenged. First, the tax is a blunt instrument: many smokers who incur smoking-related health care expenditures will pay for them themselves, either out of pocket or through private health insurance. Why should they subsidize the health care costs of other smokers more than do nonsmokers? Similarly, many of today's smokers, who pay the excise taxes, will cease smoking in time to avoid smoking-related illnesses. Further, the costs that today's generation of smokers will experience in the future are not easily predicted; perhaps some currently expensive smoking-related disease conditions will be readily and inexpensively treatable in the future. Even if these costs were knowable, they would need to be discounted to reflect the fact that they will not occur, on average, for two or more decades. As it has been advanced to date, the "user fee" argument has today's smokers paying for today's smoking-related health care costs (Warner et al., 1995). 
In the case of smoking, the benefit principle is inextricably linked to the broader issue of the negative externalities associated with smoking. We consider the evidence pertaining to externalities below. First, however, we turn to fairness arguments in favor of increasing cigarette taxes that emanate from the public health community. Economists' analyses of the external costs of smoking are highly relevant to informing the public health community's sense of the social costs of smoking.

\subsection{Public health standards}

The public health community has advocated large increases in tobacco taxes for two reasons. One is the notion that smokers should cover the social costs of smoking, with the public health conception of social costs including both private costs to smokers and their families, as well as negative externalities (Cook, 1991). The second is based on a pragmatic realization: through its effects on prices, taxation will discourage many people from smoking, particularly young people. As a consequence, literally hundreds of thousands of premature deaths could be avoided by large increases in cigarette taxes. In this context, cigarette taxation is viewed as a powerful policy tool with which to foster improvements in the public's health.

\subsubsection{The social cost of smoking}

The public health community has long argued that smoking imposes large costs on society and that smokers should bear the burden of these costs. Cost-of-smoking analyses include three categories of costs: (i) the direct medical costs of preventing, diagnosing, and treating smoking-related diseases; (ii) the indirect morbidity costs associated with lost earnings from work attributable to smokingi and (iii) the indirect mortality costs related to the loss of future earnings due to premature smoking-produced deaths. Combined, these total well over $\$ 100$ billion in the U.S. ${ }^{18}$ Although most of the cost-of-smoking analysis has employed American data, estimates have also been prepared for Canada (Forbes and Thompson, 1983; Collishaw and Myers, 1984), Great Britain [ref], China (Jin et al., 1995), and other countries. In addition, numerous state-specific analyses have been performed in the U.S., most based on the SAMMEC model (Smoking-Attributable Morbidity, Mortality, and Economic Costs) (Shultz et al., 1991).

The cost-of-smoking studies have employed a variety of methods of estimating the different cost components, with attributable-risk methodology common in estimating smoking-related disease incidence or prevalence and the human capital approach employed in placing a value on lost years of life (Hodgson and Meiners, 1982; Warner et al., 1998). Following a trend in cost-of-illness estimation in general, more recent studies have adopted an incidence approach (Manning et al., 1989, 1991; Hay, 1991; Hodgson, 1988, 1992; Oster et al., 1984), in contrast with the prevalence approach predominant in the earlier studies (e.g., Rice et al., 1986). The prevalence approach values the present costs associated with all existing cases of smoking-produced illness (including future lost earnings attributable to current deaths). In contrast, the incidence approach values all of the future costs associated with new cases of smoking-produced disease during the reference year. The former provides an estimate of the current economic burden of smoking, while the latter is more useful for analyses of interventions that might interrupt the development of smoking-related illness.

The cost-of-smoking studies can be faulted on numerous grounds. For one, they have tended to omit certain categories of smoking-related health care, such as treatment of burn victims from smoking-ignited fires ${ }^{19}$ and perinatal care for low-birth-weight babies of smoking mothers (U.S. Department of Health and Human Services, 1998). Few studies have considered the costs of treatment of diseases caused by environmental tobacco smoking. No

17 A significant amount of work loss is associated with smoking (U.S. Department of Health and Human Services, 1989). In addition, smoking may decrease productivity while smokers are on the job, due primarily to the number and length of smoking breaks they take. The latter is rarely included in studies of the social costs of smoking, although it has been raised during debates on indoor smoking restriction legislation.

18 Authors' calculations, updating estimates in Bartlett et al. (1994) and Miller et al. (1998) to contemporary dollars.

19 Cigarette smoking is the leading cause of home fires and the leading cause of burn deaths (Napier, 1996). 
study has yet attempted to value intangible costs, such as the pain and suffering of smoking-related disease victims and their families. Ironically, these intangible costs may well dominate all of those that are more readily quantified Abt, 1975).

Hodgson (1998) and his colleagues (Warner et al., 1998) have argued that, as it is being applied in this literature, the conventional attributable risk methodology considerably underestimates smoking's burden on the health care system by virtue of its failure to consider how smoking complicates the course of many illnesses not themselves directly associated with smoking. For example, diabetics who smoke often have more complications of their diabetes than diabetics who do not smoke Smokers recover more slowly from surgeries of all types than do nonsmokers, thus extending post-surgical hospital stays. HIV-infected smokers may be more likely to develop near-term AIDS than are HIV-infected nonsmokers (Napier, 1996). Inclusion of such costs in cost-of-smoking analysis might lead to an increase in estimates of 50\% or more.

The cost-of-smoking studies also fail to take account of a wide variety of direct costs in addition to medical costs, including such items as the time and transportation costs associated with getting patients to and through health care services, the direct costs of home modifications to accommodate smoking-related disabilities, damage to buildings due to smoking-produced fires, smoking-related maintenance costs in industrial settings and homes, and the increased frequency of laundering necessitated by smoking. Omission of these nonmedical costs is standard practice in nearly all of the broader costof-illness literature. Occasionally, such omissions are acknowledged, with the researchers stating that they did not view such costs as large enough to warrant the additional research.

The indirect morbidity and mortality costs have been criticized frequently as representing an inadequate means of valuing the avoidable premature loss of life. By relying exclusively on the human capital approach, they place no value on life per se, clearly contrary to the behavior of virtually all civilizedsocieties which invest in preserving the health of senior citizens after they retire. Many analysts concur that use of willingness-to-pay measures would be preferable, but they bemoan the lack of suitable instruments for assessing such values.

The cost-of-smoking analytical community includes individuals who have calculated some of the economic "benefits" of smoking, including the reduction in Social Security payments for smokers who die prematurely (Shoven et al., 1989) and medical expenditures avoided as a result of smokers' premature demise. The latter, in particular, has set off a "battle of the studies" to ascertain whether the net medical expenditures associated with smoking are positive or negative (Leu and Schaub, 1983; Manning et al., 1989; Hodgson, 1992; Barendregt et al., 1997; Warner et al., 1998). The entire question of whether such "negative costs," or cost offsets, should be included in the calculation of smoking's social costs has become a major front in the academic battle over definition of the social costs of smoking. Viscusi (1995), for example, recently concluded that consideration of medical and pension offsets makes the net social costs of smoking small, if positive at all. Harris countered that in no other area of social policy analysis is death treated as an economic benefit (Coalition on Smoking or Health, 1994; Harris, 1993).

The import of this intellectual debate is potentially substantial. At the center of the public health community's advocacy of higher cigarette taxes is the social cost argument that smokers (or the industry that feeds their addiction) are imposing a huge economic burden on the society and ought to pay for it through higher excise taxes. Using the public health construction of social cost, some analysts have concluded that in the U.S., the cigarette excise tax needs to be on the order of $\$ 3-4$ or more to cover these costs (e.g., Hay, 1991).

Economists of many political stripes have countered that, for purposes of estimating an optimal cigarette excise tax, the correct notion of social cost is the traditional economist's measure of externalities, i.e., costs imposed by smokers on others, excluding their own family members. Economists' contributions to this debate are considered below, following a brief discussion of the true heart of the public health case for higher taxes: the health benefits that would result.

\subsubsection{The health benefits of increasing cigarette taxes}

Through a variety of channels, the economics literature on tax, price, and demand has reached the public health community (Scott and Dickert, 1993; Coalition on Smoking or Health, 1994). Given the strength of the evidence linking price increases to demand decreases, with the consensus that price elasticity is inversely related to age, the public health community has become convinced that cigarette tax increases are one of the most effective policy tools for decreasing smoking, especially among children. As a 
consequence, increasing price, generally through a tax hike, is featured in nearly every comprehensive tobacco control policy proposal.

The raison d'etre underlying the public health community's desire to see smoking decline is to reduce the morbidity and disability and premature mortality associated with smoking. Economists have taken the demand elasticity evidence and combined it with data on the health consequences of quitting smoking (primarily adults) and not starting (primarily children) to project the health gains that would be achieved with tax increases of various magnitudes. For example, in the mid-1980s, the U.S. Congress had to decide whether to permit a scheduled "sun-setting" of 8 cents of the then 16-cent cigarette excise tax (increased from 8 cents in 1983). Warner (1986b) used the price elasticity estimates of Lewit et al. (1981) for children and Lewit and Coate (1982) for adults to estimate the consumption implications of permitting the sun-setting to occur or, instead, increasing the tax by 8 or 16 cents per pack. He concluded that if the tax were doubled to 32 cents, and the real value of the tax maintained thereafter, 800,000 youths would be deterred from starting to smoke and 2.7 million adults encouraged to quit. Applying the conservative assumption that one of every four lifetime smokers dies prematurely of a smoking-related illness (the proportion is now believed to be about half), the analysis estimated that this tax increase would eventually reduce premature deaths in persons then 12 years and older by 860,000 .

Harris (1987) also evaluated the consumption and health implications of the 1983 doubling of the federal excise tax, considering the implications of various elasticity estimates. He concluded that the tax increase had likely deterred 600,000 youths from smoking and that, as a consequence of their avoidance of cigarettes and adults quitting, 54,000 of the youths and an additional 100,000 adults would survive to at least 65 years of age.

The General Accounting Office (1989) employed the same elasticity estimates used by Warner (1986b) and the same assumptions about premature mortality avoided to evaluate the likely health benefits from a sustained real 21-cent federal tax increase in 1989 , which they estimated would increase retail price by $15 \%$. They predicted a further reduction in youth smoking of 500,000, with a subsequent reduction in premature mortality among these youths of 125,000 .

Recently, Moore (1996) developed a more sophisticated economeric model that, incorporating state-level data on death rates from smoking-related diseases from 1954 through 1988, could be used to evaluate the impact of higher taxes on mortality. He determined that a $10 \%$ increase in cigarette excise taxes would save approximately 5, 200 lives each year. Similarly, Evans and Ringel (forthcoming) examined whether or not higher state cigarette taxes can be used to improve birth outcomes. Using data on approximately 10.5 million births in the U.S. over the period from 1989 through 1992, the authors estimated a smoking prevalence elasticity of -0.5 for pregnant women and found that increased cigarette taxes would significantly raise birth weight.

With the help of economic consultants, the Coalition on Smoking or Health (1994) used relatively conservative estimates of price elasticity and of the mortality consequences of smoking to estimate the health implications of alternative tax hikes advocated by the Coalition's member organizations. The Coalition determined that a 75cent tax increase in 1992 would reduce premature deaths due to smoking by 900,000. A $\$ 2$ per pack increase was estimated to save 1 million more lives than the 75-cent increase.

Chaloupka (1998) did the same for the price increases included in many of therecent proposals for national tobacco legislation in the US. Based on Chaloupka andGrossman's (1996) estimates, Chaloupka estimated that a $\$ 1.50$ increase in cigarette taxes and prices, phased in quickly and maintained in real terms, would reduce overall cigarette consumption by about 30 percent while cutting youth smoking prevalence almost in half. Based on the CDC's (1996) estimates for the number of youth in the 1995 US cohort of 0 through 17 year olds who would eventually die prematurely from a smoking related illness, Chaloupka estimated that this tax increase would prevent approximately 2.5 million deaths in this cohort.

To most members of the public health community, the health benefits of a tax increase justify its imposition. However, public health professionals appeal to the social cost argument to garner public and, especially, legislative support. Given the conceptual as well as empirical problems with the public health community's construction of the social cost of smoking, discussed above, the question remains as to whether economists would find theoretical justification for increasing the cigarette tax in the analyses of external costs that have been performed to date, or for that matter in other considerations. The next section addresses the economic efficiency issues and evidence. 


\subsection{Economic efficiency and the pursuit of an optimal cigarette tax}

Most economists would concur that an economically optimal tax on cigarettes would equate the revenues generated with the net external costs produced by smoking. ${ }^{20}$ Here we review the evidence pertinent to determining such a tax and evaluate additional considerations that relate to the notion of optimality when considering taxation of an addictive substance such as cigarettes.

\subsubsection{Negative externalities associated with smoking}

As discussed above, the public health community's definition of social costs incorporates both negative externalities and private costs. While economists agree that the latter should not be considered as social costs in contemplating a corrective tax on cigarettes, there is no complete consensus on precisely what consequences warrant inclusion, and even for those for which there is consensus, estimates of the magnitude of the true social externalities vary widely. Moreover, other tobacco control policies, particularly restrictions on smoking in public places and privateworksites, may be more efficient approaches to dealing with some of these externalities.

One author found that including the costs of the long-term intellectual and physical consequences of smoking-related low-birth-weight disabilities implied a tax of $\$ 4.80$ per pack (Hay, 1991). In contrast, other studies have found much smaller per-pack negative externalities, often less than existing excise tax rates. For example, evaluating data from the RAND Health Insurance Experiment and the 1983 National Health Interview Survey in an incidence-based cost analysis, Manning et al. (1989) concluded that, for their midrange estimates, the negative externalities of smoking totaled the equivalent of 43 cents per pack (in 1986 dollars). Partially offsetting these negative externalities, however, were an estimated 27 cents in "external savings" resulting from smoking-related premature deaths, meaning that the net negative externalities equaled 16 cents The researchers thus concluded that the empirical evidence did not justify raising the cigarette tax on grounds of covering negative externalities..$^{21}$ In a later analysis that drew on the Manning et al. study, Viscusi (1995) came to the same conclusion.

The Manning et al. study and Viscusi's reanalysis hasbeen cited frequently by opponents of a cigarette tax increase. Representing the Tobacco Institute at a Senate hearing, Tollison (1994) identified the work by Manning and his colleagues, as well as that of other prominent health economists, as rejecting the propriety of an economicallymotivated tax increase. The Congressional Research Service Gravelle and Zimmerman, 1994) cited the same study in the CRS's evaluation of the grounds for a tax increase (which the authors found wanting). Updating the figures to 1995 dollars, the CRS estimated the net negative externalities at 33 cents per pack of cigarettes, two-thirds of the average 50 cents in federal and state taxes imposed on cigarettes in late 1993.

20 Pigou (1962) suggested that, for goods with market prices less than their social costs, taxes could be used to raise the marginal cost of consuming the good to the social marginal cost. For some goods, taxes could generate revenues that exceed total external costs, reflecting the fact that the taxes are based on marginal rather than average external costs (Cook and Moore, 1993).

21 Early analysis of the offsetting savings associated with smokers' premature deaths is found in the work of Leu and Schaub (1983). These authors estimated the lifetime medical expenditures of a cohort of Swiss males, which included both smokers and nonsmokers, and compared them with the simulated expenditures of a hypothetical cohort assumed to include only nonsmokers. The authors concluded that the lifetime expenditures would be very similar for both cohorts, with the higher annual costs of smokers in the "real" cohort offset by the additional years of medical expenditures in the longer-lived hypothetical no-smoker cohort. In estimating the medical costs of nonsmokers in the hypothetical cohort, Leu and Schaub recognized that those who would have been smokers in the "real" cohort would differ in ways other than just smoking from those who would be nonsmokers in both cohorts. They introduced the notion of the "non-smoker smoker type" as the conceptually correct entity to evaluate in the hypothetical cohort, for those members who would have been smokers in the "real" cohort. This useful distinction has been incorporated in the work of several economists since then, including Manning et al. (1989). Implicitly, it is embodied in all attempts to evaluate smoking-related health care costs in which smokers' other risk-taking behaviors are controlled (e.g., Bartlettet al., 1994; Miller et al., 1998). 
Although the Manning et al. study has dominated attention within the economics debate about the marginal social costs of smoking, the study reveals several problems of both omission and commission, many of which the authors have acknowledged (Manning et al., 1991). Adjustments reflecting these issues often lead to qualitatively different conclusions about the desirability of increasing the cigarette excise tax. In terms of omission, most notably the study excluded a variety of costs associated with environmental tobacco smoke (ETS) that, if included, would significantly increase the social cost estimate. Many of the health consequences of ETS were not well appreciated when Manning et al. undertook their research in the mid-1980s (e.g., the consequences of ETS for heart disease). However, the authors made the decision to consider then-known ETS costs as internal, based on the traditional economic assumption that the family is the appropriate economic unit for consumption decisions, including the decision to smoke. Further, the authors reasoned, the adverse health consequences of smoking were largely confined to the nonsmoking spouses of smokers. ${ }^{22}$

Although few economists would challenge the sanctity of the family as thebasic economic unit, the assertion about the internal nature of ETS costs is less clear. Certainly, some ETS costs are external to the family (e.g., airline attendants' ETSinduced lung disease prior to the banning of smoking on flights). Others likely represent a mix of internal and external costs. For example, disease and developmental problems associated with low birth-weight caused by mothers' smoking during pregnancy often have support costs that spill over into the broader society, as social institutions are required to pick up some of the medical, institutional, and other costs related to these conditions. Thus, regardless of one's philosophical approach to the issue of intra-family health problems caused by ETS, determining the appropriate distribution of costs between family and the rest of society is a distinct challenge.

The potential role of ETS costs in reevaluating the net negative externalities associated with smoking is seen by considering the following figures. Manning et al. (1991) noted that inclusion of the costs of 2,400 lung cancers from ETS (a fairly conservative estimate of this toll (Environmental Protection Agency, 1992)) as external costs would add approximately 19 cents per pack in external costs (updated to 1994 dollars). In addition, inclusion of the costs of neonatal care for smoking-related lowbirth-weight babies would add 3 cents to the total, while including fetal deaths attributable to smoking would add yet another 19 cents. Deaths from smoking-related fires would add a further 9 cents. The ETS costs would sky-rocket if one included the estimated 30,000-60,000 heart disease deaths recently associated with ETS Glantz and Parmley, 1995), adding perhaps 70 cents to the total social costs per pack. Similarly, inclusion of the smoking-induced respiratory tract infections and cases of aggravated asthma in children (Environmental protection Agency, 1992) would boost the total further, as would inclusion of the long-term developmental disabilities in smoking-related low-birth-weight babies (Hay, 1991). All told, the social costs per pack could easily mount toward several dollars if all of the health hazards associated with ETS are real, many are treated as external to the basic consuming unit, and if all or even a significant fraction of the associated costs are included.

ETS cost estimation is also influenced substantially by whether one employs the human capital approach or willingness-to-pay to value the lives of persons who die prematurely due to ETS exposure. Manning et al. used a conservative estimate of \$1.66 million per premature death based on the range of estimates in the literature. ${ }^{23}$ Using willingness-to-pay, the Environmental Protection Agency (1994) obtained a \$4.8 million figure. In its analysis (which included the adverse effects of ETS on heart disease and children's health, but not on fetal and perinatal health), the EPA estimated that the

22 At the time this analysis was undertaken, virtually all of the medical literature indicting ETS as a cause of disease related to the experience of nonsmoking wives of smoking husbands (U.S. Department of Health and Human Services, 1986; Environmental Protection Agency, 1992); there was no significant evidence of ETS exposure or disease effects outside of the home.

23 As discussed above, the authors' estimates of external costs attributable to ETs were negligible, making the choice of the cost of a premature death of little consequence to their calculations (Manning et al., 1989). However, had they included the full range of health consequences now attributed to ETS, the choice of a value-of-life measure would have been of much greater importance. 
benefits that would result from a ban on smoking in all worksites would total between $\$ 39$ billion and $\$ 71$ billion annually, the equivalent of from $\$ 2.45$ to $\$ 4.45$ per pack of cigarettes. The EPA used fairly conservative assumptions concerning the effects of a worksite smoking ban on smoking and exposure to ETS. They assumed a ban would reduce the number of current smokers by 3-6\%, the number of future smokers by 5-10\%, and daily consumption among continuing smokers by 10-15\%, for a total long-run reduction in cigarette consumption of 14-22\%. The EPA estimated that these consumption reductions would reduce out-of-home ETS exposure by $90 \%$ and in-home exposure by $6.4 \%$. An earlier EPA report (1992) had concluded that an estimated 73\% of ETS exposure occurs outside the home. The EPA thus predicted that a worksite ban would reduce total ETS exposure by $66.4 \%$.

Quite independent of the treatment of the effects of ETS, the Manning et al. (1989) study and "spin-offs", such as Gravelle and Zimmerman's (1994) review of the evidence and Viscusi's (1995) reanalysis, raise the issue of which types of costs ought to be included in calculations of external costs. Manning and colleagues' finding that current taxes covered external costs would have been reversed had the authors not included the value of pensions and Social Security benefits not realized by smokers by virtue of their premature demise. As demonstrated by Shoven et al. (1989), smokers subsidize nonsmokers' Social Security benefits by virtue of the smokers' early average ages of death; the same relationship should hold for defined benefit pensions as well. Some analysts have considered this a transfer, not subject to consideration as an externality, rather than a compensating external benefit of smoking, as Manning et al. treated it. However, Manning et al. did not consider it a transfer because they viewed the length of life of smokers as endogenous. As the literature on the costs of smoking demonstrates repeatedly, inclusion or exclusion of such costs can play a significant role in calculating net external costs. 24

The importance and complexity of the handling of such matters is illustrated by their differential effects in different societies and at different times. For example, as just noted, in the U.S. analysts have concluded that, by dying early, smokers subsidize nonsmokers' Social Security payments (Shoven et al., 1989; Viscusi, 1995). In the United Kingdom, by contrast, research indicated that sickness benefits paid to smokers and pensions paid to their dependents compensated for the lower direct pension benefits paid to smokers as a consequence of their earlier average age of death (Atkinson andTownsend, 1977). In developing countries in which old-age expenses are largely a private matter, the social "benefit" of smokers' dying early would not exist, and hence would not offset any negative externalities of smoking. Of course, this could change over time if and as such societies developed social security plans. Similarly, the magnitude of the offsets in the developed countries could change if and as benefit programs in those countries were altered (Warner et al., 1995).

As this discussion has demonstrated, calculation of the "true" net negative externalities associated with smoking is an exceedingly difficult challenge, one that involves conceptual questions, epidemiologic and other data considerations, and "moving targets" in terms of both knowledge and institutional structures. The relevance of the task to understanding optimal cigarette taxation recommends further research, despite its difficulty. ${ }^{25}$

24 Other candidates for inclusion are the reduction in income taxes and insurance premiums paid by smokers due to reduced earnings associated with smoking-related illnesses; smoking-related health care costs paid by public insurance plans (and conceivably private, depending on how these are treated); and increased sick pay and disability benefits paid during smoking-related illnesses. If such items are included, care must be taken to consider both reduced payments by smokers into public revenues and altered patterns of consumption of government-financed goods and services.

25 An interesting example of the problems created by institutional structures in trying to assess the relevance of ETS to determining an optimal tax lies in the effects of workplace smoking bans on the development of ETS-related diseases the more pervasive are workplace bans, the less ETS exposure nonsmokers will experience, and hence the amount of ETS-related disease will decline. This, in turn, would decrease the conceptually optimal tax. 


\subsubsection{Other efficiency considerations}

Several factors related to smoking complicate the task of defining an optimalcigarette tax. Two essential realities about smoking -- namely, that it is a behavior initiated almost exclusively during childhood (U.S. Department of Health and Human Services, 1994) and that it is addictive (U.S. Department of Health and Human Services, 1988) -- give pause in treating cigarette consumption just like any other rational economic behavior. A third reality -- that many smokers are not truly well informed about the hazards of smoking (U.S. Department of Health and Human Services, 1989; Schoenbaum, 1997) ${ }^{26}$ - also challenges a basic proposition of rational behavior. For smoking as for other consumption, rational economic behavior presumes both the existence of adequate knowledge on which to base consumption decisions and rational use of the knowledge. In the absence of adequate knowledge, higher taxes might be justified Cordes et al., 1990). One may be particularly interested in applying this concept to teenagers, although increasing taxes is a decidedly blunt instrument if its purpose is solely to better "inform" youths about the risks of smoking (Warner et al., 1995).

As discussed in an earlier section, the empirical applications of the rational addiction model suggest that addicted adult smokers do not behave myopically in contemplating the relationship between cigarette consumption and past, present, and expected future prices. However, as the evidence reviewed above indicated, youth exhibit much more myopic cigarette consumption behavior than do adults, consistent with studies that have found young smokers greatly underestimating the probability that they would still be smoking five years later (U.S. Department of Health and Human Services, 1994). Moreover, as illustrated by the Orphanides and Zervos (1995) model, the role of information (more specifically the lack of information on the potential for addiction) is particularly important in the initiation process, and results in later regret.

A group of health economists who have studied the economics of smoking recently concluded that protecting children from a future of nicotine addiction, with its associated health risks, was the most compelling reason favoring increased taxation of cigarettes (Warner et al., 1995). They perceived high taxes as appropriate to balance an environment in which children face numerous inducements to smoke, including multi-billion dollar advertising and marketing campaigns by the cigarette companies, many designed to attract children to smoking (US Department of Health and Human Services, 1994). To address this imbalance, these economists supported such measures as increased public education and increased enforcement of restrictions on youth access to tobacco products, although the limited effectiveness of such measures is well documented. (See section 5 below.) The economists observed, however, that these measures do not address children's tendency to discount the future heavily, in a manner that, as rational adults, they might come to regret. Taxation, they felt, is the best available policy instrument to address this problem, both conceptually and empirically. As observed above, two recent analyses (Orphanides and Zervos, 1995; Suranovic et al., in press) examining the initiation of smoking, continuation over time, and eventual consideration of quitting (and difficulty in doing so) lend new insight into this issue of regret.

\section{Advertising, promotion, and the demand for tobacco products}

Cigarettes are one of the most heavily advertised and promoted products in the world. In the United States, for example, the cigarette industry spent \$5.1 billion on advertising and promotion activities in 1996 (Federal Trade Commission, 1998); as a percentage of sales, these expenditures have increased dramatically since $1980 . \quad$ Cigarette advertising includes the more traditional advertising on television, radio, and billboards, in newspapers, magazines, and transit facilities, and, most recently, on the internet. Spending on promotion includes a wide variety of activities, including promotional allowances to retailers, point-of-purchase promotional materials, direct mail advertising, the distribution of free samples, coupons, and specialty items, multiple pack promotions, and retail value-added offers, as well as endorsements, sponsorship of cultural, sporting, and other entertainment events, and sponsorship of community and other organizations. Nearly 87\% of all cigarette advertising and promotional expenditures in the U.S. in 1974 were devoted to traditional advertising; by 1996, in striking contrast, this had fallen to just over $10 \%$, with the balance going to the less-traditional promotional activities. Promotional allowances (\$2.15 billion in 1996) and coupons and retail value added (\$1.31 billion in 1996) have been the largest spending categories in 
recent years.

This section begins with a brief discussion of the arguments related to cigarette advertising and demand, as well as a review of some of the economic issues related to cigarette advertising. We then examine the econometric literature on the impact of cigarette advertising on smoking, consider the limitations of the econometric approach, and review the growing literature on the impact of restrictions and bans on cigarette advertising and promotion. The section closes with a short description of the findings on cigarette advertising and demand from the non-economics literature.

\subsection{Theoretical and conceptual issues}

The impact of cigarette advertising on cigarette smoking, particularly youth smoking, has been the subject of extensive debate over the past several decades. The public health community takes it as given that advertising encourages smoking and is a particularly significant influence on smoking initiation among youth. The industry, on the other hand, contends that cigarette advertising is a form of competition that has no impact on overall cigarette smoking, but instead simply affects market share. In addition, the industry argues that advertising provides useful information to smokers about their products, including information on tar and nicotine content.

Warner (1986a) suggested several mechanisms through which cigarette advertising and promotion could affect cigarette consumption. He identified four direct mechanisms: (1) advertising can entice children and young adults to experiment with smoking and to initiate regular smoking; (2) it can reduce current smokers' willingness to quit smoking; (3) it can serve as a cue or stimulus that leads to increased daily cigarette consumption by smokers; and (4) it can induce former smokers to resume their habit by reinforcing the attractions of smoking. Two indirect mechanisms were: (1) discouraging a full discussion of the health consequences of cigarette smoking in media dependent on tobacco advertising; and (2) contributing to a social environment in which smoking is perceived to be socially acceptable. The U.S. Surgeon General (U.S. Department of Health and Human Services, 1989) added a third indirect mechanism, namely that institutions dependent on tobacco industry promotional and other support may create political opposition to strong tobacco control policies.

Warner and his colleagues (Warner, 1985; Warner and Goldenhar, 1989; Warner et al., 1992) have examined the first indirect mechanism empirically, concluding that there is strong evidence that magazines' coverage of the hazards of smoking was significantly diminished as the magazines' share of advertising revenues from cigarette advertising rises. Warner et al. (1992) found that magazines that did not carry cigarette advertising were more than $40 \%$ more likely to cover the health consequences of smoking than those with cigarette advertising. The difference was more pronounced for women's magazines, with those that did not advertise cigarettes more than 230 percent more likely to cover the hazards of smoking.

\subsection{Econometric evidence}

Other than this work by Warner and colleagues, research by economists has not addressed the hypothesized individual mechanisms by which advertising can influence cigarette consumption. However, beginning with Schmalensee's 1972 study, there have been numerous econometric studies of the impact of cigarette advertising on cigarette demand, mostly for the U.S. and the U.K, but also for several other countries as well. No consensus concerning the effects of advertising on smoking has emerged from this research, however. Several recent reviews of this literature, drawing on many of the same studies, reached opposite conclusions. Based on their review of 24 studies with estimates of the advertising elasticity of cigarette demand, Andrews andFranke (1991) concluded "that there is a significant relationship between advertising and cigarette consumption across studies, independent of study design factors. However, the estimated magnitude of this relationship varies depending on several study design factors" (page 96). Moreover, they concluded that the positive impact of advertising on cigarette demand has declined over time, a factor they attributed to the maturation of cigarette markets in most of the countries studied. Duffy (1996b), on the other hand, concluded that econometric studies of the relationship between cigarette advertising and demand generally have found that advertising has little or no impact on aggregate cigarette consumption.

In his now classic volume, The Economics of Advertising, Schmalensee (1972) introduced several concepts that reemerge repeatedly in subsequent studies of cigarette advertising and demand. In particular, he examined cigarette demand at both the industry and firm levels, allowed for the possibility that a firm's cigarette advertising expenditures might be based on current sales, and modeled not only the effects of current 
advertising expenditures on demand but also the impact of lagged expenditures. As Schmalensee observed, failing to account for the potential endogeneity of cigarette advertising expenditures would lead to biased estimates of the impact of advertising on demand. Similarly, failing to account for the cumulative or "stock" effects of advertising could lead to an omitted variables problem, although the evidence is mixed concerning the durability of cigarette advertising (Boyd and Seldon, 1990). Schneider et al. (1981) extended the use of the "stock" of advertising to allow the marginal productivity of advertising expenditures in the U.S. to fall after the 1971 ban on broadcast cigarette advertising.

An additional issue raised by Schmalensee relates to the measurement of advertising expenditures. In half of his industry-level models, he used the absolute level of cigarette advertising, while in the other half, he used the ratio of cigarette advertising to total advertising, providing an intuitive argument favoring the latter analogous to the use of relative rather than absolute price. Subsequent theoretical models of consumer behavior have made this argument more formally (Theil, 1980; Duffy, 1987).

The numerous econometric studies on the impact of aggregate cigarette advertising expenditures on aggregate cigarette consumption differ with respect to many of the issues raised by Schmalensee, as well as in several other respects. Almost none follows Schmalensee and treats advertising expenditures as endogenous. A few estimate firmspecific demand (e.g., Roberts and Samuelson, 1988), while most examine industry demand. Several introduce measures of past advertising expenditures; some do so directly (e.g., Goel and Morey, 1995), while others construct a cumulative "stock" of advertising (e.g., Schneider et al., 1981). Most look at absolute or per capita measures of cigarette advertising expenditures, while a few employ measures of expenditures on cigarette advertising relative to overall advertising expenditures (e.g., Duffy, 1996a). Many estimate single equation models of cigarette demand; several, however, estimate simultaneous equations models of supply and demand (e.g., Porter, 1986). Most estimate conventional demand models, while some estimate myopic demand models that include a measure of past cigarette consumption (e.g., Baltagi and Levin, 1986) or an alternative approach (Fujii, 1980); one estimates demand in the context of the rational addiction model (Duffy, 1996a).

Schmalensee (1972) and many subsequent econometric studies based on aggregate data from the U.S., U.K., and a few other countries found no statistically significant effect of aggregate cigarette advertising expenditures on cigarette consumption (Hamilton, 1972; Lambin, 1976; Grabowski, 1976, 1978; Metra Consulting Group, 1979; Schneider et al., 1981; Johnson, 1986; Baltagi and Levin, 1986; Stavrinos, 1987; Tegene, 1991; Duffy, 1991, 1996a; Wilcox and Vacker, 1992; U.K. Department of Health, 1992; Wilcox et al., 1994; Franke, 1994; Goel and Morey, 1995). A few of these studies, however, did find some evidence that lagged cigarette advertising had a significant positive impact on current cigarette consumption, providing some support for the durability of advertising Schmalensee, 1972; U.K. Department of Health, 1992; Goel and Morey, 1995). Several other studies have found that cigarette advertising has a positive and significant impact on aggregate cigarette demand (McGuiness and Cowling, 1975, 1980; Fujii, 1980; Witt and Pass, 1981; Reuijl, 1982;

Radfar, 1985; Bishop and Yoo, 1985; Leeflang and Reuijl, 1985; Abernethy and Teel, 1986; Porter, 1986; Roberts and Samuelson, 1988; Chetwynd et al., 1988; McAuliffe, 1988; Kao and Tremblay, 1988; Seldon and Doroodian, 1989; Seldon and Boyd, 1991; Valdes, 1993; Tremblay and Tremblay, 1995). However, the magnitude of the estimated effect is generally small. Differences in the design, data, and empirical methods account for the inconsistent findings.

Based on the mixed evidence from the studies using aggregate data, aggregate cigarette advertising appears to have a small or negligible impact on aggregate cigarette sales. However, as a number of researchers have observed, the nature of competition in the cigarette industry and the limitation of econometric analysis to estimating marginal effects imply that there should be at most a small impact of aggregate cigarette advertising expenditures on aggregate cigarette consumption (Cox, 1984; Warner, 1986a; Warner et al., 1986; U.S. Department of Health and Human Services, 1989; Saffer, 1995, 1998; Pollay, 1996).

As Saffer $(1995,1998)$ has noted, advertising expenditures will have diminishing marginal productivity. Drawing on the "advertising response functions" used to characterize brand-level advertising in the empirical marketing literature, which clearly imply diminishing returns to advertising at the brand level Rao and Miller, 1975; Ackoff and Ernshoff, 1975), Saffer concluded that an "industry advertising response function" will also show diminishing returns to increasing expenditures and marginal effects could be well below average effects. Moveover, in a highly concentrated market with a virtual 
absence of price competition, where the "personality" of the product is very important to consumers, total advertising expenditures will almost certainly exceed the "rational" level associated with joint profit maximization that would be expected to show a significant positive impact on overall demand. Instead, in an effort to increase or protect market share, firms will advertise beyond the level where one would expect to find a sizable positive marginal effect of total advertising on total demand, assuming that the firms do not collude in deciding upon the amount of advertising. A number of econometric studies have looked at the impact of advertising on demand at the firm or brand level. These generally have found that increases in advertising expenditures have a positive and significant effect on market share (Telser, 1962; Peles, 1971; Schnabel, 1972; Grabowski, 1978; Holak and Reddy 1986; Pollay 1996). Pollay (1996), for example, estimated that "share of voice" (brand share of advertising expenditures) has a significant impact on market shares, and that brand choice among teenagers is about three times more sensitive to advertising than it is for adults (a result surprisingly similar to the estimates for youth and adult price sensitivity).

In short, given that the econometric analyses of aggregate expenditures and consumption are designed to assess the impact of a marginal change in advertising expenditures on total cigarette sales, it is not surprising that most of these analyses estimate small or insignificant effects of advertising on demand. In addition, critics of these analyses suggest several methodological shortcomings, including the lack of appropriate measures of advertising exposure and other problems with the measures of advertising employed; the failure to distinguish between the impact of advertising and promotional activities; problems with the simultaneity between advertising expenditures and sales; the omission of other key variables, such as concurrent counteradvertising; and more (Cox, 1984; Warner, 1986a; Warner et al., 1986; U.S. Department of Health and Human Services, 1989; Chapman, 1989; U.K. Department of Health, 1992; Luik, 1994; Saffer, 1995, 1998; Duffy, 1996b; Pollay, 1996). These and other critics have suggested that more appropriate approaches include the examination of more disaggregated data and the analysis of non-marginal changes in advertising expenditures, such as those that result from significant restrictions or complete bans on cigarette advertising and promotion.

To date, only one econometric study has examined the impact of cigarette advertising employing individual level data and more appropriate measures of advertising exposure. Lewit et al. (1981) used data on about 6,700 youth ages 12-17 years taken from Cycle III of the U.S. Health Examination Survey conducted from 1966 through 1970 . Based on measures of televised cigarette advertising and counter-advertising, and self-reported information on time spent watching television, Lewit and his colleagues estimated the number of proand anti-smoking commercials each youth would have seen. Their estimates provide support for the hypothesis that televised pro-smoking advertisements significantly increased youth smoking.

There are a number of studies examining the impact of restrictions and bans on cigarette advertising on smoking. Many of the older studies look at the impact of the U.S. ban on broadcast cigarette advertising that began January 2, 1971 Ippolito et al., 1979; Schneider et al, 1981; Bishop and Yoo, 1985; Porter, 1986; Baltagi and Levin, 1986; Kao and Tremblay, 1988; McAuliffe, 1988; Seldon and Dooroodian, 1989; Seldon and Boyd, 1991; Simonich, 1991; Franke, 1994; Goel and Morey, 1995; Tremblay and Tremblay, 1995). In general, these studies produced mixed evidence on the impact of the ban on television and radio advertising. Most concluded that the ban did not significantly reduce cigarette smoking in the U.S. A few suggested that the marginal productivity of cigarette advertising fell after the ban (for example, Tremblay and Tremblay, 1995). Several, including Hamilton (1972) and Warner (1979), suggested that the net impact of the 1971 ban was to raise cigarette consumption because it also led to the elimination of effective anti-smoking commercials broadcast under the Fairness Doctrine (discussed below). Schneider et al. (1981) supported this argument empirically, concluding that the advertising ban led to a net increase of nearly 5\% in per capita tobacco consumption, in part due to a price reduction resulting from the reduced costs associated with less advertising. In addition, they argued, the advertising ban limited the provision of information to smokers concerning the tar and nicotine content of different brands and, consequently, reduced the likelihood that smokers would switch to lower tar and nicotine brands.

Others examined the impact of other country-specific restrictions, including: the 1965 U.K. ban on televised cigarette advertising (Atkinson and Skegg, 1973; Witt and Pass, 1984); the ban on advertising in electronic media in Australia (Johnson, 1986; McLeod, 1986); the Finnish extension of its television ad ban to other media fekurinen, 1989, 1991); and Spain's partial ban on broadcast advertising Naldes, 1993). Hamilton (1977) 
Economics of Smoking - p. 33

presented similar estimates from separate regressions for 11 countries over the period 1948-1973. These studies also produced mixed evidence on the effectiveness of these partial bans. In general, they suggested that the bans led to a temporary reduction in cigarette smoking, but that they had little impact in the long run. However, more extensive restrictions coupled with anti-smoking publicity, strong health warnings, and other activities appear to have led to more permanent reductions in demand fekurinen, 1989,1991 ).

Still others have conducted cross-country analyses of the impact of restrictions and bans on cigarette advertising and promotion (Hamilton, 1977; Cox and Smith, 1984; Laugesen and Meads, 1991; and Stewart, 1993). These, too, have yielded mixed findings. In addition to country-specific regressions, Hamilton (1977) included models pooling some of the countries in his sample. As in the country-specific models, he found no evidence that advertising restrictions reduced cigarette demand. Cox and Smith (1984) took an indirect approach to estimating the impact of advertising bans on demand. Using data from 15 OECD countries, they sorted countries by their use of legislative versus voluntary strategies to reduce smoking, where limits on advertising reflected a more legislative strategy. Based on a series of country-specific regression models, they concluded that smoking declines more rapidly in countries that take a legislative approach to tobacco control, suggesting that advertising restrictions are effective in reducing demand.

Laugesen and Meads (1991) pooled annual aggregate data from 22 OECD countries for the period 1960-1986 in their examination of the impact of advertising and promotion restrictions. Rather than focusing on a specific type of restriction (e.g., a broadcast advertising ban), Laugesen and Meads constructed an advertising restriction index that ranges from zero (no restrictions) to 10 (complete bans on advertising and sponsorships coupled with multiple, strong warning labels on cigarette packaging). Estimates from this model imply that cigarette consumption would be about 6\% lower with the strongest restrictions than it would be with no restrictions. In their preferred specification, to account for the lagged effects of advertising, the coefficient on the advertising restriction index was interacted with time. In this specification, Laugesen and Meads found that advertising restrictions actually had a positive effect on cigarette demand through the early 1970s, but then reduced consumption after 1973. Estimates for the final year of their data implied that each additional point in the restriction index reduced cigarette consumption by about 1.5 percent, well above their estimate for the specification that does not allow the effect to vary over time. Laugesen and Meads attributed the positive effects of the ban early in their sample to the industry's ability to substitute other marketing activities for broadcasting advertising in response to early restrictions. However, its ability to substitute other media for banned media diminished over time as the restrictions became more comprehensive.

Stewart (1992) raised a number of concerns about the approach taken by Laugesen and Meads. Specifically, stewart argued that errors in variables for the dependent and several independent variables will bias the estimates on the advertising restriction coefficients. In addition, he argued that the Laugesen and Meads approach failed to account for unmeasured, country-specific factors (i.e., culture, tastes, and attitudes) that should be important determinants of cigarette consumption, and that the omission of these factors leads to biased estimates of the advertising restriction coefficients. Laugesen and Meads (1993) defended the estimates from their research, arguing that after correcting for errors in the data, the estimates confirmed their earlier finding that bans on advertising significantly reduce cigarette consumption. The authors did not present these revised estimates in their response, however.

Using data on 22 OECD countries for the period 1964-1990, Stewart (1993) presented his own empirical analysis of the impact of restrictions on cigarette advertising on demand. He estimated fixed effects models to control for unmeasured country-specific influences on demand. Rather than using a comprehensive measure of restrictions on cigarette advertising, however, Stewart focused on bans on the televised advertising of cigarettes. Also, in contrast to Laugesen and Meads, Stewart did not allow the impact of the advertising restriction to change over time. He estimated that the ban on cigarette advertising on television has had a positive but insignificant impact on cigarette demand, consistent with the findings from several other studies on the effects of broadcast advertising bans alone.

In late 1992 the United Kingdom's Department of Health reviewed the evidence on the impact of cigarette advertising and restrictions on advertising on cigarette demand (U.K. Department of Health, 1992). The "Smee Report," known by the name of the project director, also contains two original econometric analyses on the impact of advertising restrictions, one for Norway and the other for Canada. Estimates from these analyses 
suggest that the countries' relatively comprehensive advertising and promotion bans did lead to significant reductions in smoking. Given this evidence as well as that from the numerous qualitative and quantitative studies reviewed, the Smee Report concluded that cigarette advertising has a positive impact on smoking and that bans on advertising would reduce demand.

In a subsequent edited volume, critics of the Smee Report argued that it was flawed in several ways, including the following: the literature review omitted several qualitative and quantitative studies that found no impact of advertising or ad restrictions on cigarette demand; the findings from some of the literature reviewed are misstated; the empirical analyses contained methodological and other errors fuik, 1994).

Stewart (1994), for example, compared the estimates for the countries common to his 1993 econometric analysis with those presented in the smee Report, concluding that advertising bans in Norway, Finland and Canada have actually increased tobacco consumption.

The Smee Report, Saffer (1998), Stewart (1993), and others have indicated several factors that complicate the ability of econometric analysis to examine the impact on cigarette demand of restrictions on cigarette advertising and promotion. The potential endogeneity of advertising restrictions has not been carefully examined in any of the econometric studies. Similarly, with the exception of Stewart (1993), social, cultural, and other differences among countries have not been well controlled for in the econometric research. However, efforts to control for these, using fixed effects modeling for example, create severe multicollinearity problems that make it difficult to isolate the impact of the advertising restrictions on demand from other key determinants. Similarly, as Saffer noted, a majority of the studies to date have examined the impact of restrictions on advertising in one or two media, leaving firms free to substitute towards other media and to develop new marketing approaches. The findings from several studies, which suggest at best a temporary negative effect of a relatively limited set of advertising restrictions, are consistent with the argument that effective alternatives are developed in response to the ban. So to are the findings from the few studies that have found that relatively comprehensive restrictions significantly reduce demand.

\subsection{Findings from the noneconomic literature}

While econometric methods are powerful tools for examining the demand for cigarettes and other tobacco products generally, they are relativelyill-suited for evaluating the effects of cigarette advertising and promotion and related restrictions, as described above. Evidence from a number of other disciplines, however, supports the argument that cigarette advertising and promotion directly and indirectly increase cigarette demand

(Warner, 1986a; U.S. Department of Health and Human Services, 1989, 1994, 1996, 1998; U.K. Department of Health, 1992).

A major source of noneconomic evidence is survey research and experiments that assess reactions to and recall of cigarette advertising and smoking behavior, particularly among children. These studies have concluded that cigarette advertising is effective in getting children's attention and that the ads are recalled, with strength of interest correlated with current or anticipated smoking behavior or smoking initiation (U.S. Department of Health and Human Services, 1989, 1994; Food and Drug Administration, 1996; Goldstein et al., 1987; Difranza et al., 1991; Evans et al., 1995; Pierce et al., 1998). However, these studies generally cannot assess the potential endogeneity between an interest in smoking and behavior (U.S. Department of Health and Human Services, 1989 , 1996).

Others have articulated logical arguments that conclude that cigarette advertising and promotional activities are not consistent with the tobacco industry's claim that the market for tobacco products is mature and that marketing activities are designed to promote brand share rather than market expansion. For example, Tye et al. (1987) calculated that cigarette firms' battling only for brand share did not make financial sense in a U.S. market in which the top two firms now control 75\% of cigarette sales (and one company has 95\% of smokeless tobacco sales) and in which brand loyalty is notoriously strong. The authors argued that if the industry believed its own brand-share argument, it would have welcomed the opportunity for a legislated ban on tobacco advertising, proposed in the U.S. Congress in the mid-1980s. Instead, the industry fought the ban vigorously. Similarly, Warner (1986a) noted that even if the industry is a mature or declining one,

27 The Smee Report's estimate for Finland is based on the work by Pekurinen (1989, 1991) rather than an original econometric analysis. 
retaining existing consumers and recruiting new ones would be particularly important in the cigarette market in which about 5\% of consumers are lost annually to cessation and death. Finally, while the overall market may be mature, there are segments of the market that appear to be potential growth markets, such as youth in the U.S., for whom smoking prevalence has risen throughout the 1990s (University of Michigan News and Information Services, 1997), or specific minority groups, such as Hispanic females for whom smoking rates are well below those of other groups of women (U.S. Department of Health and Human Services, 1998). Substantial evidence, including recently released internal industry documents (www.house.gov/commerce/TobaccoDocs/documents.html), indicates that increasing shares of advertising and promotion activities have been directed towards these growth or potential growth markets (U.S. Department of Health and Human Services, 1989, 1994, 1998; U.K. Department of Health, 1992; King et al., 1998; industry documents - need refs.).

Clearly, there is no "smoking gun" that proves that advertising and promotion play a significant role in expanding or maintaining the market for tobacco products, or that they do not. Examining all of the evidence collectively, Warner (1986a) concluded that it is more likely than not that advertising and promotion do stimulate cigarette consumption. However, he also characterized the extent of the influence of advertising as unknown and possibly unknowable.

To date, economists' contributions to the relevant body of knowledge about cigarette advertising have been less numerous, and likely less consequential, than in other areas of smoking and health, such as the highly productive work on the relationship between cigarette price and demand, reviewed in section 2. Still, the econometric research in this area has offered important insights into the challenge of evaluating the effects of advertising. The door is open for creative new work to follow.

\section{Other tobacco control policies and demand}

This section focuses on the impact on cigarette demand of some of the more widely used tobacco control policies in addition to taxation and advertising restrictions, including the dissemination of information on the health consequences of smoking, restrictions on smoking in public places and work places, and limits on youth access to tobacco products. Other policies, such as the disclosure of tobacco product constituents and the funding of school-based smoking prevention programs, have not been the subject of economic analysis.

\subsection{Health information and counter-advertising}

In both the early 1950s and the mid-1960s, smoking-related "health scares" received substantial public attention in the United States. The first was prompted by coverage in the popular media of the then-new scientific evidence linking smoking to lung cancer (Wynder and Graham, 1950; Doll and Hill, 1954). Illustrative was an article in the December, 1952 Reader's Digest entitled "Cancer by the Carton" (Norr, 1952). The second followed release of the first Surgeon General's report on smoking and health (U.S. Department of Health, Education, and Welfare, 1964), the first official government document to label smoking a cause of lung cancer and to call for "appropriate remedial action." Media attention to the report ranked it as one of the year's most covered news stories.

The impact of these "health scares" has been the subject of extensive econometric analysis (Sumner, 1971; Hamilton, 1972; Schmalensee, 1972; Atkinson and Skegg, 1973; McGuiness and Cowling, 1975; Thompson and McLeod, 1976; Warner, 1977, 1981a, 1989; Ippolito et al., 1979; Fujii, 1980; Schneider et al., 1981; Leu, 1984; Porter, 1986; Bishop and Yoo, 1985; Kao and Tremblay, 1988; Simonich, 1991; Pekurinen, 1989, 1991; Meier and Licari, 1997). In general, these and other studies concluded that cigarette smoking fell significantly in response to the new information on its health consequences. Warner (1977, 1981a), for example, found that the public scares in the early 1950s significantly reduced smoking in 1953 and 1954, but that their negative impact diminished through the decade. He concluded that the 1964 Surgeon General's report led to an immediate 5\% decline in cigarette consumption. Schneider et al. (1981) estimated that U.S. per capita tobacco consumption was about 39 percent lower in 1978 than it would have been in the absence of the two health scares.

The evidence linking cigarette smoking to morbidity and premature mortality led to a number of public policy efforts to disseminate information on the health consequences of smoking. Numerous countries have adopted policies requiring health warning labels on cigarette packaging and advertising; in general, these warnings have become stronger and more prominent over time. Non-econometric evaluations of warning labels have concluded that small, inconspicuous labels that provide little specific information about the 
consequences of smoking are generally ineffective. However, multiple, strong, and direct messages that are prominently displayed have been found to be effective (World Health Organization, 1997). The limited econometric evidence also suggests that health warning labels have led to small but significant reductions in cigarette smoking Abernethy and Teel, 1986; Tansel, 1993; Meier and Licari, 1997; Bardsley and Olekans, 1998).

Mass media "counter-advertising" campaigns have been widely used to discourage cigarette smoking and other tobacco use. Econometric analyses of anti-smoking publicity and paid counter-advertising generally, but not universally, have concluded that these campaigns have significantly reduced cigarette smoking (Hamilton, 1972; Warner, 1977, 1981a, 1989; Ippolito et al., 1979; Metra Consulting Group, 1979; Fujii, 1980; Schneider et al., 1981; Lewit et al., 1981; Porter, 1986; Abernethy and Teel, 1986; Baltagi and Levin, 1986; Stavrinos, 1987; Kao and Tremblay, 1988; Pekurinen, 1989, 1991; Simonich, 1991; Tansel, 1993; Hu et al., 1994, 1995b, 1995c; Tremblay and Tremblay, 1995; Goel and Morey, 1995; Hsieh et al., 1996). Much of the econometric evidence from the U.S. is based on two major counter-advertising campaigns: the anti-smoking messages broadcast in the late-1960s under the Federal Communications Commission's Fairness Doctrine (Hamilton, 1972; Warner, 1977, 1981a, 1989; Ippolito et al., 1979; Fujii, 1980; Schneider et al., 1981; Lewit et al., 1981; Porter, 1986; Baltagi and Levin, 1986; Simonich, 1991; Tremblay and Tremblay, 1995; Goel and Morey, 1995) and the anti-smoking media campaign in California in the early 1990s, funded by an earmarked tax on cigarettes Hu et al., 1994, 1995b, 1995c).

From 1967 until January 2, 1971, the date television and radio advertising of cigarettes was banned, anti-smoking messsages were broadcast to "compensate" for prosmoking advertisements, initially at the rate of one anti-smoking message for every eight cigarette ads and eventually at a 1:3 ratio. Television time for these counteradvertisements was donated by broadcasters under the Fairness Doctrine which required broadcasters to air both sides of a controversial issue if one side was being aired. Per capita cigarette consumption dropped four years in a row, for the first time in history (Warner, 1977, 1979). Schneider et al. (1981) concluded that the counter-advertising reduced per capita consumption by approximately 5\%. Using individual-level data on smoking among youth ages 12-17, taken from Cycle III of the Health Examination Survey, Lewit and his colleagues (1981) found that the anti-smoking messages significantly reduced youth smoking prevalence.

In 1988, California voters passed Proposition 99, the California Tobacco Tax and Health Promotion Act. The Act raised the state cigarette tax by 25 cents per pack and earmarked 20 percent of new tax revenues for health education programs to reduce cigarette smoking, including a statewide media campaign. Similar tax increases with funds earmarked for counter-advertising campaigns have been adopted in Massachusetts, Arizona, Oregon, and elsewhere. In addition, part of the funds received by several other American states that have recently settled lawsuits with the tobacco industry are earmarked for counteradvertising campaigns. Hu and his colleagues (1994, 1995b) concluded that California's anti-smoking media campaign has significantly reduced smoking in California. They estimated an elasticity of cigarette sales with respect to expenditures on the antismoking media campaign of -0.05 (Hu et al., 1995c). Comparing the impact of the tax increase with that of the media campaign, they estimated that the tax increase reduced per capita cigarette sales by over 27 packs, while sales declined by just under eight packs per person in response to the media campaign. Early evidence from Massachusetts suggests a comparable decline in sales after that state's tax-funded anti-smoking campaign (Harris et al., 1996). Chaloupka and Grossman (1996) concluded that similar counter-advertising campaigns financed by earmarked cigarette taxes lead to significant reductionsin both the prevalence of youth smoking and average cigarette consumption by young smokers.

Econometric evidence from Greece (Stavrinos, 1987), Finland (Pekurinen, 1989, 1991), Turkey (Tansel, 1993), Australia (Bardsley and Olekalns, 1998), and the U.K. (Townsend, 1998) indicates that the U.S. experience is not unique. In each of these studies, mass media campaigns aimed at reducing cigarette smoking by providing information on the health consequences of smoking were estimated to have led to significant reductions in smoking prevalence and in cigarette consumption.

The evidence described above clearly indicates that cigarette demand has declined in response to dissemination of new information on the health effects of cigarette smoking. Viscusi (1990, 1991, 1992, 1995) and others have concluded that individuals have heard and comprehended the health warnings and are making rational, well-informed choices when it comes to smoking. Indeed, as noted above Viscusi (1992) believes that smokers overestimate the risk of dying from lung cancer as a result of smoking. As such, he suggested (Viscusi, 1992, 1995) that the scope for further government intervention to 
reduce cigarette smoking is relatively limited. Kenkel (1991), however, concluded that while knowledge about the health effects of smoking is relatively common and has significantly reduced smoking, it is incomplete. Moreover, his estimates implied that improved health knowledge would lead to significant changes in cigarette smoking, in contrast to his findings for health knowledge concerning alcohol use and exercise. As was noted earlier, a wealth of additional evidence further supports the view that, while general knowledge concerning the health consequences of smoking is relatively widespread, it is often superficial and does not extend to risks other than those associated with lung cancer, heart disease, and chronic lung disease (U.S. Department of Health and Human Services, 1989). Further, many smokers, particularly including heavy smokers, do not personalize the health risks that they acknowledge as applying to smokers "in general" (Schoenbaum, 1997). Warner et al. (1995), Brownson et al. (1992), Grossman et al. (forthcoming), and others argue that some populations, particularly younger and less educated/low-income groups, significantly understate the health consequences of smoking; for example, children in particular may be prone to underestimate the risk of becoming addicted.

\subsection{Restrictions on cigarette smoking}

As information on the health consequences of exposure to environmental tobacco smoke (ETS) has become more widespread (U.S. Department of Health and Human Services, 1986 ; U.S. Environmental Protection Agency 1992; Steenland, 1992; Steenland et al., 1996), governments at all levels have adopted policies limiting smoking in public places and private workplaces. Beginning with Arizona in 1973, states started adopting "clean indoor air" laws with the explicit objective of limiting nonsmokers' exposure to ETS (U.S. Department of Health and Human Services, 1986). In general, these laws prohibit smoking in elevators, health care facilities, public transportation, indoor cultural and recreational facilities, government buildings, public meeting rooms, schools, shopping malls, and retail stores. The most extensive laws also include restaurants and private workplaces. A recent World Health Organization (1997) survey of tobacco control policies in 134 countries indicated that the vast majority of countries now have some form of restriction on smoking in public places.

Although the restrictions are primarily intended to reduce nonsmokers' exposure to ETS, they can also lead to significant reductions in cigarette smoking since they reduce the smoker's opportunities to smoke or otherwise raise the "cost" of smoking. This is particularly true for adult smokers restricted from smoking at the workplace. In addition, restrictions on smoking may alter the perceived norms related to smoking by changing attitudes concerning the social acceptability of smoking (U.S. Department of Health and Human Services, 1994).

A number of recent econometric and other studies have examined the impact of smoking restrictions on cigarette demand in the U.S. and elsewhere Wasserman et al., 1991; Chaloupka, 1992; Chaloupka and Saffer, 1992; Keeler et al., 1993; Chaloupka and Grossman, 1996; Evans et al., 1996; Chaloupka and Wechsler, 1997; Chaloupka and Pacula, 1998a, 1998b; Ohsfeldt et al., 1998; Bardsley and Olekalns, 1998; Townsend, 1998). In general, restrictions on smoking in public places and private workplaces have been found to reduce both smoking prevalence and average daily cigarette consumption among smokers. Wasserman et al. (1991) estimated that expanding smoking restrictions from those limiting smoking in a small number of relatively minor public places (elevators, waiting rooms, etc.) to more comprehensive restrictions, including restaurants and private workplaces, would reduce overall per capita smoking by almost 6\%. Similarly, Chaloupka and Grossman (1996) and Chaloupka and Wechsler (1997) concluded that strong restrictions on smoking significantly reduce both smoking prevalence and average daily cigarette consumption for youth and young adults, respectively.

Using annual state-level data for 1975-1985, Chaloupka and Saffer (1992) examined the possibility that smoking restrictions are endogenous. They found that states with the strongest restrictions, those with limits on smoking in private workplaces, were also the states in which anti-smoking sentiment was relatively high and smoking was relatively low. After accounting for this, Chaloupka and Saffer concluded that the strongest restrictions had no impact on cigarette demand. However, they did find that relatively comprehensive restrictions on smoking in public places (those including restaurants in addition to a number of other public places) significantly reduced smoking even after accounting for their potential endogeneity. In a more recent analysis of this issue, using data from the September 1992, January 1993, and May 1993 tobacco use supplements to the Current Population Survey, Ohsfeldt et al. (1998) concluded that the strongest restrictions on smoking lead to significant reductions in smoking prevalence, after accounting for their 
potential endogeneity.

Evans and colleagues (1996) examined whether workplace restrictions led to selfselection, with nonsmokers attracted to worksites at which smoking was not permitted and smokers seeking out worksites permitting smoking. Using data from the 1991 and 1993 National Health Interview Surveys, the authors examined self-reported information on whether or not workers were in firms that had policies restricting smoking. If the respondent answered affirmatively, more detailed information on the policies was collected. Evans et al. estimated the impact of the restrictions on cigarette demand in a simultaneous equations model that allows for individuals to self-select worksites based on their smoking status and smoking policies. The authors found that, after accounting for workers' potential self-selection, smoking bans diminished the probability of adult smoking by 5\%, while reducing average daily cigarette consumption among smokers by $10 \%$. As such, the authors concluded that recent declines in smoking among workers relative to non-workers in the U.S. can be attributed to the growing number of workplace bans on smoking.

\subsection{Limits on youth access to tobacco products}

According to the World Health Organization (1997), 43 countries ban the sale of cigarettes to minors, typically by establishing a minimum legal purchase age for cigarettes and restricting the distribution of free samples of to underage youth. The non-economics literature provides mixed evidence on the effectiveness of these youth access limits. A few studies have found that raising retailer compliance with the minimum age laws reduces the prevalence of youth smoking (Jason et al., 1996; Forster et al., 1998). Others, however, have found little impact on youth smoking, even with high compliance by retailers (Rigotti et al., 1998). A few recent econometric analyses have examined the impact of these limits on youth tobacco use in the U.S., generally finding little or no impact on youth cigarette smoking and other tobacco use wasserman et al., 1991; Chaloupka and Grossman, 1996; Chaloupka et al., 1997; Chaloupka and Pacula, 1998a). Chaloupka and Grossman (1996) attributed this to the relatively weak enforcement of these laws.

Chaloupka and Pacula (1998a) examined the impact of enforcement of and compliance with the limits on youth access on youth smoking using data collected in a special 1994 survey of state activities related to the Synar amendment (Downey andGardiner, 1996). This amendment requires states to establish minimum purchase ages for tobacco products and to demonstrate that these laws are being enforced by conducting random, unannounced compliance checks of retailers selling tobacco products. Failure to do so can lead to the loss of state block grant funds for substance abuse prevention and treatment programs. Chaloupka and Pacula's estimates suggest that when the limits on youth access are comprehensively and aggressively enforced and highly complied with, they significantly reduce the prevalence of youth smoking.

\section{Agricultural policy and the macroeconomic implications of tobacco}

Most of the policy-relevant economic research on tobacco has focused on the arguments in the cigarette demand function, discussed in the preceding sections. With a few exceptions, the literature cited has addressed how policy variables directly influence smoking by individuals. There is another domain in which economic issues arise and economic analysis has produced important understanding, however how policy effects on the economic welfare of the industry indirectly influence smoking and health. In this section, we examine the literature pertaining to two such issues, each of which has been raised in the course of the social debate on the economic and health consequences of tobacco.

The first involves economic policy intended to benefit the agricultural sector of the U.S. tobacco industry: how the unorthodox regulation of domestic tobacco growing in the U.S. affects the price and quantity of tobacco grown, and through this channel influences the price and consumption of cigarettes. The tobacco "subsidy" has been a source of contention within the U.S. public health community for years, with most health professionals believing that the "subsidy" encourages tobacco growing and thereby smoking.

As economists will appreciate immediately, the direct effect of a tobacco price support system is the opposite: it discourages smoking by artificially inflating the price of tobacco in cigarettes. Economic analysis has provided insight into the extent of this effect, permitting policy analysts to consider it in the broader context of the overall implications of the price support program.

The second issue addresses the broad question of how dependent nations' economies are on preservation of a robust tobacco industry for employment, tax revenue, and a 
positive contribution to the trade balance. A central thrust of the tobacco industry's strategy to combat tobacco control policies has long been to argue that, regardless of the health consequences of its products, the economic vitality of America (and other countries) depends on a strong tobacco industry. In recent years, macroeconomic research has been undertaken in several countries to challenge the premise with empirical evidence.

Prior to addressing these issues, this section opens with background on both the global and U.S. tobacco industries.

\subsection{Size and nature of the tobacco industry}

\subsubsection{The global industry}

In 1983, ${ }^{28}$ an estimated 47 million people directly owed their livelihoods, in whole or in part, to tobacco cultivation, product manufacture, distribution, and retailing (representing 18.2 million full-time equivalent jobs), with 30 million of these in farming (11 million FTEs), nearly half in China alone. ${ }^{29}$ In addition, over 10 million people (8 million FTEs) were employed in supplier industries, those providing materials and services to the tobacco industry (e.g., harvesting tools and cigarette papers, insurance coverage and transportation and shipping) (Agro-Economic Services, 1987).

In the 69 countries included in this evaluation of the global industry (covering 90\% of the world's population), an average of $0.3 \%$ of arable land was devoted to tobacco, although tobacco accounted for 1.3\% of full-time agricultural employment, reflecting the labor intensity of tobacco growing. Tobacco constituted 1\% of total agricultural output, $0.8 \%$ of total manufacturing output, and 3 percent of total retail sales Agro-Economic Services, 1987).

International trade in tobacco and tdbacco products represented $0.5 \%$ of total exports and $0.4 \%$ of imports, the difference reflecting a robust international contraband trade (Agro-Economic Services, 1987) which appears to have grown considerably in recent years (Joosens, 1998). For a handful of countries, tobacco exportation represents an international economic lifeline. In Zimbabwe, for example, tobacco accounts for approximately one-third of the country's export revenues (Chapman and Wong, 1990; "Zimbabwe...", 1998 ).

Tobacco's economic importance worldwide derives also from its use as a source of governmental revenues. Excise (and other) taxation generates many tens of billions of dollars annually. Several countries derive 10\% or more of total government revenues from tobacco taxation (Chapman and Wong, 1990).

\subsubsection{The U.S. tobacco industry}

In 1995, Americans spent $\$ 48.7$ billion on tobacco products most of it on just under 490 billion cigarettes. In addition, U.S. farms and cigarette companies shipped abroad, respectively, $\$ 1.4$ billion worth of unmanufactured tobacco leaf and $\$ 5$ billion in manufactured product (Gale, 1997).

The five core sectors of the tobacco industry -- tobacco growing, auction warehousing, product manufacturing, wholesale trade, and retail trade -- collectively employ up to half a million Americans in tobacco-related activity (Gale, 1997). Industry activity generates an additional 650,000 to 2 million spin-off jobs, representing purchases from suppliers and spending by the recipients of incomes from tobacco product sales. In 1992, the emotional and political heart of the U.S. industry, tobacco

28 We are not aware of any contemporary figures on the size of the global industry. The data presented here, covering the year 1983, suggest a rough order-of-magnitude estimate of the industry's importance, albeit one that likely underrepresents the contemporary industry given that tobacco consumption has increased worldwide annually since that year.

29 China is the world's largest producer and consumer of cigarettes.

30 Estimates of direct, indirect, and expenditure-induced employment are taken from several sources, including Warner et al. (1996), Price Waterhouse (1992), Tobacco Merchants Association (1995), and Gale (1997). The smallest total employment associated with tobacco industry activity is Gale's estimate of 1.2 million, although Gale also reported a high estimate of direct employment (500,000). The largest total employment estimate is that of the WEFA Group at 3 million jobs, although we believe that this and several other industry-commissioned estimates rely on improbably large multipliers in estimating expenditure-induced employment. Reviewing the Price Waterhouse analysis, 
farming, included 124,000 farms on which tobacco was grown in some 20 states. However, just three states -- North Carolina, Kentucky, and Tennessee -- accounted for 82\% of the 91,000 farms officially designated as tobacco farms (defined by the U.S. Department of Agriculture as farms on which tobacco accounts for at least 50\% of sales). A further three states -- Georgia, South Carolina, and Virginia -- accounted for an additional 10\% of tobacco farms. Collectively, these six southeastern tobacco states were responsible for a comparable percentage of tobacco production as well Grise, 1995).

Estimating tobacco farm employment is difficult because so few farmers rely exclusively on tobacco for their full-time economic activity. Employing the arbitrary assumption that each job is half time (1000 hours), the USDA estimated the number of tobacco farming jobs in 1995 at 156,000 (i.e., fewer than 80,000 FTE jobs). The largest employment contribution associated with tobacco was in the retail sector, however, with an estimated 257,000 jobs spread all over the country. The other politically "visible" component of the industry -- workers employed in cigarette manufacturing -- numbered only 25,600. They were concentrated primarily in only three cities in which the vast majority of U.S. cigarettes are manufactured: Richmond, VA, Winston-Salem, NC, and Louisville, KY (Gale, 1997).

Although the tobacco farmer is the "heart" of the indutry in emotional and political terms, economically the farmer appears to be little more than a minor appendage. Domestically-grown tobacco represented only about $2 \%$ of the domestic retail tobacco dollar in 1995, with imported tobaccos constituting another $1-2 \% 31$ Once one accounts for leases of tobacco-growing quotas, farm supplies and equipment, overhead, and marketing costs, farm workers actually took home only about 30\% of tobacco farm gross receipts for their labor, under $1 \%$ of the nearly $\$ 50$ billion Americans spent on cigarettes and other tobacco products. By comparison, the largest share of the tobacco dollar went to manufacturing (38\%), with additional major participants being wholesale and retail trade (27\%) and government, through excise taxation (26\%) (Gale, 1997).

Although tobacco growing and cigarette manufacturing might seem like excellent candidates for a highly competitive marketplace, they do not come close to conforming to the economist's ideal of the smoothly functioning unregulated competitive market. The manufacturing industry is characterized by a high degree of concentration, with two companies, Philip Morris and R.J. Reynolds, selling three-quarters of all cigarettes purchased in the U.S. and three others (Brown \& Williamson, Lorillard, andLiggett) accounting for the vast majority of the rest; Philip Morris alone captures half the market (with one of its brand lines, Marlboro, accounting for more than half of the company's sales) (Kluger, 1996). Four other companies round out this highly concentrated oligopoly. Although one can readily imagine barriers to entry into the cigarette market (e.g., brand-name marketing advantages, distribution channels, etc.), tobacco farming seems a less obvious domain for noncompetitive forces. Nonetheless, this purely agricultural endeavor is not subject to the conventional laws of supply and demand in the U.S. Rather, a convoluted system of price supports and allotments regulates who can grow tobacco, where and how much they can grow, and what minimum prices they can expect at market. The existence of this system, and the concentration of the industry in the six southeastern states, has been credited with responsibility for the unusual political power wielded by the six tobacco bloc states in Congress (Taylor, 1984; Warner, 1988; Gale 1997). We turn now to a consideration of the nature of this system and its implications for both tobacco agriculture and smoking and health.

Arthur Andersen Economic Consulting (1993) identified what they believed to be serious methodological flaws and concluded that "employment and job loss figures are grossly inflated."

Other analysts have suggested that the industry substantially underestimates employment associated with tobacco, since they fail to include health care personnel who care for the victims of tobacco-produced diseases, undertakers who bury them several years earlier than nonsmokers, professional launderers who clean and repair smokers' clothing more frequently, and so on (Schelling, 1986; Warner, 1987).

31 The tobacco crop value in 1995 was less than $\$ 2.6$ billion, much of which was exported as raw leaf or in manufactured cigarettes (Gale, 1997). 


\subsection{The impact of the U.S. tobacco agriculture regulatory system \\ 6.2.1 Nature of the system and its impact on tobacco farming}

Since the early $1930 \mathrm{~s}$, the U.S. federal government has implemented a variety of tobacco farm programs designed to limit tobacco growing and prop up tobacco prices. Born of Depression-era concerns about the traumatic effects on farmers of cyclical prices and the vagaries of the weather, the programs have ensured stability but also limited innovation in production techniques and farm size. Although the specifics of the programs have varied over time, they have shared certain core elements in common: restriction of the supply of tobacco, by restricting who can grow tobacco and how much they can grow, and the assurance of minimum prices.

The tobacco farm programs began with the Agricultural Adjustment Act of 193 through which cash payments were made to tobacco farmers who agreed to limit production. The Agricultural Act of 1938 established the principle of marketing quotas, with penalties for growers who exceeded them. Price supports were originally set at 75\% of base-period prices and have varied up and down since then. The continued existence of the price support system rested on a vote of tobacco farmers every three years. If two-thirds of the farmers supported the system, as they have during each vote (with some minor exceptions), legally enforceable marketing quotas are put in place.

The growers of tobacco, and the acreage they can farm, are limited through a system of allotments, in essence a license to grow tobacco, allocated to farms existing at the time the system was established. Under the first of the allotment programs, only farmers possessing the allotments, or renting or purchasing land with allotments, could grow tobacco. Since 1962, however, farmers have been permitted to rent or purchase allotments without having to use the allotment holder's land, although subject to a number of restrictions as to type of tobacco and how far the quota could be transported (e.g., some quotas could be applied only within the county of the allotment holder). Supplies of tobacco were thus limited through allotments and marketing quotas, as well as restrictions on imported tobacco. Quotas are established based on the intended purchases by cigarette manufacturers, anticipated exports and imports, and the amount of tobacco needed to achieve a specified level of reserves. The Secretary of Agriculture can further adjust the quotas by $+3 \%$ of the amount determined by formula.

The price support is based on a loan program through which farmers are guaranteed a pre-specified minimum price. Farmers attempt to sell their tobacco at auction. If the high bid does not at least match the loan price, a farmer-owned cooperative purchases the tobacco at that guaranteed price, using money loaned by the USDA's Commodity Credit Corporation (CCC). The cooperative stores the tobacco as collateral for the CCC loan. When the cooperative later resells the tobacco, it forwards the proceeds to the cCC to cover the loan principal and interest.

Until 1982, general tax revenues were used to cover CCC losses. Although the amounts of money involved were modest by federal government program standards (Warner, 1988), the image of taxpayers' subsidizing the growing of a product that health officials characterized as deadly became politically untenable. As a result, Congress passed the No-Net-Cost Tobacco Program Act of 1982 which eliminated the taxpayer subsidy. Since then, farmers and buyers have paid an assessment per pound of tobacco to cover any losses in the loan program. The federal government continues to cover the cost of administering the program, as well as providing a variety of other services to growers through the USDA.

In 1993, the total federal outlay on these activities was \$26 million.

Over time, variations in the tobacco program have modified import policies and imposed and then removed domestic-content requirements for U.S. cigarette manufacturers, as well as tinkering with quota determination and allocation, price support, and so on. For a discussion of specific revisions of the relevant laws, see Capehart (1997) and Grise (1995).

The net effect of the program on tobacco agriculture has been multi-faceted. It has brought the stability to the tobacco farm economy that it was designed to ensure. It has restricted domestic tobacco supplies. The program has clearly restricted tobacco farm size and limited the development of more capital-intensive methods of tobacco farming; indeed, the growing of tobacco entails greater labor intensity than for nearly all other U.S. crops. The program has increased the price of domestic tobaccos and, as a consequence, the price of cigarettes (discussed below). As a result of boosting prices,

32 This section's description of the tobacco agriculture program is based on material from Capehart (1997), Grise (1995), and Zhang and Husten (1998). 
it has likely restrained the amount of raw leaf exportation from the U.S. It has created an economically entrenched political constituency, the allotment holders, the principal beneficiaries of the program (Babcock and Foster, 1992).

\subsubsection{Relevance of the tobacco program to smoking and health}

The tobacco program has had two effects directly germare to the issue of smoking and health, one ostensibly favorable, the other not. By restricting the supply of tobacco and increasing its price, the program has likely boosted the price of the finished product, cigarettes, and thereby decreased the quantity demanded. The extent of this effect -arguably the less important of the two (Warner, 1988; Zhang and Husten, 1998) -- has been studied by economists and is the focal point of this section. In contrast, by allocating the right to grow tobacco, or to earn money by leasing allotments, to a select group of citizens in the tobacco southeast, and by ensuring stable and relatively high prices for farmers, the tobacco program has created a highly concentrated economic and thus political interest that has long wielded substantial power within the halls of Congress (Taylor, 1984; Babcock and Foster, 1992). Long-time observers of both Congress and tobacco concur that the existence of the tobacco bloc has thwarted the development of effective tobaccoand-health policies frequently over the past 35 years (Taylor, 1984; Fritschler and Hoefler, 1996).

Whether the consumption-discouraging effects of the increased price of tobacco or the consumption-encouraging effects of a lack of aggressive federal tobacco control policy have dominated has been the subject of some informed speculation but no formal analysis. Having reviewed the evidence, both Warner (1988) and Zhang and Husten (1998) concluded that the latter was more important than the former, but in each case this conclusion rested as much on the finding that the direct effect of the tobacco program on cigarette price was very small. It is here that economic analysis has provided useful empirical evidence. ${ }^{33}$

The economic effects of the tobacco price support program have been the subject of formal economic analysis for at least three decades (Johnson, 1965). Since the mid-1980s, four analyses have estimated the impact of abandonment of the tobacco price support program on tobacco supplies and prices. Using a simultaneous equations model of the supply of and demand for tobacco and cigarettes, which included the possibility of substitution of foreign for domestic tobaccos, Sumner and Alston (1985) estimated that eliminating the program in 1983 would have reduced the price of U.S. tobacco by $20-30 \%$. The authors estimated an increase in domestic tobacco output of 50-100\% or more with supply restrictions ended, with cigarette manufacturers likely to buy more domestic tobacco and exports likely to double. Reflecting this expanded output, Sumner and Alston estimated that tobacco growing revenues would have risen by 15-60\% despite the price decrease. Because domestic tobacco represented under $10 \%$ of the retail price of cigarettes, the authors concluded that the price support program boosted the retail price of cigarettes by no more than 3\%. Employing a price elasticity of demand of -0.3, they estimated that the direct effect of the price support program was to decrease the demand for cigarettes by about 1\%. A decade later, economists at the USDA produced a similar if less detailed analysis that supported Sumner and Alston's findings. Grise (1995) concluded that the price support program raised domestic tobacco prices by 30-40\%. He estimated that this tobacco price effect raised cigarette prices by 1-2\%.

33 This analysis has been particularly useful simply to help correct the misimpression of the lay public that the tobacco price support program, or the "tobacco subsidy," as it is more commonly referred to, has directly encouraged smoking by encouraging tobacco growing. The public has not generally appreciated that, to the contrary, the program has limited the quantities of tobacco grown and brought to market.

34 Sumner and Alston (1985) assumed that tobacco price increases attributable to the price support system would be fully passed on to retail consumers. This is a reasonable assumption. Although the evidence is mixed, most previous research has characterized the tobacco industry as a constant-cost industry. Research has also demonstrated that the industry has exploited its oligopolistic character with a strong price-leadership model, passing on more than $100 \%$ of federal excise tax increases (Harris, 1987). A recent study concluded that the industry engages in a minor amount of price discrimination by state, passing along slightly more than states' excise tax increases (Keeler et al., 1996). Obviously, the permeability of state borders limits the extent of such price discrimination. 
Still more recently, researchers at the federal Office on Smoking and Health (OSH) in the Centers for Disease Control and Prevention analyzed contemporary data and determined that the price support program increased tobacco prices by 18-23\% (Zhang et al., 1997). In contrast with the early 1980s, domestic tobacco accounted for only 3\% of cigarette retail price in 1991. This decline in the domestic tobacco farm value share of retail cigarette value reflected several developments pertaining to the amount and price of domestic tobaccos. First, the amount of tobacco employed in manufacturing a given number of cigarettes has declined significantly since the $1980 \mathrm{~s}$, as it has since well before then (from the early 1950s to the present, the amount of tobacco per cigarette has declined by over a third (Congressional Research Service, 1994)). This has resulted from reduced wastage, in part as a consequence of new production technologies that allow manufacturers to blend in parts of the tobacco plant previously discarded, such as tobacco stems, and to expand the volume of tobacco per unit of weight (called "puffing"). It also reflects a shift in demand from relatively large-barreled cigarettes some unfiltered, to filtered and small-diameter cigarettes.

A second reason for the decline in the domestic tobacco share of the cigarette dollar is manufacturers' increasing reliance on less expensive imported tobaccos. At various times, as much as a third or more of the tobacco in U.S. cigarettes has been imported. From 1980 to 1991, for example, the imported tobacco share rose from 29\% to 35\%. More recently, the share of imported tobaccos quickly decreased and then increased. ${ }^{35}$ The 1993 Omnibus Budget Reconciliation Act (OBRA) included a provision requiring that $75 \%$ of the tobacco in U.S.-manufactured cigarettes be domestically grown. Shortly after the domestic content provision was implemented, it was determined to be inconsistent with the requirements of the General Agreement on Tariffs and Trade (GATT). It was replaced in september 1995 by a complicated tariff-rate quota (TRQ) designed to restrict imports but to conform to GATT requirements. ${ }^{36}$

A third factor in the declining share of cigarette expenditures attributable to domestic tobacco has been the stability of tobacco prices compared to more rapidly inflating prices for the manufactured product. From 1980 to 1991, the farm price of tobacco rose only 18\%. During the same period, cigarette price increased 187\%.

Accounting for the reduced role of domestic tobacco in cigarette price, Zhang and colleagues concluded that the tobacco price support program likely increased the retail price of cigarettes by no more than 1\%. To assess the impact on smoking, the researchers employed a more recent estimate of the price elasticity of demand for cigarettes and then allocated half of the price response to decisions of whether or not to smoke and the other half to number of cigarettes per day per continuing smoker. Given these assumptions, they estimated that the direct effect of the tobacco price support program was to decrease the number of smokers by $0.14 \%$. As such, they concluded that the beneficial effect of the price support program, from a public health point of view, was very modest at best.

In the most recent attempt to evaluate the implications of the tobacco price support system, Brown (1998) examined a mix of likely provisions in comprehensive federal tobacco control legislation that would directly affect domestic tobacco growing. Combining the

35 Imported and domestic tobaccos are not perfect substitutes. Tobaccos come in numerous varieties, each with its own characteristics, and soil and weather conditions combine to alter those characteristics from one growing location to another. As a consequence, the world price of tobacco does not necessarily reflect the marginal price. Some American-grown tobaccos, prized by cigarette manufacturers, can command a higherthan-average price on world markets.

36 The TRQ imposes quotas on imported tobaccos by exporting country, with imports above quota levels subject to a $350 \%$ ad valorem duty. However, most of the duty is refunded if the excess imported tobacco is included in cigarettes made in the U.S. for export.

37 The authors' assumptions are subject to challenge. In particular, as indicated earlier in this chapter, most of the research on cigarette price elasticities to date suggests that the dominant effect of increasing prices on adult consumption is to lower daily cigarette consumption for continuing smokers, rather than decrease smoking prevalence. The OSH authors' estimate of the impact on numbers of smokers is so small, however, that alternative assumptions will not alter the qualitative conclusion that the impact on smoking is very small. 
Economics of Smoking - p. 44

effects of eliminating the price support program with adoption of a $\$ 1.50$ per pack federal cigarette excise tax increase, he predicted a long-run decline in tobacco leaf price of 20-30\%, not inconsistent with the OSH estimates, which did not incorporate an excise tax increase.

The consistency of the findings from these studies provides strong support for the conclusion that the direct effect of the U.S. tobacco price support program on discouraging smoking, by virtue of raising cigarette prices, is very small.

\subsection{The contribution of the tobacco industry to the economy}

\subsubsection{States and nations}

Since the late 1970s, the U.S. tobacco industry has commissioned numerous prominent economics consulting firms to produce estimates of the industry's contributions to employment, incomes, and tax revenues for the country as a whole, the individual states, and occasionally specific cities and counties (Wharton Applied Research Center, 1979; Chase Econometrics, 1985; Price Waterhouse, 1990, 1992; Tobacco Merchants Association, 1995; American Economics Group, 1996b). When tobacco control policy measures have been under consideration by legislative bodies, industry representatives have used the findings from these analyses to try to convince legislators that adoption of the policy would inflict economic damage on the state's or nation's citizens, in particular by causing widespread loss of jobs (Warner, 1987). In a few instances, the industry's consultants have observed in their formal written reports to their clients that alternative spending patterns would generate compensating employment (Chase Econometrics, 1985; American Economics Group, 1996a) ${ }^{38}$. When meeting with legislators, however, the industry's representatives have never mentioned this.

That the decline or demise of one economic activity would be replaced by alternative economic activity, each of which would eventually produce comparable national levels of employment, is obvious to economists. The compensating benefits of replacement economic activities are not generally contemplated by the lay public, however. As such, legislators, journalists, and other members of the public are susceptible to the industry's argument that reduced purchase of tobacco products will lead to substantial economic dislocation, and that such dislocation exacts a high price from communities. industry has used its estimates in two ways: to indicate the overall significance of tobacco in the economies of the states and the nation as a whole; and to make projections of lost jobs and tax revenues that would result from the adoption of specific tobacco control policy measures.

To respond to this argument, economists have performed macroeconomic analyses that essentially complete the analysis initiated by the industry's consultants. Where the industry-sponsored studies estimate the gross economic contribution of tobacco -- the numbers of jobs, earnings, taxes paid -- the independent studies estimate the net contribution, i.e., the benefit of tobacco-related economic activity after one considers the implications of redistribution of the same resources to alternative uses. Researchers at the University of Michigan employed the REMI Model (Regional Economic Models, Inc.) (Treyz, 1993) to estimate how both declining tobacco consumption and the complete elimination of tobacco consumption would affect employment in the state of Michigan (Warner and Fulton, 1994) and in the principal regional economies of the U.S., as defined by the U.S. Bureau of Economic Analysis (BEA) (Warner et al., 1996). The study of the effects on Michigan was intended to demonstrate how declining tobacco consumption impacts the economy of a nontobacco state, since nontobacco states comprise the large majority of U.S. states and they have often been the targets of the industry's economic argument. The study of the regional economies of the U.S. was intended to contrast effects within the southeast tobacco-state region (consisting of half the 12 states in the BEA's southeast region) with implications for the 8 nontobacco regions (one, "southeast nontobacco," consisting of the six nontobacco states in the BEA's southeast region).

38 In the most telling example of this, buried in chapter $V$ of volume 1 of the detailed technical report prepared by analysts at Chase Econometrics (1985) is the acknowledgment that money not spent on tobacco products would be reallocated to other spending, and that nationwide (combining tobacco and nontobacco states), the economic results with and without tobacco "would be substantially the same." The report authors explicitly observed that compensatory responses to the absence of tobacco spending "that would occur automatically within the Chase Econometrics Macroeconomic Model... were constrained from taking place within [the firm's] analysis." 
To illustrate the procedure (the basics of which were conceptually identical for the two studies), in the regional analysis the researchers first generated a baseline forecast of the economies of each of the 9 regions for the years 1993 to 2000, assuming no changes in the expected pattern of spending on tobacco (which included an expected annual decline in consumption, based on the trend in the decade preceding the period of the simulation).

The eight-year period selected for the simulation was intended to permit analysis of dynamic short- and medium-run impacts on the regional economies. To evaluate the gross contribution of tobacco to employment, analogous to what the industry's consultants have done, the researchers then generated an alternative forecast in which all of the expected spending on tobacco was removed from the baseline forecast. Comparison of the two forecasts, with and without tobacco spending, permitted assessment of the amount of employment associated with tobacco spending, by region, economic sector, and year. To estimate the net employment implications resulting from consumers devoting their former tobacco expenditures to other goods and services, the analysts reallocated this amount according to consumers' normal spending patterns, with tobacco excluded. Net employment was estimated by comparing the employment projections in the baseline simulation with those from the simulation in which tobacco spending is reallocated to other goods and services.

To examine the implications of a more realistic scenario which might be expected if effective tobacco control policy measures were adopted, namely an increasing rate of decline in tobacco product consumption, the researchers assumed that the recent historical rate of decline would double. The simulations were repeated with the appropriate amount of tobacco spending removed (gross model) and reinjected into the alternative goods and services (net model).

In the first study, Warner and Fulton (1994) demonstrated that in a nontobacco state, declining spending on tobacco products would increase the state's employment, and that this effect would persist over several years. The finding reflected the fact that tobacco products represent imports for Michigan (and other nontobacco states). Since some of the reallocated spending would be devoted to goods and services produced within the state, more state spending would recycle within Michigan, thereby producing more Michiganbased jobs. Although this is obvious to economists, it represented a revelation to many noneconomists in the policy community.

In the second study (Warner et al., 1996), the researchers found that with either a decline or the complete elimination of domestic tobacco spending, each of the eight nontobacco regions would gain employment during the period studied, while the southeast tobacco region would lose employment. The study further demonstrated that the losses within the tobacco region would be considerably smaller than those suggested by the industry's analyses, which again have never included the effects of alternative spending, which would benefit the tobacco states as well as the nontobacco states. One of the study's most important conclusions was that plausible declines in tobacco consumption would have exceedingly small impacts on employment even in the southeast tobacco region. Under the more realistic scenario, the estimated loss of 36,600 jobs in the region by the year 2000 would amount to only $0.2 \%$ of regional employment.

Similar analyses have been performed in other countries. The idea was first introduced by Allen (1993) in a qualitative consideration of the economic implications of the tobacco industry in Canada. Subsequently, Buck and colleagues (1995) used an inputoutput model to study the employment implications of tobacco in the United Kingdom. Most recently, van der Merwe (1998b) evaluated the same issue in South Africa. Despite variations in basic methods (e.g., input-output vs. dynamic models) and more specific assumptions (most notably, the nature of the alternative spending pattern), all of these studies have arrived at the same conclusion: spending on tobacco does not generate greater employment for the country in question than would alternative spending patterns.

The tobacco industry's consultants report on other industry-related impacts in addition to employment. The two most important are the tax revenues generated by spending on tobacco and the positive contribution of tobacco to certain countries' trade balances.

No non-industry analysis has attempted to evaluate the net effects of reductions in tobacco spending on these two variables. The results are obvious, however. For most countries, reductions in tobacco spending would produce reductions in government revenues, reflecting the fact that cigarettes, unlike most other products, are subject to excise taxation. Thus, governments that succeed in reducing tobacco consumption through tobacco control policies generally will need to seek alternative sources of revenue to replace those lost due to declining tobacco product sales. The one exception, of course, is a sales reduction occasioned by an increase in an excise tax. In this instance, as is discussed earlier in the chapter, government revenues will rise at the same time that 
consumption falls.

Reductions in spending on tobacco could adversely affect the balance of payments in those countries in which exports of tobacco and tobacco products exceed imports. However, tobacco exports play a truly central role in the balance of payments in only a handful of countries; most notably, Zimbabwe relies on tobacco for approximately a third of its foreign exchange earnings (Chapman and Wong, 1990; "Zimbabwe...", 1998). In contrast to the net exporters, in countries in which tobacco product imports exceed exports, decreasing consumption could improve the trade balance (Warner and Fulton, 1995).

\subsubsection{Tobacco farm communities}

As the regional analysis of the U.S. demonstrated, reductions in tobacco product sales can harm the economies of specific areas of countries highly dependent on tobacco economic activity. That analysis also demonstrated, however, that plausible policyinduced decreases in tobacco consumption would have extremely modest effects on employment within the United States' major tobacco region (Warner et al., 1996).

Less clear, however, and likely more important from both a political and humanitarian point of view, is the impact of declining tobacco sales on the local communities that are most heavily dependent on tobacco farming or product manufacture. In the popular mind in the U.S., large numbers of counties in North Carolina, Kentucky, and the four other tobacco states are virtually wholly dependent on tobacco farming. ${ }^{39}$

Substantial decreases in tobacco product sales would, it is widely believed, wreak havoc with these communities' economies. Sympathy with this view has ledto the inclusion of significant benefits to tobacco farmers in all of the comprehensive tobacco control legislative proposals under consideration by the U.S. Congress in 1998.

According to work by agricultural economists, however, the image distorts a more benign reality. Relatively few tobacco counties in the U.S. are so dependent on tobacco that plausible policy-induced decreases in tobacco consumption would inflict serious economic hardship. Indeed, Gale (1998) stated recently that he expects merely a continuation of the kinds of economic adjustments that tobacco farmers have been making for decades; and, he observed, tobacco farm communities today have more diversified economies upon which to draw in making those adjustments than in years gone by. He summarized the essence of the situation by noting, "Tobacco has an important historical role in many Southern communities. Today, however, tobacco plays a minor economic role in most local economies where it is grown" ( $p$. 43).

That the importance of tobacco farming within the tobaccobelt states has diminished substantially is made clear by data supplied by the Economic Research Service tRS) of the USDA. From 1964 to 1993, the number of tobacco farms declined from 330,000 to 124,00040

Domestic consumption of domestically-produced tobaccos has declined from 1.6 billion pounds in 1952 to 900 million pounds in 1993. Adjusted for inflation, the value of domestically grown tobacco has fallen.

For most tobacco farmers, tobacco growing represents only part-time, seasonal work.

Further, most tobacco farms are small, with over 70\% having annual gross sales of less than $\$ 20,000$. Nearly two-thirds of farm operators work off of their farms, as well as on them, with 42\% working off-farm at full-time jobs (Gale, 1998). Also telling are data indicating that the share of income from all farming, not just tobacco, in tobacco counties fell from 5\% in the early 1970s to well under 2\% today. The ERS classifies counties as "farm dependent" if earnings from all farming constitute at least a fifth of the county's total earnings. By this definition, there were only 27 "farm dependent" tobacco counties in the U.S. In the mid-1990s, out of 424 tobacco counties. And among

${ }^{39}$ Because, compared with tobacco growing, cigarette manufacturing involves many fewer, higher paid workers whose employment is concentrated in three economically diversified cities, public sympathy resides more with the farmers. The remainder of this section focuses exclusively on tobacco farming communities.

40 The decline in the number of farms is not matched by declining acreage devoted to tobacco. During the most recent six years for which data are available, the number of farms fell from 179,000 to 124,000, but acreage increased from 587,000 to 745,000 acres. This trend toward larger farms, permitted by relaxation of some of the stricter limitations of the quota system, would greatly accelerate were the price support program ended.

41 A tobacco county is a county in which tobacco is grown for commercial purposes. 
these farm dependent tobacco counties, only one derives a majority of its farm receipts from tobacco. The next four most tobacco-dependent derive 25-35\% of their farm earnings from tobacco, while the remaining 22 counties each receives less than 5\% of its farm earnings from tobacco sales. Most tobacco counties are not classified as "farm dependent." Across all tobacco counties, the USDA estimates that tobacco sales account for approximately a fifth of total farm receipts. However, there are a number of counties on the North Carolina-Virginia border and in eastern Kentucky in which tobacco's share of farm sales exceeds $70 \%$.

To put the role of tobacco into perspective, USDA calculates the ratio of tobacco gross receipts to total proprietor and labor income within a county. By this measure, almost half of tobacco counties (199) have a tobacco-income ratio of less than 0.01. 33 counties have a ratio exceeding 0.1 (Gale, 1998). USDA also calculates an index of a tobacco county's ability to replace tobacco income through economic growth in other sectors. The index measures the ratio of annual growth in inflation-adjusted local personal income from all sources to tobacco gross receipts. USDA interprets an index value exceeding 1.0 as meaning that the county is creating sufficient new economic opportunities to potentially completely replace tobacco income. Approximately half of all tobacco counties have index values greater than 1.0 (Gale, 1997).

All told, the evidence indicates that America's tobacco farming communities are far less dependent on tobacco than is widely believed. That abrupt declines in tobacco consumption would inflict severe economic pain on selected individuals is almost certainly true; that many others would experience temporary economic dislocation is certainly possible. The notion, however, that realistic policy-induced decreases in tobacco consumption would wreak havoc throughout much of the tobacco belt is simply not consistent with the evidence. Appeals to the welfare of tobacco farmers may resonate politically; but economically they appear to have little justification. 42 Indeed, the major economic losers would be the allotment holders, a less politically-appealing group of people.

\section{$7 . \quad$ Conclusion}

In the complicated ethical, social, and political domain of tobacco policy, economic analysis has introduced a base of objective and increasingly sophisticated knowledge into debates in which rhetoric has often dominated. Particularly with regard to the crucial issue of how price influences the demand for tobacco products, and how taxation affects price, economists have contributed empirically-based insights that, in many instances, have played essential roles in guiding the formulation of tobacco control policy. Indeed, it is no exaggeration to credit the work of economists with the contemporary global interest in using tobacco taxation as perhaps the primary tool of tobacco control policy.

In the process of examining the empirical relationship between tobacco price and consumption, economists have contributed to the evolving theoretical and methodological literature on the effects of addiction on consumer demand. A "problem" in the traditional economic model of rational economic behavior, addiction is now receiving the attention that promises important future contributions of both a conceptual and empirical nature. Public health policy making will be enriched in the process.

In addition to addressing issues of taxation, price, and demand, economic research has also offered important understanding of the effects of other tobacco policy measures, ranging from media counteradvertising to the introduction of restrictions on smoking in public places. The work of economists has lent perspective to emotional issues in debates on tobacco policy, such as the implications of tobacco control for employment both inside and outside of tobacco-dependent regions of states and countries.

In other areas, economics research has been less successful in answering policy questions. A notable example involves the politically central issue of whether cigarette advertising increases consumption, and whether ad bans decrease it. Econometric research has contributed empirical evidence to the debate, but without offering much by way of resolution. In part this reflects limitations inherent in econometric methods; in part it reflects the inadequacy of the data needed to quantify "advertising" (and exposure to it) and evaluate its consequences. Recent work on the impacts of national advertising bans, both partial and complete, shows promise but is decidedly in its infancy.

42 In the absence of data on the economic vitality of tobacco-growing regions in other countries, these conclusions cannot be extended to tobacco farm communities outside of the U.S. 
In addition to having enlightened debates on tobacco policy, economic analysis of smoking serves a broader purpose as well, one not examined in the present chapter. Constituting by far the largest body of economic research on the consumption of addictive substances, utilizing the best data available, economic research on smoking informs both research and policy debates on other addictive substances (Warner et al., 1990; Warner, 1991). This is particularly important in the case of illicit drugs, such as marijuana and cocaine, for which the availability of useful data has been severely constrained. More generally, understanding the economics of tobacco lends insight into a whole host of social, political, and economic issues, such as the political economy of product regulation and the relationship between, and even meaning of, consumer sovereignty and paternalism.

The use of tobacco, and particularly cigarette smoking, constitutes one of the great public health plagues of the latter half of the 20 th century, one sure to define much of global health status far into the 21 st century as well. As such, it is critical to understand the determinants of tobacco use, perhaps especially those that can be addressed by public policy. Using the conventional tools of their trade, often in novel and creative ways, economists have been at the forefront of advancing knowledge in this central area of public health. The impressive body of work described in this chapter augers a bright future for the contribution of economics to grappling with what will soon become the leading cause of disease and death worldwide. 
Economics of Smoking - p. 49

\section{References}

Abernethy A, Teel JE. Advertising for cigarettes. Journal of Advertising 1986;15(4):515 .

Abt $C$. The social costs of cancer. Social Indicators Research 1975;2:175-190.

Ackoff RL, Ernshoff JR. Advertising research at Anheuser-Busch, Inc. (1963-68). Sloan Management Review 1975;16(3):1-15.

Advisory Commission on Intergovernmental Relations. Cigarette Bootlegging: A State and Federal Responsibility. A Commission Report. Washington: Advisory Commission on Intergovernmental Relations, 1977.

Advisory Commission on Intergovernmental Relations. Cigarette Tax Evasion: A Second Look. Washington: Advisory Commission on Intergovernmental Relations, 1985.

Agro-Economic Services Ltd. and Tabacosmos Ltd. The Employment, Tax Revenue and Wealth that the Tobacco Industry Creates. London: Agro-Economic Services, 1987.

Akerlof GA. Procrastination and obedience. American Economic Review 1991;81:1-19.

Allen RC. The False Dilemma: The Impact of Tobacco Control Policy on Employment in Canada. Ottawa (Ontario): National Campaign for Action on Tobacco, 1993.

American Economics Group. Economic Impact in the States of Proposed FDA Regulations Regarding the Advertising, Labeling and Sale of Tobacco Products. Washington: American Economics Group, March 1996a.

American Economics Group. The U.S. Tobacco Industry in 1994 : Its Economic Impact on the States. Washington: American Economics Group, March 1996b.

Andrews RL, Franke GR. The determinants of cigarette consumption. Journal of Public Policy \& Marketing 1991;10(1):81-100.

Arthur Andersen Economic Consulting. Tobacco Industry Employment: A Review of the Price Waterhouse Economic Impact Report and Tobacco Institute Estimates of "Economic Losses from Increasing the Federal Excise Tax." Los Angeles (CA): Arthur Andersen Economic Consulting, 1993 .

Ashenfelter O, Sullivan D. Nonparametric tests of market structure: an application to the cigarette industry. Journal of Industrial Economics 1987;35(4):483-98.

Atkinson AB, skegg JL. Anti-smoking publicity and the demand for tobacco in the UK. The Manchester School of Economic and Social Studies 1973;41:265-82.

Atkinson AB, Townsend JL. Economic aspects of reduced smoking. Lancet 1977;ii:492-5.

Babcock BA, Foster WE. Economic rents under supply controls with marketable quota. American Journal of Agricultural Economics 1992;74(3):630-7.

Baltagi BH, Goel RK. Quasi-experimental price elasticities of cigarette demand and the bootlegging effect. American Journal of Agricultural Economics 1987;69(4):750-4.

Baltagi BH, Levin D. Estimating dynamic demand for cigarettes using panel data the effects of bootlegging, taxation, and advertising reconsidered. Review of Economics and Statistics $1986 ; 68(1): 148-55$.

Bardsley P, Olekalns N. Cigarette and Tobacco Consumption: Have Anti-smoking Policies Made a Difference? Working Paper. Department of Economics, The University of Melbourne, 1998 .

Barendregt JJ, Bonneux L, van der Maas PJ. The health care costs of smoking. New England Journal of Medicine 197;337(15):1052-7. 
Economics of Smoking - p. 50

Barnett $\mathrm{PG}$, Keeler TE, Hu T-W. Oligopoly structure and the incidence of cigarette excise taxes. Journal of Public Economics 1995;57(3):457-70.

Bartlett JC, Miller LS, Rice DP, Max WB. Medical care expenditures attributable to cigarette smoking -- United States 1993. MMWR 1994;43:469-72.

Barzel Y. An alternative approach to the analysis of taxation. Journal of Political Economy 1976;84(6):1177-97.

Becker GS, Grossman M, Murphy KM. Rational addiction and the effect of price on consumption. American Economic Review 1991;81:237-41.

Becker GS, Grossman M, Murphy KM. An empirical analysis of cigarette addiction. American Economic Review 1994;84(3):396-418.

Becker GS, Mulligan CB. The endogenous determination of time preference. Quarterly Journal of Economics $112(3): 729-58$.

Becker GS, Murphy KM. A theory of rational addiction. Journal of Political Economy $1988 ; 96(4): 675-700$.

Bickel WK, DeGrandpre RJ, Higgins ST. Behavioral economics: a novel experimental approach to the study of drug dependence. Drug and Alcohol Dependence 1993;33(2):173-92.

Bickel WK, DeGrandpre RJ. Modeling drug abuse policy in the behavioral economics laboratory. In: Green L, Kagel JH, editors. Advances in Behavioral Economics. Volume 3: Substance Use and Abuse. Norwood (NJ): Ablex Publishing Corporation, 1996.

Bickel WK, DeGrandpre RJ, Higgins ST, Hughes JR. Behavioral economics of drug selfadministration. I. Functional equivalence of response requirement and drug dose. Life Science 1990;47:1501-10.

Bickel WK, DeGrandpre RJ, Higgins ST, Hughes JR, Badger G. Effects of simulated employment and recreation on cigarette smoking: a behavioral economic analysis. Experimental and Clinical Psychopharmacology 1995;3:467-76.

Bickel WK, DeGrandpre RJ, Hughes JR, Higgins ST. Behavioral economics of drug selfadministration. II. A unit-price analysis of cigarette smoking. Journal of the Experimental Analysis of Behavior 1991;55(2):145-54.

Bickel WK, Madden GJ. The Behavioral Economics of Smoking. National Bureau of Economic Research Working Paper Number6444, 1998.

Bishop JA, Yoo JH. "Health scare," excise taxes and advertising ban in the cigarette demand and supply. Southern Economic Journal 1985;52(2):402-11.

Boyd R, Seldon BJ. The fleeting effect of advertising: Empirical evidence from a case study. Economic Letters 1990;34:375-9.

Boyer M. A habit forming optimal growth model. International Economic Review $1978 ; 19: 585-609$.

Boyer M. Rational demand and expenditures patterns under habit formation." Journal of Economic Theory 1983;31:27-53.

British American Tobacco. Tobacco Taxation Guide: A Guide to Alternative Methods of Taxing Cigarettes and Other Tobacco Products. Woking (England): Optichrome The Printing Group, 1994 .

Broders AC. Squamous-cell epithelioma of the lip. A study of five hundred and thirtyseven cases. Journal of the American Medical Association 1920;74:656-64.

Brown AB. Farm Level Effects of an Increase in Federal Cigarette Excise Taxes Under Two 
Economics of Smoking - p. 51

Scenarios: Keep vs. Eliminate the Tobacco Program. USDA Outlook Conference, Washington, March 9, 1998.

Brownson RC, Jackson-Thompson J, Wilkerson JC, et al. Demographic and socioeconomic differences in beliefs about the health effects of smoking. American Journal of Public Health 1992;82:99-103.

Buck D, Godfrey C, Raw M, Sutton M. Tobacco and Jobs. York (England): Society for the Study of Addiction and the Centre for Health Economics, University of York, 1995.

Bulow JI, Pfleiderer P. A note on the effect of cost changes on prices. Journal of Political Economy 1983;91(1):182-5.

Cameron S. Are Greek smokers rational addicts? Applied Economics Letters 1997;4(7):4012 .

Capehart T. The tobacco program - a summary and update. Tobacco Situation \& Outlook Report U.S. Department of Agriculture, Economic Research Service, TBS-238; 1997.

Centers for Disease Control. Projected smoking related deaths among youth - United States. Morbidity and Mortality Weekly Report 1996;45(44):966-70.

Chaloupka FJ. An economic analysis of addictive behavior the case of cigarette smoking [dissertation]. New York: City University of New York Graduate School, 1988.

Chaloupka FJ. Men, Women, and Addiction: The Case of Cigarette Smoking. National Bureau of Economic Research Working Paper Number 3267, 1990.

Chaloupka FJ. Rational addictive behavior and cigarette smoking. Journal of Political Economy 1991;99(4):722-42.

Chaloupka FJ. Clean indoor air laws, addiction, and cigarette smoking. Applied Economics $1992 ; 24(2): 193-205$.

Chaloupka FJ. The Impact of Proposed Cigarette Price Increases. Policy Analysis No. 9, Health Sciences Analysis Project. Washington: Advocacy Institute, 1998.

Chaloupka FJ, Grossman M. Price, Tobacco Control Policies and Youth Smoking. National Bureau of Economic Research Working Paper No. 5740, 1996.

Chaloupka FJ, Pacula RL. Limiting Youth Access to Tobacco: The Early Impact of the Synar Amendment on Youth Smoking. Working Paper. Department of Economics, University of Illinois at Chicago, 1998 a.

Chaloupka FJ, Pacula RL. An Examination of Gender and Race Differences in Youth Smoking Responsiveness to Price and Tobacco Control Policies. National Bureau of Economic Research Working Paper No. 6541, 1998b.

Chaloupka FJ, Saffer H. Clean indoor air laws and the demand for cigarettes. Contemporary Policy Issues 1992;10(2):72-83.

Chaloupka FJ, Tauras JA, Grossman M. Public policy and youth smokeless tobacco use. Southern Economic Journal 1997;64(2):503-16.

Chaloupka FJ, Wechsler H. Price, tobacco control policies and smoking among young adults. Journal of Health Economics 1997;16(3):359-73.

Chapman S. The limitations of econometric analysis in cigarette advertising studies. British Journal of Addiction 1989;84:1267-74.

Chapman S, Richardson J. Tobacco excise and declining consumption: The case of Papua New Guinea. American Journal of Public Health 1990;80(5):537-40. 
Economics of Smoking - p. 52

Chapman S, Wong WL. Tobacco Control in the Third World: A Resource Atlas. Penang, Malaysia: International Organization of Consumers Unions, 1990.

Chase Econometrics. The Economic Impact of the Tobacco Industry on the United States Economy in 1983. Bala Cynwyd (PA): Chase Econometrics, 1985.

Chetwynd J, Coope P, Brodie RJ, Wells E. Impact of cigarette advertising on aggregate demand for cigarettes in New Zealand. British Journal of Addiction 1988;83:409-14.

Chow G. Statistical demand functions for automobiles and their use for forecasting. In: Harberger AC, ed. The Demand for Durable Goods. Chicago: University of Chicago Press, $1960: 149-178$.

Coalition on Smoking OR Health. Saving Lives and Raising Revenue: The Case for a $\$ 2$ Federal Tobacco Tax Increase. Washington: Coalition on Smoking OR Health, 1994a.

Collishaw NE, Myers G. Dollar estimates of the consequences of tobacco use in Canada, 1979. Canadian Journal of Public Health 1984;75(3):192-9.

Congressional Budget Office. Federal Taxation of Tobacco, Alcoholic Beverages, and Motor Fuels. Washington: US Government Printing Office, 1990 .

Congressional Research Service. U.S. Tobacco Production: Prospects for the Future. Congressional Research Service, The Library of Congress. CRS Publication No. 94-672 ENR, August 24, 1994 .

Conniffe D. Models of Irish tobacco consumption. Economic and Social Review $1995 ; 26(4): 331-47$.

Cook PJ. The social costs of drinking. In: Norwegian Ministry of Health and Social Affairs. The Negative Social Consequences of Alcohol Use. Oslo: Norwegian Ministry of Health and Social Affairs, 1991:49-81.

Cook PJ, Moore MJ. Taxation of alcoholic beverages. In: Hilton ME, Bloss G, editors. Economics and the Prevention of Alcohol-Related Problems. Research monograph no. 25. Rockville (MD): US Department of Health and Human Services, Public Health Service, National Institutes of Health, National Institute on Alcohol Abuse and Alcoholism, 1993:33-58. NIH Publication No. 93-3513.

Cordes JJ, Nicholson EM, Sammartino FJ. Raising revenue by taxing activities with social costs. National Tax Journal 1990;43(3):343-56.

Cox H. Smoking, tobacco promotion, and the voluntary agreements. British Medical Journal $1984 ; 288: 303-5$.

Cox H, Smith R. Political approaches to smoking control: a comparative analysis. Applied Economics 1984;16(4):569-82.

Cromwell J, Bartosch WJ, Fiore MC, et al. Cost-effectiveness of the clinical practice recommendations in the AHCPR guideline for smoking cessation. Journal of the American Medical Association 1997;278(21):1759-66.

DeCicca P, Kenkel D, Mathios A. Putting out the fires: will higher cigarette taxes reduce youth smoking? Presented at the Annual Meetings of the American Economic Association, 1998 .

DeCicca P, Kenkel D, Mathios A. Putting out the fires: will higher cigarette taxes reduce youth smoking. Working Paper. Department of Policy Analysis and Management, Cornell University, 1998 b.

Dee TS, Evans WN. A Comment on DeCicca, Kenkel, and Mathios. Working Paper. School of Economics, Georgia Institute of Technology, 1998.

DeGrandpre RJ, Bickel WK. Human drug self-administration in a medium of exchange. 
Economics of Smoking - p. 53

Experimental and Clinical Psychopharmacology 1995;3:349-57.

DeGrandpre RJ, Bickel WK, Higgins ST, Hughes JR. A behavioral economic analysis of concurrently available money and cigarettes. Journal of the Experimental Analysis of Behavior 1994;61(2):191-201.

DeGrandpre RJ, Bickel WK, Hughes JR, Higgins ST. Behavioral economics of drug selfadministration III. A reanalysis of the nicotine regulation hypothesis. Psychopharmacology $1992 ; 108(1-2): 1-10$.

Difranza JR, Rishards JW, Paulman PM, et al. RJR Nabisco's cartoon camel promotes Camel cigarettes to children. Journal of the American Medical Association 1991;266(22):3149-53.

Dixit A, Norman V. Advertising and welfare. Bell Journal of Economics 1978;9:1-17.

Doll R, Hill AB. The mortality of doctors in relation to their smoking habits a preliminary report. British Medical Journal 1954;1:1451-5.

Doll R, Hill AB. Lung cancer and other causes of death in relation to smoking. A second report on the mortality of British doctors. British Medical Journal 1956;2:1071-81.

Douglas S. The duration of the smoking habit. Economic Inquiry 1998;36(1):49-64.

Douglas S, Hariharan G. The hazard of starting smoking: estimates from a split population duration model. Journal of Health Economics 1994;13(2):213-30.

Downey LA, Gardiner JA. Reducing Youth Access to Tobacco: A Partial Inventory of State Initiatives. Chicago: Office of Social Science Research, University of Illinois at Chicago, 1996.

Duesenberry JS. Income, Saving, and the Theory of Consumer Behavior. Cambridge (MA): Harvard University Press, 1949.

Duffy M. Advertising and the inter-product distribution of demand a Rotterdam Model approach. European Economic Review 1987;31(5):1051-70.

Duffy M. Advertising and the consumption of tobacco and alcoholic drink a system-wide analysis. Scottish Journal of Political Economy 1991;38(4):369-85.

Duffy M. An econometric study of advertising and cigarette demand in the United Kingdom. International Journal of Advertising 1996a;15:262-84.

Duffy M. Econometric studies of advertising, advertising restrictions, and cigarette demand: a survey. International Journal of Advertising 1996b;15:1-23.

El-Safty AE. Adaptive behavior, demand, and preferences. Journal of Economic Theory $1976 a ; 13: 298-318$.

El-Safty AE. Adaptive behavior and the existence of Weizsäcker's Long-Run Indifference Curves. Journal of Economic Theory 1976b;13:319-28b.

Elster J. Ulysses and the Sirens: Studies in Rationality and Irrationality. Cambridge: Cambridge University Press, 1979.

Environmental Protection Agency. Respiratory Health Effects of Passive Smoking: Lung Cancer and other Disorders. Environmental Protection Agency, Office of Research and Development, Office of Air and Radiation, 1992. EPA/600/6-90/006F.

Environmental Protection Agency. The Costs and Benefits of Smoking Restrictions: An Assessment of the Smoke-free Environment Act of 1993 (H.R. 3434). Indoor Air Division, Office of Radiation and Indoor Air. Washington: Environmental Protection Agency, April 1994.

Evans N, Farkas A, Gilpin E, et al. Influence of tobacco marketing and exposure to 
Economics of Smoking - p. 54

smokers on adolescent susceptibility to smoking. Journal of the National Cancer Institute $1995 ; 87: 1538-45$.

Evans WN, Farrelly MC. The compensating behavior of smokers: taxes, tar and nicotine. RAND Journal of Economics, forthcoming.

Evans WN, Farrelly MC, Montgomery E. Do Workplace Smoking Bans Reduce Smoking? National Bureau of Economic Research Working Paper No. 5567, 1996.

Evans WN, Huang LX. Cigarette taxes and teen smoking: new evidence from panels of repeated cross-sections. Working paper. Department of Economics, University of Maryland, 1998 .

Evans WN, Ringel JS. Can higher cigarette taxes improve birth outcomes? Journal of Public Economics, forthcoming.

Farrell MJ. Irreversible demand functions. Econometrica 1952;20:171-86.

Farrelly MC, Bray JW, Office on Smoking and Health. Response to increases in cigarette prices by race/ethnicity, income, and age groups - United States, 1976-1993. Morbidity and Mortality Weekly Report 1998;47(29):605-9.

Farkas AJ. When Does Cigarette Fading Increase the Likelihood of Future Cessation? Cancer Prevention and Control Program, Cancer Center. La Jolla (CA): University of California, San Diego, May 1998.

Federal Trade Commission. Competition and the Financial Impact of the Proposed Tobacco Industry Settlement. Washington, DC: Federal Trade Commission, 1997.

Federal Trade Commission. Federal Trade Commission Report to Congress for 1996: Pursuant to the Federal Cigarette Labeling and Advertising Act. Washington: Federal Trade Commission, 1998 .

Flewelling RL, Kenney E, Elder JP, Pierce J, Johnson M, Bal DG. First-year impact of the 1989 California cigarette tax increase on cigarette consumption. American Journal of Public Health 1992;82(6):867-9.

Food and Drug Administration. Regulations Restricting the Sale and Distribution of Cigarettes and Smokeless Tobacco to Protect Children and Adolescents; Final Rule. Washington: Federal Register, 1996.

Forbes WF, Thompson ME. Estimating the health care costs of smokers. Canadian Journal of Public Health 1983; 74(3):183-90.

Forster JL, Murray DM, Wolfson M, et al. The effects of community policies to reduce youth access to tobacco. American Journal of Public Health 1998;88(8):1193-98.

Franke GR. U.S. cigarette demand, 1961-90: econometric issues, evidence, and implications. Journal of Business Research 1994;30:33-41.

Fritschler AL, Hoefler JM. Smoking \& Politics: Policy Making and the Federal Bureaucracy. 5th ed. Upper Saddle River (NJ): Prentice Hall, 1996.

Fujii ET. The demand for cigarettes: further empirical evidence and its implications for public policy." Applied Economics 1980;12:479-89.

Galbraith JK. The Affluent Society. Cambridge (MA): Houghton Mifflin Company, 1958.

Galbraith JK. The New Industrial State. 2nd edition. New York: Pelican Books, 1972.

Gale F. Tobacco dollars and jobs. Tobacco Situation \& Outlook U.S. Department of Agriculture, Economic Research Service, TBS-239; Sept. 1997:37-43.

Gale F. Economic structure of tobacco-growing regions. Tobacco Situation \& Outlook U.S. 
Economics of Smoking - p. 55

Department of Agriculture, Economic Research Service, TBS-24l; April 1998:40-7.

Garcia dos Santos J. Estimating the durability of consumers' durable goods. Review of EConomics and Statistics 1972;54:475-9.

General Accounting Office. Teenage Smoking: Higher Excise Tax Should Significantly Reduce the Number of Smokers. Washington: General Accounting Office, 1989.

Glantz SA, Parmley WW. Passive smoking and heart disease: mechanisms and risk. Journal of the American Medical Association 1995;73(13):1047-53.

Goel RK, Morey MJ. The interdependence of cigarette and liquor demand. Southern Economic Journal 1995;62(2):451-9.

Goldstein AO, Fisher PM, Richards JW, Creten D. Relationship between high school student smoking and recognition of cigarette advertisements. Journal of Pediatrics $1987 ; 110(3): 488-91$.

Goodman J. Tobacco in History: The Cultures of Dependence. New York: Routledge, 1993. Gorman WM. Tastes, habits, and choices. International Economic Review 1967;8:218-22. Grabowski HG. The effect of advertising on the inter-industry distribution of demand. Explorations in Economic Research 1976;3:21-75.

Grabowski HG. The effects of advertising on intra-industry shifts in demand. Explorations in Economic Research 1978;3:675-701.

Gravelle JG, Zimmerman D. Cigarette Taxes to Fund Health Care Reform: An Economic Analysis. Washington: Congressional Research Service, The Library of Congress, 1994. CRS Publication No. 94-214E.

Grise VN. Tobacco: Background for 1995 Farm Legislation. Agricultural economic report no. 709. Washington: US Department of Agriculture, Economic Research Service, 1995.

Grossman M, Chaloupka FJ. Cigarette taxes: The straw to break the camel's back. Public Health Reports 1997;112(4):290-7.

Grossman M, Chaloupka FJ, Saffer H. Addiction. The New Palgrave Dictionary of Economics and the Law. London: Macmillan Reference Ltd., forthcoming.

Grossman M, Coate D, Lewit EM, Shakotko RA. Economic and Other Factors in Youth Smoking. Washington: National Science Foundation, 1983.

Haavelmo T. The probability approach in econometrics. Econometrica 1944;12:96-124.

Hamilton JL. Advertising, the health scare, and the cigarette advertising ban. Review of Economics and Statistics 1972;54:401-11.

Hamilton JL. The effect of cigarette advertising bans on cigarette consumption. In: Steinfeld J, Griffiths W, Ball K, Taylor RM, eds. Proceedings of the Third World Conference on Smoking and Health. Vol. II: Health Consequences, Education, Cessation Activities, and Social Action. Washington: US Department of Health, Education, and Welfare, 1977:829-40.

Hammond ED, Horn D. Smoking and death rates - report on forty-four months of follow-up on 187,783 men. I. Total mortality. Journal of the American Medical Association $1958 a ; 166: 1159-72$.

Hammond ED, Horn D. Smoking and death rates - report on forty-four months of follow-up on 187,783 men. II. Death rates by cause. Journal of the American Medical Association $1958 b ; 166: 1294-308$.

Hammond PJ. Changing tastes and coherent dynamic choice. Review of Economic Studies 
Economics of Smoking - p. 56

$1976 a ; 43: 159-73$

Hammond PJ. Endogenous tastes and stable long-run choice. Journal of Economic Theory $1976 \mathrm{~b} ; 13: 329-40$.

Harris JE. Taxing tar and nicotine. American Economic Review 1980;70(3):300-11.

Harris JE. The 1983 increase in the federal cigarette excise tax. In: Summers LH, editor. Tax Policy and the Economy. Vol. 1. Cambridge (MA): MIT Press, 1987.

Harris JE. Testimony before the Committee on Ways and Means, U.S. House of Representatives. Public Hearings on the Financing Provisions of the Administration's Health Security Act. Washington, DC, November 18, 1993.

Harris JE. A Working Model for Predicting the Consumption and Revenue Impacts of Large Increases in the U.S. Federal Cigarette Excise Tax. Working paper no. 4803. Cambridge (MA): National Bureau of Economic Research, 1994.

Harris JE, Connolly GN, Davis B. Cigarette smoking before and after an excise tax increase and an antismoking campaign - Massachusetts, 1990-1996. Morbidity and Mortality Weekly Report 1996;45(44):966-9.

Hay JW. The harm they do to others: a primer on the external costs of drug abuse. In: Krauss MB, Lazear EP, editors. Searching for Alternatives: Drug-Control Policy in the United States. Stanford (CA): Hoover Institution Press, 1991:200-25.

Hodgson TA. Annual costs of illness versus lifetime costs of illness and implications of structural change. Drug Information Journal 1988;22:323-41.

Hodgson TA. Cigarette smoking and lifetime medical expenditures. Milbank Quarterly $1992 ; 70(1): 81-125$.

Hodgson TA. The health care costs of smoking. New England Journal of Medicine $1998 ; 338(7): 470$.

Hodgson TA, Meiners MR. Cost-of-illness methodology: a guide to current practices and procedures. Milbank Memorial Fund Quarterly 1982;60:429-62.

Holak SL, Reddy SK. Effects of a television and radio advertising ban: a study of the cigarette industry. Journal of Marketing 1986;50:219-27.

Houthakker HS, Taylor LD. Consumer Demand in the United States, 1929-1970: Analyses and Projections. Cambridge (MA): Harvard University Press, 1966.

Houthakker, HS, Taylor LD. Consumer Demand in the United States, 1929-1970: Analyses and Projections. 2nd ed. Cambridge (MA): Harvard University Press, 1970.

Hsieh $\mathrm{C}-\mathrm{R}$, Hu $\mathrm{T}-\mathrm{W}$. The Demand for Cigarettes in Taiwan: Domestic versus Imported Cigarettes. Discussion Paper No. 9701. Nankang, Taipei: The Institute of Economics, Academia Sinica, 1997 .

Hsieh C-R, Yen L-L, Liu J-T, Lin CJ. Smoking, health knowledge and anti-smoking campaigns: An empirical study in Taiwan. Journal of Health Economics 1996;15(1)87-104.

Hu T-W, Bai J, Keeler TE, Barnett PG, Sung H-Y. The impact of California Proposition 99, a major anti-cigarette law, on cigarette consumption. Journal of Public Health Policy $1994 ; 15(1): 26-36$.

Hu T-W, Ren Q-F, Keeler TE, Bartlett J. The demand for cigarettes in California and behavioural risk factors. Health Economics 1995a;4(1):7-14.

Hu T-W, Sung H-Y, Keeler TE. Reducing cigarette consumption in California: tobacco taxes vs an anti-smoking media campaign. American Journal of Public Health 1995b;85(9):1218-22. 
Economics of Smoking - p. 57

Hu T-W, Sung H-Y, Keeler TE. The state antismoking campaign and the industry response the effects of advertising on cigarette consumption in California. American Economic Review 1995c;85 (2):85-90.

Hu T-W, Sung H-Y, Keeler TE, Marciniak M, Keith A, Manning R. Cigarette Consumption and Sales of Nicotine Replacement Products. Berkeley (CA): University of California, Berkeley, 1998 .

Hursh SR, Bauman RA. The behavioral analysis of demand. In: Green L, Kagel JH, editors. Advances in Behavioral Economics. Volume 1. Norwood (NJ): Ablex Publishing Corporation, 1987:117-65.

Ippolito RA, Murphy RD, Sant D. Staff Report on Consumer Responses to Cigarette Health Information. Washington: Federal Trade Commission, 1979.

Jason LA, Billows WD, Schnopp-Wyatt DL, King C. Long-term findings from Woodridge in reducing illegal cigarette sales to older minors. Evaluation and the Health Professions $1996 ; 19: 3-13$.

Jin SG, Lu BY, Yan DY, et al. An evaluation of smoking-induced health costs in China (1988-1989). Biomedical and Environmental Sciences 1995;8:342-9.

Johnson LW. Advertising expenditure and the aggregate demand for cigarettes in Australia. International Journal of Advertising 1986;1:45-58.

Johnson PR. The social cost of the tobacco program. Journal of Farm Economics $1965 ; 47: 242-255$.

Johnson TR. Additional evidence on the effects of alternative taxes on cigarette prices. Journal of Political Economy 1978;86(2 Pt 1):325-8.

Jones AM. A systems approach to the demand for alcohol and tobacco. Bulletin of Economic Research 1989;41:85-105.

Jones AM. Health, addiction, social interaction and the decision to quit smoking. Journal of Health Economics 1994;13:93-110.

Jones A, Posnett $J$. The revenue and welfare effects of cigarette taxes. Applied Economics $1988 ; 20: 1223-32$.

Joossens L. Tobacco smuggling: An optimal policy approach. In: Abedian I, van der Merwe R, Wilins N, Jha P, editors. The Economics of Tobacco Control: Towards an Optimal Policy Mix. Cape Town (South Africa): Applied Fiscal Reseach Centre, University of Cape Town, 1998.

Joossens L, Raw M. Smuggling and cross border shopping of tobacco in Europe. British Medical Journal 1995;310:1393-7.

Joossens L, Raw M. Cigarette smuggling in Europe: who really benefits? Tobacco Control 1998; 7: in press.

Joossens L, van der Merwe R. Cigarette trade and smuggling. Project Update \#7, The Economics of Tobacco Control Project, Cape Town, South Africa, 1997.

Kao K, Tremblay VJ. Cigarette 'health scare,' excise tax, and advertising ban comment. Southern Economic Journal 1988;54(3):770-6.

Keeler TE, Hu T-W, Barnett PG, Manning WG. Taxation, regulation and addiction a demand function for cigarettes based on time-series evidence. Journal of Health Economics $1993 ; 12(1): 1-18$.

Keeler TE, Hu TW, Barnett PG, Manning WG, Sung HY. Do cigarette producers pricediscriminate by state? An empirical analysis of local cigarette pricing and taxation. Journal of Health Economics 1996;15:499-512. 
Economics of Smoking - p. 58

Kenkel DS. Health behavior, health knowledge, and schooling. Journal of Political Economy 1991;99(2):287-305.

King C, Siegel M, Celebucki C, Connolly GN. Adolescent exposure to cigarette advertising in magazines: an evaluation of brand-specific advertising in relation to youth readership. Journal of the American Medical Association. 1998;279(7):516-20.

Kluger R. Ashes to Ashes: America's Hundred-Year Cigarette War, the Public Health, and the Unabashed Triumph of Philip Morris. New York: Alfred A. Knopf, 1996.

Lambin JJ. Advertising, Competition, and Market Conduct in Oligopoly Over Time. Amsterdam: North-Holland, 1976.

Laugesen M, Meads C. Tobacco advertising restrictions, price, income, and tobacco consumption in OECD countries 1960-1986. British Journal of Addiction 1991;86:1343-54.

Laugesen M, Meads C. The authors reply to 'Tobacco consumption and advertising restrictions: a critique of Laugesen and Meads (1991)'. International Journal of Advertising 1993;12:75-80.

Leeflang PSH, Reuijl JC. Advertising and industry sales: an empirical study of the West German cigarette market. Journal of Marketing 1985;49:92-8.

Leu RE. Anti-smoking publicity, taxation, and the demand for cigarettes. Journal of Health Economics 1984;3(2):101-16.

Leu RE, Schaub T. Does smoking increase medical expenditures? Social Science \& Medicine $1983 ; 17: 1907-14$.

Lewit EM, Coate D. The potential for using excise taxes to reduce smoking. Journal of Health Economics 1982;1(2):121-45.

Lewit EM, Coate D, Grossman M. The effects of government regulation on teenage smoking. Journal of Law and Economics 1981;24(3):545-69.

Lewit EM, Hyland A, Kerrebrock N, Cummings KM. Price, public policy and smoking in young people. Tobacco Control 1997;6(S2):17-24.

Lluch C. Expenditure, savings, and habit formation. International Economic Review $1974 ; 15: 786-97$.

Lombard HL, Doering CR. Classics in oncology. Cancer studies in Massachusetts. 2. Habits, characteristics and environment of individuals with and without cancer. New England Journal of Medicine 1928;198:481-7.

Luik JC, editor. Do Tobacco Advertising Bans Really Work? A Review of the Evidence. Niagara-on-the-Lake, Ontario: The Niagara Institute, 1994.

Lyon AB, Schwab RM. Consumption taxes in a life-cycle framework are sin taxes regressive? Review of Economics and Statistics 1995;77(3):389-406.

Manchester PB. Interstate cigarette smuggling. Public Finance Quarterly 1976;4:225-38.

Manning WG, Keeler EB, Newhouse JP, Sloss EM, Wasserman J. The taxes of sin: do smokers and drinkers pay their way? Journal of the American Medical Association $1989 ; 261(11): 1604-9$.

Manning WG, Keeler EB, Newhouse JP, Sloss EM, Wasserman J. The Costs of Poor Health Habits. Cambridge (MA): Harvard University Press, 1991.

Mao ZZ. Demand for Cigarettes and Price Policy: A Time-Series Analysis (in Chinese). Working Paper. School of Public Health, West China University of Medical Sciences, 1996.

Maranvanyika E. The search for an optimal tobacco control policy in Zimbabwe. In: Abedian 
Economics of Smoking - p. 59

I, van der Merwe R, Wilins N, Jha P, editors. The Economics of Tobacco Control: Towards an Optimal Policy Mix. Cape Town (South Africa): Applied Fiscal Reseach Centre, University of Cape Town, 1998.

Marshall A. Principles of Economics. 8th ed. London: Macmillan and Co., 1920.

McAuliffe R. The FTC and the effectiveness of cigarette advertising regulations. Journal of Public Policy and Marketing 1988; 7:49-64.

McGuinness T, Cowling K. Advertising and the aggregate demand for cigarettes. European Economic Review 1975;6:311-28.

McGuinness T, Cowling K. Advertising and the aggregate demand for cigarettes: a reply. European Economic Review 1980;14(1):127-30.

McKenzie RB. The non-rational domain and the limits of economic analysis. Southern Economic Journal 1979;46(1):145-57.

McLeod, PB. Advertising bans, tobacco and cigarette consumption. Economic Letters $1986 ; 20(4): 391-6$.

Meier KJ, Licari MJ. The effect of cigarette taxes on cigarette consumption, 1955 through 1994. American Journal of Public Health 1997;87(7):1126-30.

Metra Consulting Group. The Relationship between Total Cigarette Advertising and Total Cigarette Consumption in the UK. London: Metra Consulting Group, 1979.

Miller LS, Zhang $\mathrm{X}$, Rice DP, Max W. State estimates of total medical expenditures attributable to cigarette smoking, 1993. Public Health Reports 1998;113:447-458.

Modigliani F. Fluctuations in the savings-income ratio: a problem in economic forecasting. In: Studies in Income and Wealth. New York: National Bureau of Economic Research, 1949;11:371-443, 1949.

Moore MJ. Death and tobacco taxes. RAND Journal of Economics 1996;27(2):415-28.

Mullahy J. Cigarette smoking: habits, health concerns, and heterogeneous unobservables in a micro-econometric analysis of consumer demand [dissertation]. Charlottesville (VA): University of Virginia, 1985.

Murray CJL, Lopez AD, eds. The Global Burden of Disease, vol. I: A Comprehensive Assessment of Mortality and Disability from Diseases, Injuries, and Risk Factors in 1990 and Projected to 2020. Cambridge (MA): Harvard University Press, 1996.

Napier K. Cigarettes: What the Warning Label Doesn't Tell You. The First Comprehensive Guide to the Health Consequences of Smoking. New York: American Council on Science and Health, 1996.

Norr R. Cancer by the carton. Reader's Digest 1952 (December);61:7-8.

Ohsfeldt RL, Boyle RG. Tobacco excise taxes and rates of smokeless tobacco use in the US: an exploratory ecological analysis. Tobacco Control 1994;3(4):316-23.

Ohsfeldt RL, Boyle RG, Capilouto EI. Effects of tobacco excise taxes on the use of smokeless tobacco products. Health Economics 1997;6(5):525-32.

Ohsfeldt RL, Boyle RG, Capilouto EI. Tobacco Taxes, Smoking Restrictions, and Tobacco Use. National Bureau of Economic Research Working Paper Number 6486, 1998.

Orphanides A, Zervos D. Rational addiction with learning and regret. Journal of Political Economy 1995;103:739-58.

Oster G, Colditz GA, Kelly NL. The Economic Costs of Smoking and Benefits of Quitting. Lexington (MA): D.C. Heath and Company, 1984. 
Oster G, Delea TE, Huse DM, et al. The benefits and risks of over-the-counter availability of nicotine polacrilex ("nicotine gum"). Medical Care 1996;34:389-402.

Pashardes P. Myopic and forward looking behavior in a dynamic demand system. International Economic Review 1986;27:387-97.

Pearl R. Tobacco smoking and longevity. Science 1938;87:216-7.

Peles y. Rates of amortization of advertising expenditures. Journal of Political Economy $1971 ; 79(5): 1032-58$.

Pekurinen M. The demand for tobacco products in Finland. British Journal of Addiction $1989 ; 84: 1183-92$.

Pekurinen M. Economic Aspects of Smoking: Is There a Case for Government Intervention in Finland? Helsinki: Vapk-Publishing, 1991.

Peterson DE, Zeger SL, Remington PL, Anderson HA. The effect of state cigarette tax increases on cigarette sales 1955-1988. American Journal of Public Health 1992;82(1):946 .

Peto R, Lopez AD, Boqi L. Global tobacco mortality: monitoring the growing epidemic. In: Lu R, Mackay J, Niu S, Peto R, eds. The Growing Epidemic. Singapore: SpringerVerlag, in press.

Phlips L. Applied Consumption Analysis. Advanced Textbooks in Economics. Amsterdam: North-Holland Publishing Company, 1983.

Phlips L, Spinnewyn, F. Rationality versus myopia in dynamic demand systems. In: Basman RL, Rhodes GF, Jr., eds. Advances in Econometrics, vol. 1. Greenwich (CT): JAI Press, $1982: 3-33$.

Pigou AC. A Study in Public Finance. 3rd rev. ed. London: Macmillan and Co., 1962. Pierce JP, Choi WS, Gilpin EA, et al. Tobacco industry promotion of cigarettes and adolescent smoking. Journal of the American Medical Association 1998;279(7):511-5.

Pollak RA. Consistent planning. Review of Economic Studies 1968;35:201-8.

Pollak RA. Habit formation and dynamic demand functions. Journal of Political Economy $1970 ; 78: 745-63$.

Pollak RA. The intertemporal cost of living index. Annals of Economic and Social Measurement 1975;4:179-95.

Pollak RA. Habit formation and long-run utility funcions. Journal of Economic Theory $1976 ; 13: 272-97$.

Pollak RA. Price dependent preferences. American Economic Review 1977;67:64-75.

Pollak RA. Endogenous tastes in demand and welfare analysis. American Economic Review $1978 ; 68: 374-9$.

Pollay RA. The last straw? Cigarette advertising and realized market shares among youths and adults, 1979-1993. Journal of Marketing 1996;60:1-16.

Porter RH. The impact of government policy on the U.S. cigarette industry. In: Ippolito PM, Scheffman DT, editors. Empirical Approaches to Consumer Protection Economics. Washington: US Government Printing Office, 1986.

Price Waterhouse. The Economic Impact of the Tobacco Industry on the United States Economy. Arlington (VA): Price Waterhouse, 1990. 
Economics of Smoking - p. 61

Price Waterhouse. The Economic Impact of the Tobacco Industry on the United States Economy. Arlington (VA): Price Waterhouse, 1992.

Radfar M. The effect of advertising on total consumption of cigarettes in the UK. European Economic Review 1985;29:225-33.

Rao R, Miller P. Advertising/sales response functions. Journal of Advertising Research $1975 ; 15: 7-15$.

Reuijl JC. On the Determination of Advertising Effectiveness: An Empirical Study of the German Cigarette Market. Boston: Kluwer-Nijhoff, 1982 .

Rice DP, Hodgson TA, Sinsheimer P, Browner W, Kopstein AN. The economic costs of the health effects of smoking, 1984. Milbank Quarterly 1986;64(4):489-547.

Rigotti NA, DiFranza JR, Chang YC, et al. The effect of enforcing tobacco-sales laws on adolescents' access to tobacco and smoking behavior. New England Journal of Medicine $1997 ; 337(15): 1044-51$.

Roberts MJ, Samuelson L. Am empirical analysis of dynamic, nonprice competition in an oligopolistic industry. RAND Journal of Economics 1988;19(2):200-20.

Roemer R. Legislative Action to Combat the World Tobacco Epidemic. 2nd ed. Geneva: World Health Organization, 1993.

Royal College of Physicians. Smoking and Health. Summary and Report of the Royal College of Physicians of London on Smoking in Relation to Cancer of the Lung and other Diseases. New York: Pitman Publishing Co., 1962.

Ryder HE, Heal GM. Optimal growth with intertemporally dependent preferences. Review of Economic Studies 1973;40:1-31.

Saba RP, Beard TR, Ekelund RB, Ressler RW. The demand for cigarette smuggling. Economic Inquiry 1995; $33(2): 189-202$.

Saffer H. Alcohol advertising and alcohol consumption: Econometric studies. In: Martin SE, ed. The Effects of the Mass Media on the Use and Abuse of Alcohol. Bethesda:

National Institute on Alcohol Abuse and Alcoholism, 1995.

Saffer H. Economic issues in cigarette and alcohol advertising. Journal of Drug Issues $1998 ; 28(3): 781-93$.

Schelling TC. Egonomics, or the art of self-management. American Economic Review 1978; 68:290-4.

Schelling TC. The intimate contest for self-command. The Public Interest 1980;60:94-113. Schelling TC. Choice and Consequence. Cambridge (MA): Harvard University Press, 1984 . Schelling TC. Self-command in practice, in policy, and in a theory of rational choice. American Economic Review 1984b; 74:1-11.

Schelling TC. Economics and cigarettes. Preventive Medicine 1986;15(5):549-60.

Schmalensee RL. On the Economics of Advertising. Amsterdam: North Holland, 1972.

Schmidt $\mathrm{P}$, witte $\mathrm{AD}$. Predicting criminal recidivism using 'split population' survival time models. Journal of Econometrics 1989;40(1):141-59.

Schnabel M. An oligopoly model of the cigarette industry. Southern Economic Journal 1972 ; 38 (3):325-35. 
Economics of Smoking - p. 62

Schneider L, Klein B, Murphy K. Government regulation of cigarette health information. Journal of Law and Economics 1981;24:575-612.

Schoenbaum M. Do smokers understand the mortality effects of smoking? Evidence from the Health and Retirement Survey. American Journal of Public Health 1997;87(5):755-9.

Scitovsky T. The Joyless Economy: An Inquiry into Consumer Satisfaction and Human Dissatisfaction. Oxford: Oxford University Press, 1976.

Scott E, Dickert J. From Research to Policy: The Cigarette Excise Tax. Case Studies in Public Policy and Management, \#C16-93-1233.0. Cambridge (MA): John F. Kennedy School of Government, 1993 .

Seldon BJ, Boyd R. The stability of cigarette demand. Applied Economics 1991;23:319-26.

Seldon BJ, Doroodian K. A simultaneous model of cigarette advertising: effects on demand and industry reponse to public policy. Review of Economics and Statistics 1989;71:673-7.

Shoven JB, Sundberg JO, Bunker JP. The social security cost of smoking. In: Wise DA, editor. The Economics of Aging. Chicago: University of Chicago Press, 1989:231-54.

Showalter MH. Essays in applied econometrics. Essay III: monopoly behavior with intertemporal demands [dissertation]. Cambridge (MA): Massachusetts Institute of Technology, 1991 .

Showalter MH. Firm Behavior in a Market with Addiction: The Case of Cigarettes. Working Paper. Department of Economics, Brigham Young University, 1998.

Shultz JM, Novotny TE, Rice DP. Quantifying the disease impact of cigarette smoking with SAMMEC II software. Public Health Reports 1991;106:326-33.

Simonich WL. Government Antismoking Policies. New York: Peter Lang Publishing, 1991.

Spinnewyn F. Rational habit formation. European Economic Review 1981;15:91-109.

Stavrinos VG. The effects of an anti-smoking campaign on cigarette consumption empirical evidence from Greece. Applied Economics 1987;19(3):323-9.

Steenland $\mathrm{K}$. Passive smoking and the risk of heart disease. Journal of the American Medical Association 1992;267:94-9.

Steenland K, Thun M, Lally C, Heath C Jr. Environmental tobacco smoke and coronary heart disease in the American Cancer Society CPS-II cohort. Circulation 1996;94(4):622-8.

Stewart MJ. Tobacco consumption and advertising restrictions a critique of Laugesen and Meads (1991). International Journal of Advertising 1992;11:97-118.

Stewart $\mathrm{MJ}$. The effect on tobacco consumption of advertising bans in OECD countries. International Journal of Advertising 1993;12:155-80.

Stewart MJ. Advertising bans in Norway, Finland and Canada: A comparison of C. Smee (1992) and M.J. Stewart (1992). In: Luik JC, editor. Do Tobacco Advertising Bans Really Work? Niagara-on-the-Lake, Ontario: The Niagara Institute, 1994.

Stigler G, Becker GS. De gustibus non est disputandum. American Economic Review $1977 ; 67: 76-90$.

Strotz RH. Myopia and inconsistency in dynamic utility maximization. Review of Economic Studies 1956;23:165-80.

Sullivan D. Testing hypotheses about firm behavior in the cigarette industry. Journal of Political Economy 1985;93(3):586-98.

Sullum J. For Your Own Good: The Anti-Smoking Crusade and the Tyranny of Public Health. 
Economics of Smoking - p. 63

New York: The Free Press, 1998.

Sumner DA. Measurement of monopoly behavior: an application to the cigarette industry. Journal of Political Economy 1981;89(5):1010-9.

Sumner DA, Alston JM. Removal of Price Supports and Supply Controls for U.S. Tobacco: An Economic Analysis of the Impact. Washington: National Planning Association, 1985.

Sumner DA, Wohlgenant MK. Effects of an increase in the federal excise tax on cigarettes. American Journal of Agricultural Economics 1985;67(2):235-42.

Sumner MT. Demand for tobacco in the U.K. The Manchester School of Economic and Social Studies $1971 ; 39: 23-36$.

Sumner MT, Ward R. Tax changes and cigarette prices. Journal of Political Economy $1981 ; 89(6): 1261-5$.

Sung H-Y, Hu T-W, Keeler TE. Cigarette taxation and demand: an empirical model. Contemporary Economic Policy 1994;12(3):91-100.

Suranovic SM, Goldfarb RS, Leonard TC. An economic theory of cigarette addiction. Journal of Health Economics, in press.

Sweanor DT. Global Cigarette Taxes and Prices. Ottawa (Canada): Smoking and Health Action Foundation, 1997.

Sweanor DT, Martial LR. The Smuggling of Tobacco Products: Lessons from Canada. Ottawa (Canada): Non-Smokers' Rights Association/Smoking and Health Action Foundation, 1994.

Tansel A. Cigarette demand, health scares and education in Turkey. Applied Economics $1993 ; 25(4): 521-9$.

Tauras JA, Chaloupka FJ. Price, Clean Indoor Air Laws, and Cigarette Smoking: Evidence from Longitudinal Data for Young Adults. Working Paper. Department of Health Management and Policy, University of Michigan, 1998.

Taylor P. The Smoke Ring: Tobacco, Money, and Multinational Politics. New York: Pantheon Books, 1984 .

Tegene A. Kalman filter and the demand for cigarettes. Applied Economics $1991 ; 23(7): 1175-82$.

Telser LG. Advertising and cigarettes. Journal of Political Economy 1962;70(5):471-99.

Tennant RB. The American Cigarette Industry: A Study in Economic Analysis and Public Policy. New Haven (CT): Yale University Press, 1950.

Thaler R, Shefrin HM. An economic theory of self control. Journal of Political Economy $1981 ; 89: 392-406$.

Theil H. System-wide Explorations in International Economics, Input-Output Analysis, and Marketing Research. Amsterdam: North Holland, 1980.

Thompson ME, McLeod I. The effects of economic variables upon the demand for cigarettes in Canada. Mathematical Scientist 1976;1;121-32.

Thursby JG, Thursby MC. Interstate Cigarette Bootlegging: Extent, Revenue Losses, and Effects of Federal Intervention. National Bureau of Economic Research Working Paper No. 4763,1994 .

Tobacco Institute. The Tax Burden on Tobacco. Historical Compilation 1995. Vol. 30. Washington: Tobacco Institute, 1998.

Tobacco Merchants Association. Tobacco's Contribution to the National Economy. Princeton 
(NJ): Tobacco Merchants Association, 1995.

Tollison RD. Testimony. Committee on Finance, United States Senate. Tax Treatment of Organizations Providing Health Care Services, and Excise Taxes on Tobacco, Guns and Ammunition. Hearing, April 28, 1994. Washington: US Government Printing Office, $1994: 40$.

Tollison RD, Wagner RE. The Economics of Smoking. Boston: Kluwer Academic Publishers, 1992 .

Townsend JL. Cigarette tax, economic welfare, and social class patterns of smoking. Applied Economics 1987; 19:355-65.

Townsend JL. U.K. smoking targets: Policies to attain them and effects on premature mortality. In: Abedian I, van der Merwe R, Wilins N, Jha P, editors. The Economics of Tobacco Control: Towards an Optimal Policy Mix. Cape Town (South Africa) : Applied Fiscal Reseach Centre, University of Cape Town, 1998.

Townsend JL, Roderick P, Cooper J. Cigarette smoking by socioeconomic group, sex, and age: effects of price, income, and health publicity. British Medical Journal $1994 ; 309(6959): 923-6$.

Tremblay $\mathrm{CH}$, Tremblay VJ. The impact of cigarette advertising on consumer surplus, profit, and social welfare. Contemporary Economic Policy 1995;13(1):113-24.

Treyz GI. Regional Economic Modeling: A Systematic Approach to Economic Forecasting and Policy Analysis. Boston: Kluwer Academic Publishers, 1993.

Tye JB, Warner KE, Glantz SA. Tobacco advertising and consumption: evidence of a causal relationship. Journal of Public Health Policy 1987;8:492-508.

UK Department of Health. Effect of Tobacco Advertising on Tobacco Consumption: A Discussion Document Reviewing the Evidence. London: U.K. Department of Health, Economics and Operational Research Division, 1992.

US Department of Health and Human Services. The Health Consequences of Involuntary Smoking. A Report of the Surgeon General. Rockville (MD): US Department of Health and Human Services, Public Health Service, Centers for Disease Control, Center for Health Promotion and Education, Office on Smoking and Health. Washington: US Government Printing Office, 1986 .

US Department of Health and Human Services. The Health Consequences of Smoking: Nicotine Addiction. A Report of the Surgeon General. Rockville (MD): US Department of Health and Human Services, Public Health Service, Centers for Disease Control, Center for Health Promotion and Education, Office on Smoking and Health, 1988. DHHS Publication No. (CDC) 88-8406.

US Department of Health and Human Services. Reducing the Health Consequences of Smoking: 25 Years of Progress. A Report of the Surgeon General. Atlanta: US Department of Health and Human Services, Public Health Service, Centers for Disease Control, National Center for Chronic Disease Prevention and Health Promotion, Office of Smoking and Health, 1989. DHHS Publication No. (CDC) 89-8411.

US Department of Health and Human Services. Preventing Tobacco Use Among Young People: A Report of the Surgeon General. US Department of Health and Human Services, Public Health Service, Centers for Disease Control, National Center for Chronic Disease Prevention and Health Promotion, Office on Smoking and Health. Washington: US Government Printing Office, 1994 .

US Department of Health and Human Services. The FTC Cigarette Test Method for Determining Tar, Nicotine, and Carbon Monoxide Yields of U.S. Cigarettes: Report of the NCI Expert Committee. Bethesda (MD): National Cancer Institute, August 1996. NIH publication no. 96-4028. 
US Department of Health and Human Services. Tobacco Use Among U.S. Racial/Ethnic Minority Groups: A Report of the Surgeon General. Atlanta: US Department of Health and Human Services, Public Health Service, Centers for Disease Control, National Center for Chronic Disease Prevention and Health Promotion, Office on Smoking and Health. Washington, DC: Government Printing Office, 1998.

U.S. Department of Health, Education, and Welfare. Smoking and Health. Report of the Advisory Committee to the Surgeon General of the Public Health Service. U.S. Department of Health, Education, and Welfare, Public Health Service, Center for Disease Control. PHS Publication No. 1103, 1964 .

University of Michigan News and Information Services. Cigarette smoking rates may have peaked among younger teens. Press Release. Ann Arbor. University of Michigan News and Information Services, December 20, 1997.

Valdes B. Cigarette consumption in Spain: empirical evidence and implications for public health policy. Applied Economics 1993;25(20:149-56.

van der Merwe R. The economics of tobacco control in South Africa. In: Abedian I, van der Merwe R, Wilins N, Jha P, editors. The Economics of Tobacco Control: Towards an Optimal Policy Mix. Cape Town (South Africa): Applied Fiscal Reseach Centre, University of Cape Town, 1998 a.

van der Merwe R. The implications of falling tobacco consumption for employment in South Africa. In: The Economics of Tobacco Control in South Africa. Cape Town: School of Economics, University of Cape Town, June 1998b:107-30.

Viscusi WK. Do smokers underestimate risks? Journal of Political Economy $1990 ; 98(6): 1253-69$.

Viscusi WK. Age variations in risk perceptions and smoking decisions. Review of Economics and Statistics $1991 ; 73(4): 577-88$.

Viscusi WK. Smoking: Making the Risky Decision. New York, Oxford University Press, 1992 .

Viscusi WK. Cigarette taxation and the social consequences of smoking. In: Poterba JM, ed. Tax Policy and the Economy. Cambridge (MA): Massachusetts Institute of Technology Press, 1995:51-101.

von Weizsäcker, CC. Notes on endogenous change of tastes. Journal of Economic Theory $1971 ; 3: 345-72$.

Vuchinich RE, Simpson CA. Delayed Reward Discounting in Alcohol Abuse. National Bureau of Economic Research Working Paper Number 6410, 1998.

Warner KE. The effects of the anti-smoking campaign on cigarette consumption. American Journal of Public Health 1977;67:645-650.

Warner KE. Possible increases in the underreporting of cigarette consumption. Journal of the American Statistical Association 1978;73(362):314-8.

Warner KE. Clearing the airwaves: the cigarette ad ban revisited. Policy Analysis $1979 ; 5: 435-450$.

Warner KE. Cigarette smoking in the 1970s: the impact of the antismoking campaign on consumption. Science 1981a;211:729-31.

Warner KE. State legislation on smoking and health: a comparison of two policies. Policy Sciences 1981b;13(2):139-52.

Warner KE. Cigarette advertising and media coverage of smoking and health. New England Journal of Medicine 1985;312:384-388. 
Economics of Smoking - p. 66

Warner KE. Selling Smoke: Cigarette Advertising and Public Health. Washington: American Public Health Association, $1986 \mathrm{a}$.

Warner KE. Smoking and health implications of a change in the federal cigarette excise tax. Journal of the American Medical Association 1986b;255(8):1028-32.

Warner KE. Health and economic implications of a tobacco-free society. Journal of the American Medical Association 1987;258:2080-6.

Warner $\mathrm{KE}$. The tobacco subsidy: does it matter? Journal of the National Cancer Institute $1988 ; 80(2): 81-3$.

Warner KE. Effects of the antismoking campaign: an update. American Journal of Public Health 1989; 79:144-151.

Warner KE. Tobacco taxation as health policy in the Third World. American Journal of Public Health 1990;80:529-531.

Warner KE. Legalizing drugs: lessons from (and about) economics. Milbank Quarterly $1991 ; 69: 641-661$.

Warner KE. Cost-effectiveness of smoking cessation therapies interpretation of the evidence and implications for coverage. PharmacoEconomics 1997;11:538-549.

Warner KE, Chaloupka FJ, Cook PJ, et al. Criteria for determining an optimal cigarette tax. Tobacco Control 1995;4:380-6.

Warner KE, Citrin T, Pickett G, et al. Licit and illicit drug policies: a typology. British Journal of Addiction 1990;85:255-262.

Warner KE, Ernster VL, Holbrook JH, et al. Promotion of tobacco products: issues and policy options. Journal of Health Politics, Policy and Law 1986;11:367-392.

Warner KE, Fulton GA. The economic implications of tobacco product sales in anontobacco state. Journal of the American Medical Association 1994;271(10):771-6.

Warner KE, Fulton GA. Importance of tobacco to a country's economy an appraisal of the tobacco industry's economic argument. Tobacco Control 1995; 4:180-3.

Warner KE, Fulton GA, Nicolas P, Grimes DR. Employment implications of declining tobacco product sales for the regional economies of the United States. Journal of the American Medical Association 1996;275:1241-6.

Warner KE, Goldenhar LM. The cigarette advertising broadcast ad ban and magazine coverage of smoking and health. Journal of Public Health Policy 1989;10:32-41.

Warner KE, Goldenhar LM, McLaughlin CG. Cigarette advertising and magazine coverage of the hazards of smoking: a statistical analysis. New England Journal of Medicine $1992 ; 326: 305-309$.

Warner KE, Hodgson TA, Carroll CE. The Medical Costs of Smoking in the United States: Estimates, Their Validity, and Their Implications. Ann Arbor (MI): Dept. of Health Management \& Policy, Univ. of Michigan, 1998.

Wasserman J, Manning WG, Newhouse JP, Winkler JD. The effects of excise taxes and regulations on cigarette smoking. Journal of Health Economics 1991;10(1):43-64.

Watkins BG III. The tobacco program: an econometric analysis of its benefits to farmers. American Economist 1990;34(1):45-53.

Wharton Applied Research Center. A Study of the Tobacco Industry's Economic Contribution to the Nation, Its Fifty States, and the District of Columbia. Philadelphia: Wharton Applied Research Center and Wharton Econometric Forecasting Associates, Inc., University of Pennsylvania, 1979. 
Wilcox GB, Tharp M, Yang K-T. Cigarette advertising and consumption in South Korea. International Journal of Advertising 1994;13:333-46.

Wilcox GB, Vacker B. Cigarette advertising and consumption in the United States. International Journal of Advertising 1992;11:269-78.

Winston GC. Addiction and backsliding: a theory of compulsive consumption. Journal of Economic Behavior and Organization 1980;1(4):295-324.

Witt SF, Pass CL. The effects of health warnings and advertising on the demand for cigarettes. Scottish Journal of Political Economy 1981;28(1):86-91.

World Health Organization. Tobacco or Health: A Global Status Report. Geneva: World Health Organization, 1997.

Wynder EL, Graham EA. Tobacco smoking as a possible etiologic factor inbronchiogenic carcinoma: a study of 684 proved cases. Journal of the American Medical Association $1950 ; 143: 329-96$.

Xu X, Hu T-W, Keeler TE. Optimal Cigarette Taxation: Theory and Estimation. Working Paper. Department of Economics, University of California, Berkeley, 1998.

Young, T. The demand for cigarettes: alternative specifications of Fujii's model. Applied Economics 1983;15:203-11.

Zhang $\mathrm{P}$, Husten $\mathrm{C}$. Impact of the tobacco price support program on tobacco control in the United States. Tobacco Control 1998; 7:176-182.

Zhang P, Husten C, Giovino G. The Impact of the Price Support Program on Cigarette Consumption in the United States. Atlanta: Office on Smoking and Health, Centers for Disease Control and Prevention, 1997.

Zimbabwe tobacco climb on week, seen firming. Reuters World Report, June 12, 1998 (off the Internet). 